University of Redlands

"Explore Fullerton"

An ArcGIS Server Web Mapping Application

for the City of Fullerton, California

A Major Individual Project submitted in partial satisfaction of the requirements for the degree of Master of Science in Geographic Information Systems

by

Patrick Joseph Ward

Committee in Charge:

Mark P. Kumler, Ph.D., Chair

Bryan D. Baker, Ph.D.

August 2007 


\section{"Explore Fullerton" \\ An ArcGIS Server Web Mapping Application for the City of Fullerton, California}

Copyright (C) 2007

by

Patrick Joseph Ward 
The report of Patrick Joseph Ward is approved.
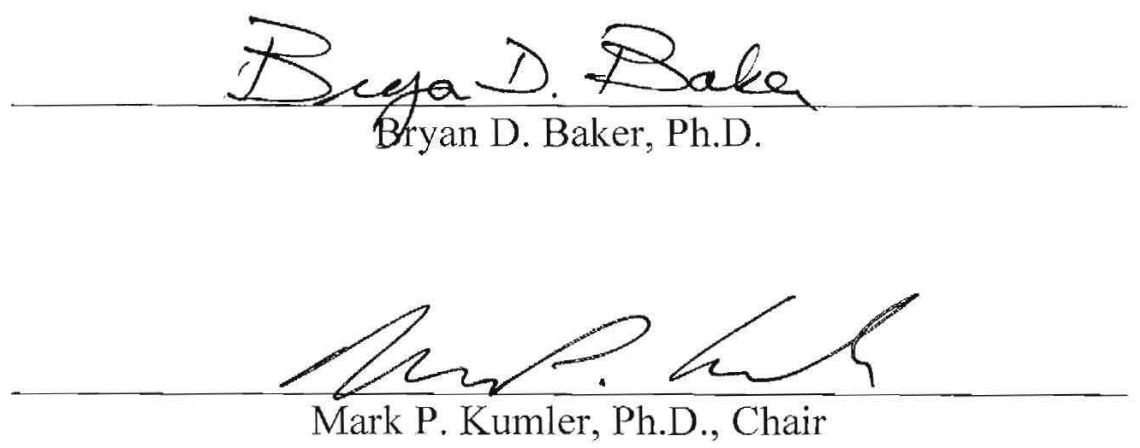

August 2007 



\section{ACKNOWLEDGEMENTS}

I would like to start by thanking my wife, Priscilla, and my daughter, Destiny, for their support through the many ups and downs of this journey. Without them, this project would not have been completed.

Also, I am thankful for all of the help and guidance that my advisor, Dr. Mark Kumler, and committee member, Dr. Bryan Baker, offered during the completion of my MIP.

I am very grateful for and want to offer many thanks to Theresa Ellis, the MS GIS Program Coordinator, for everything she has done to help me and everyone in the program. Theresa was always willing and open to help in any way, whether my questions were about financial aid or how to format this very paper.

I would also like to thank my client, Jon Orndorff, and the City of Fullerton, California, for their support and supplying me with the necessary data for this project.

Finally, I would like to thank all of my friends in Cohort 9, 10, and 11 . Thank you for your support, guidance, lunch, late night study sessions, laughs, and sometimes even a place to sleep. 



\author{
ABSTRACT \\ "Explore Fullerton" \\ An ArcGIS Server Web Mapping Application \\ for the City of Fullerton, California \\ by \\ Patrick Joseph Ward
}

\begin{abstract}
The City of Fullerton, California, is home to a revitalized downtown business district, five institutions of higher education, and three critical freeways. "Explore Fullerton" is an ArcGIS Server Web mapping application that promotes tourism for the numerous businesses located in and around the city's central business district (CBD). The application also displays the city's streets, traffic control points, road projects, parking lots, parks, and city boundary for the public to view. Moreover, because the application is driven by ArcGIS Network Analyst extension, residents can geocode two addresses within the city limit and receive driving routes as well as written step-by-step directions. The application was built using ArcGIS Server Manager's out-of-the-box functionality, and customized with VB.NET in Microsoft Visual Studio 2005.
\end{abstract}





\section{Table of Contents}

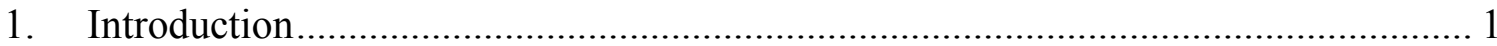

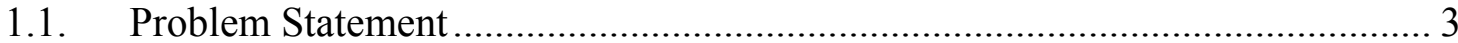

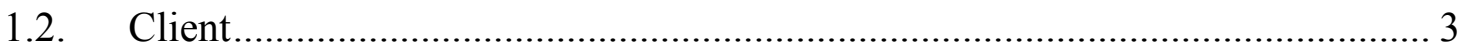

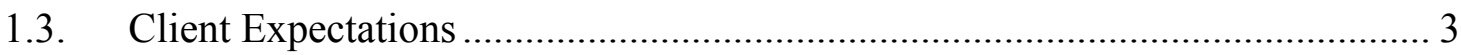

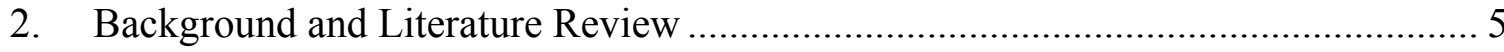

2.1. Proposed Solution ................................................................................. 12

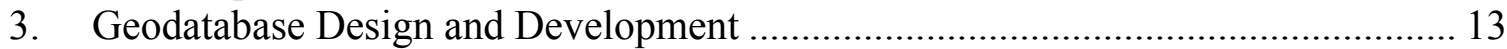

3.1. Destinations Feature Dataset...................................................................... 13

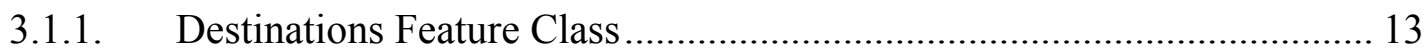

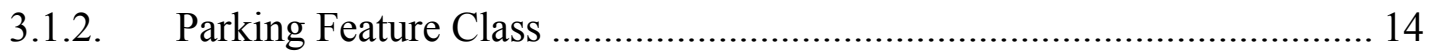

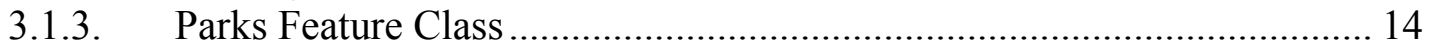

3.2. Traffic_Division Feature Dataset................................................................... 14

3.2.1. Road_Projects Feature Class............................................................... 14

3.2.2. Streets_All Feature Class .................................................................... 14

3.2.3. Traffic_Control Feature Class................................................................ 15

3.2.4. Traffic_Division_ND Network Dataset................................................. 15

3.2.5. Traffic_Division_ND_Junctions Feature Class ........................................ 16

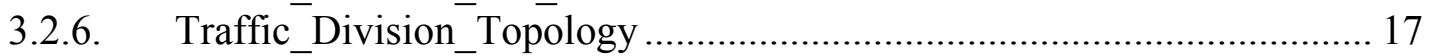

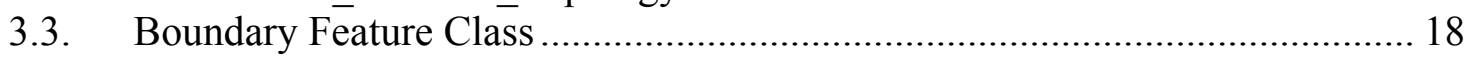

3.4. Fullerton Ortho Raster ...................................................................... 18

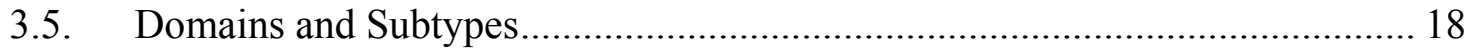

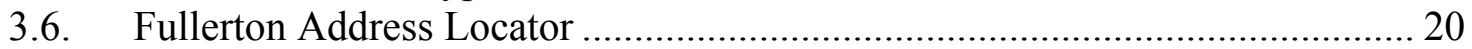

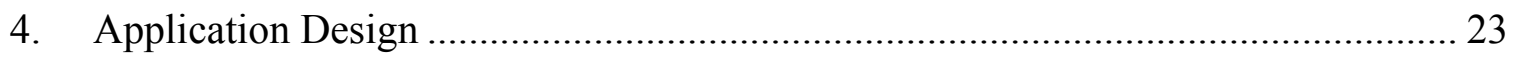

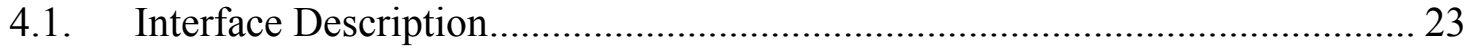

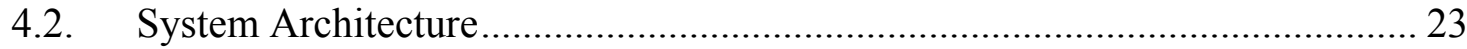

4.3. Server Object Container Permissions …………............................................... 24

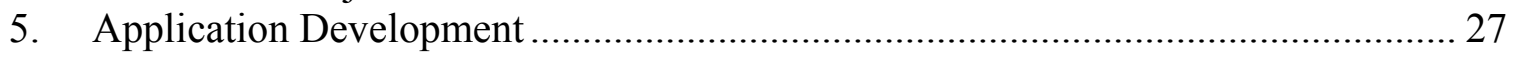

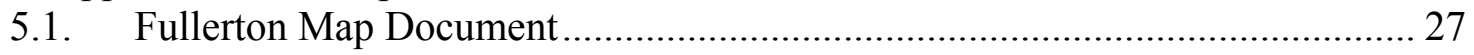

5.2. Publishing Services in ArcCatalog .............................................................. 29

5.3. Designing Explore Fullerton with ArcGIS Server Manager............................. 30

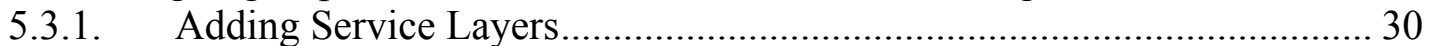

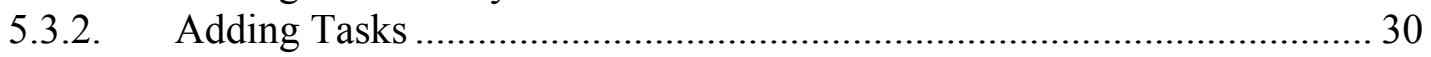

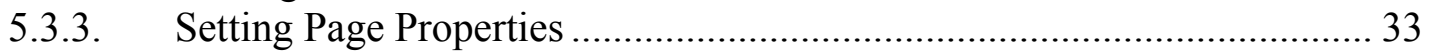

5.3.4. Enabling Map Elements ......................................................................... 34

5.4. Application Customization in Microsoft Visual Studio 2005.......................... 35

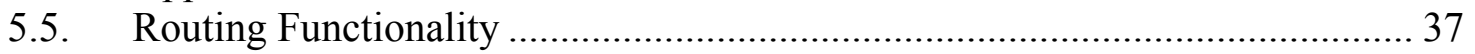

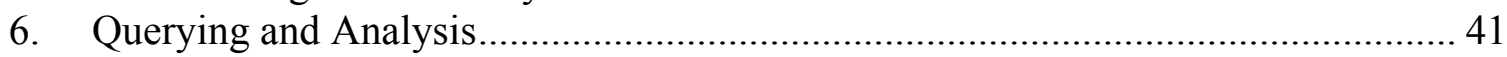

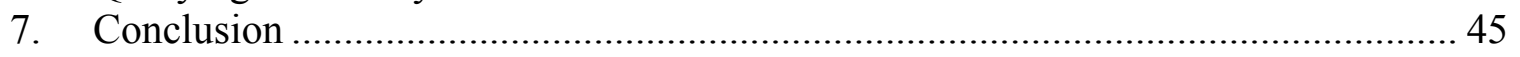

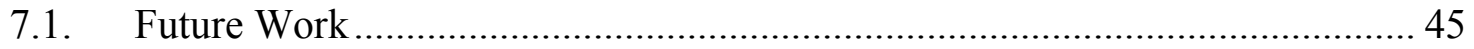

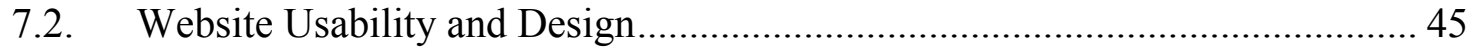

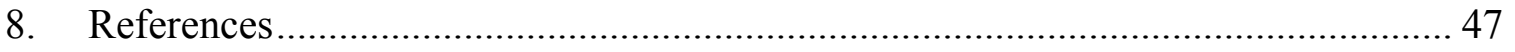

Appendix A - "Explore Fullerton" Installation Manual................................................... 51 


\section{Table of Figures}

Figure 1-1 - Luxury Apartments Located on Commonwealth Avenue. ........................... 1

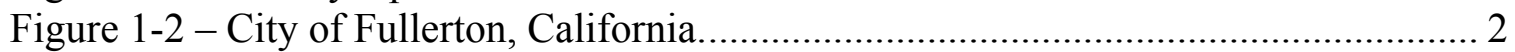

Figure 2-1 - City of Fullerton Downtown Interactive Map. ………………………......... 6

Figure 2-2 - Maine Office of Tourism Interactive Map. ............................................... 7

Figure 2-3 - Destination Nova Scotia Attractions Interactive Map. ………………….... 8

Figure 2-4 - ViaMichelin Route Planner Website. ………….......................................... 9

Figure 2-5 - MapQuest Route Planner Website. ........................................................ 10

Figure 2-6 - Yahoo! Maps Route Planner Website. …………………………………..... 11

Figure 2-7 - Google Transit Trip Planner Website. ………………………………….... 12

Figure 3-1 - Fullerton Workgroup Geodatabase ………….................................... 13

Figure 3-2 - Network Dataset Attribute Properties. ………......................................... 16

Figure 3-3 - Network Dataset Direction Properties. ………............................................ 16

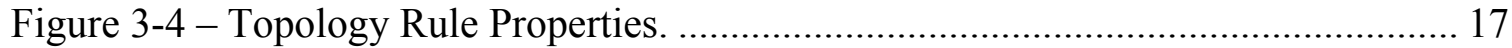

Figure 3-5 - US Streets Address Locator with Streets_All as Reference Data................ 21

Figure 4-1 - "Explore Fullerton" System Architecture.................................................. 24

Figure 4-2 - SOC Permissions on the Database Server.................................................. 25

Figure 4-3 - SOC Read/Write Permissions on the Fullerton Geodatabase. ..................... 25

Figure 5-1 - Fullerton Map Document Layer Scale Dependency.................................... 27

Figure 5-2 - Destinations Symbology...................................................................... 27

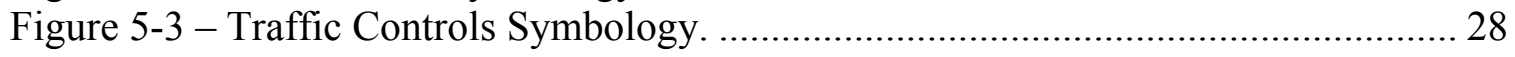

Figure 5-4 - Traffic Signal Symbol Property Editor. ....................................................... 28

Figure 5-5 - Streets_All Symbology. …………………………………………..... 28

Figure 5-6 - Enabling Network Analysis while Publishing to ArcGIS Server. ............... 29

Figure 5-7 - Adding the Fullerton Map Service in ArcGIS Server Manager.................... 30

Figure 5-8 - Find Destination by Name Task Configuration.......................................... 31

Figure 5-9 - Find Destination by Name Form Entry.................................................. 32

Figure 5-10 - Find Fullerton Address Task Configuration. ............................................... 32

Figure 5-11 - Print Your Map Task Configuration. …………..................................... 33

Figure 5-12 - Explore Fullerton's Page Properties........................................................ 34

Figure 5-13 - Table of Contents Element Settings......................................................... 35

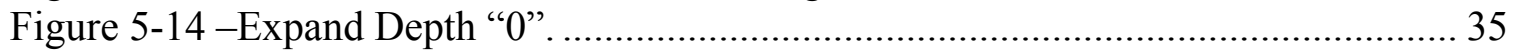

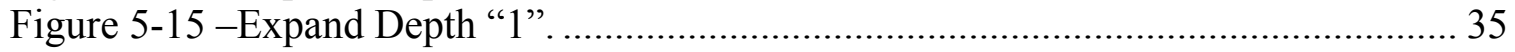

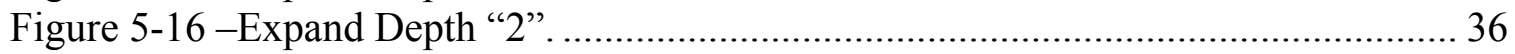

Figure 5-17 - "Explore Fullerton” Web Mapping Application........................................ 36

Figure 5-18 - "Explore Fullerton" Customized Help Page. ............................................. 37

Figure 5-19 - NAServer Example Geocoding with Multiple If Statements...................... 38

Figure 5-20 - Explore Fullerton Geocoding with Single If Statement............................. 38

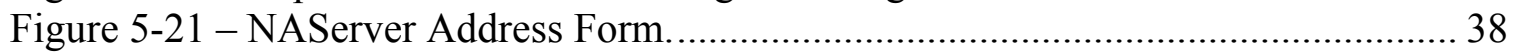

Figure 5-22 - "Explore Fullerton" Address Form. …………………............................. 39

Figure 5-23 - Setting Map Service in the Map Resource Definition Editor. ................... 39

Figure 5-24 - Setting Locator Service within the NAServer Code .................................. 40

Figure 6-1 - Find Destination by Name Query Task....................................................... 41

Figure 6-2 - Results of a Find Destination by Type Query Task for "BAR"................... 41

Figure 6-3 - Map Display Zoomed In on Destination...................................................... 42 


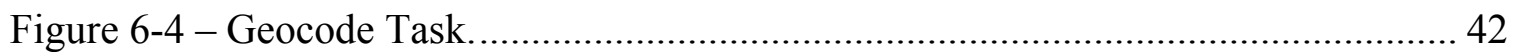

Figure 6-5 - Multiple Results from Geocode Task. ………………......................... 43

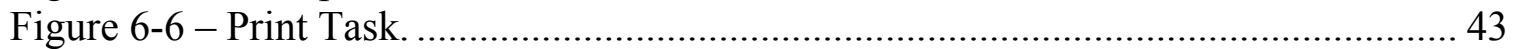

Figure 6-7 - Driving Route and Written Step-by-Step Directions................................... 44

Appendix Figure 1 - Adding a Database Server. ………………..................................... 51

Appendix Figure 2 - Creating and Naming the Database Server..................................... 51

Appendix Figure 3 - Creating and Naming the New Geodatabase.................................52

Appendix Figure 4 - Copying the Fullerton Address Locator. .........................................53

Appendix Figure 5 - Giving ArcGIS SOC Account User Read/Write Permissions. ....... 54

Appendix Figure 6 - Source Tab in Layer Properties. .................................................... 55

Appendix Figure 7 - Selecting Feature Class as Data Source......................................... 55

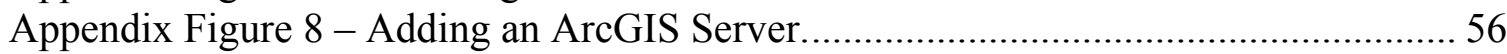

Appendix Figure 9 - Adding an ArcGIS Server to Manage GIS Services....................... 56

Appendix Figure 10 - Setting Server URL and Host Name........................................... 57

Appendix Figure 11 - Publishing FullertonAddressLocator to ArcGIS Server............... 57

Appendix Figure 12 - Naming the FullertonAddressLocator Service. ............................ 58

Appendix Figure 13 - Naming the FULLERTON Service. .............................................. 59

Appendix Figure 14 -Necessary Capabilities for the FULLERTON Service................... 59

Appendix Figure 15 - Print Task intergration with Visual Studio and Manager............. 60

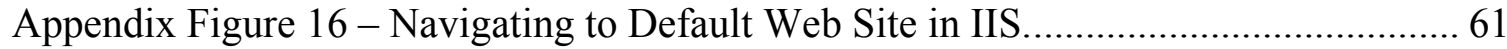

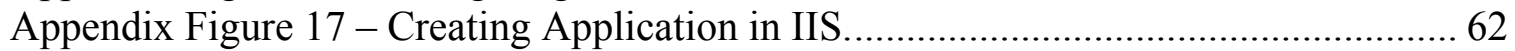

Appendix Figure 18 - Opening Web Site in Visual Studio................................................ 62

Appendix Figure 19 - Opening Default.aspx in Solution Explorer................................... 63

Appendix Figure 20 - Opening the MapResourceManager.............................................. 63

Appendix Figure 21 - Opening the MapResource Definition DataSource. ....................... 64

Appendix Figure 22 - Setting ArcGIS Server Local as Type of Map Resource ............. 64

Appendix Figure 23 - Setting ArcGIS Server Connection................................................ 65

Appendix Figure 24 - Setting FULLERTON as the Map Service.................................... 65

Appendix Figure 25 - Opening GeocodeResourceManager. ............................................. 65

Appendix Figure 26 - Opening the GeocodeResource Definition DataSource. ............... 66

Appendix Figure 27 - Setting ArcGIS Server Local as Type of Geocode Resource....... 66

Appendix Figure 28 - Setting FullertonAddressLocator as the Geocode Service. ........... 67

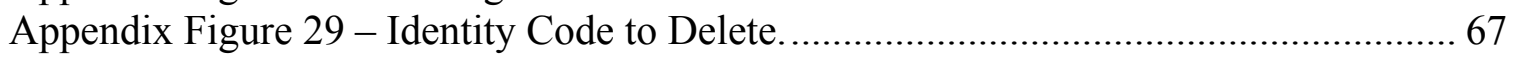

Appendix Figure 30 - Adding an ArcGIS Identity...........................................................6 68

Appendix Figure 31 - Entering User Name, Password, and Domain for Identity........... 68

Appendix Figure 32 - Opening the MapResourceManager.............................................. 69

Appendix Figure 33 - Opening the MapResource Definition DataSource. ...................... 70

Appendix Figure 34 - Setting ArcGIS Server Local as Type of Map Resource............... 70

Appendix Figure 35 - Setting ArcGIS Server Connection............................................... 71

Appendix Figure 36 - Setting FULLERTON as the Map Service.................................... 71

Appendix Figure 37 - Identity Code to Delete............................................................... 72

Appendix Figure 38 - Adding an ArcGIS Identity........................................................ 72

Appendix Figure 39 - Entering User Name, Password, and Domain for Identity........... 73 


\section{List of Tables}

Table 1-1 - Institutions of Higher Education Located in Fullerton, California.................. 2

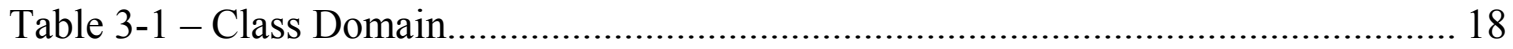

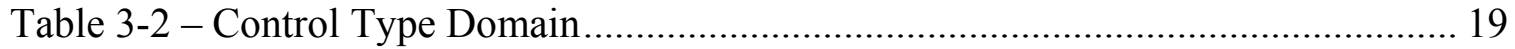

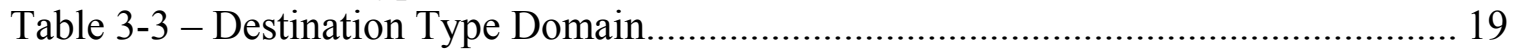

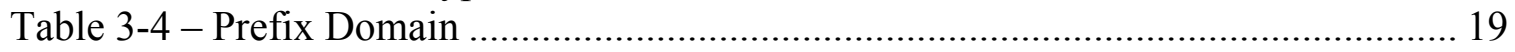

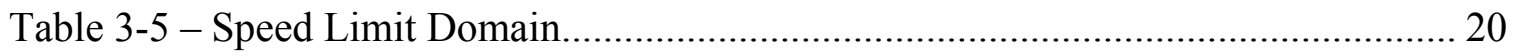

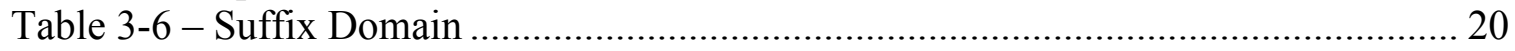

\section{List of Acronyms}

$\begin{array}{ll}\text { ArcIMS } & \text { Arc Internet Map Server } \\ \text { CBD } & \text { Central Business District } \\ \text { DOQQ } & \text { Digital Orthophoto Quarter Quadrangles } \\ \text { EDN } & \text { ESRI Developer Network } \\ \text { ESRI } & \text { Environmental Systems Research Institute } \\ \text { FCC } & \text { Feature Class Code } \\ \text { GIS } & \text { Geographic Information Systems } \\ \text { MXD } & \text { Map Document } \\ \text { NAD } & \text { North American Datum } \\ \text { NAServer } & \text { Network Analyst Server } \\ \text { SOC } & \text { Server Object Container } \\ \text { SOM } & \text { Server Object Manager } \\ \text { TOC } & \text { Table of Contents } \\ \text { USGS } & \text { United States Geological Survey } \\ \text { WAN } & \text { Wide Area Network }\end{array}$




\section{Introduction}

Located 25 miles southeast of Los Angeles, in North Orange County, California, the City of Fullerton is a bustling and growing town. This fast-paced city is the destination of thousands of commuters each day, as well as a stopping point to other destinations. The city's population in the year 2006 was estimated at more than 132,000 people (U.S. Census Bureau, n.d.). With an area of 22.2 square miles, Fullerton has a busy central business district (CBD), and is home to five institutions of higher education. It is also traversed by three critical freeways.

Over the past 20 years, Fullerton's CBD has been revitalized and now offers many new amenities, such as free wireless Internet service, decorative walkways, gathering areas, sidewalk cafes, gourmet restaurants, unique shops, and luxury apartments (City of Fullerton, n.d.) (Figure 1-1).

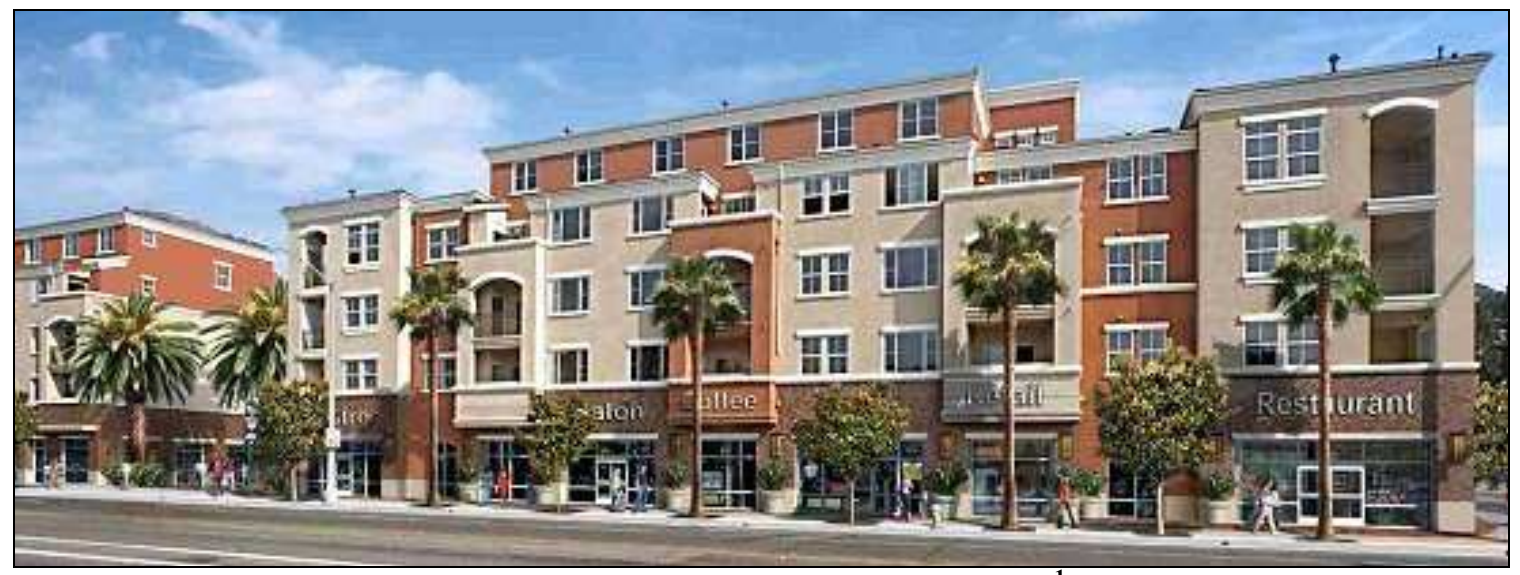

Figure 1-1 - Luxury Apartments Located on Commonwealth Avenue. ${ }^{1}$

This part of the city also offers a vibrant night-life with bars and pubs frequently crowded with students and tourists alike. The Fullerton Transportation Center is located at the Burlington Northern Santa Fe Railway's original Fullerton stop. Amtrak and Metrolink, the regional commuter train service, run daily from the station. The center is also a major bus depot for the Orange County Transportation Authority. As a result, downtown Fullerton is now a destination for visitors from all over Southern California (City of Fullerton, n.d.).

The institutions of higher education in Fullerton contribute a great number of commuters and visitors. The majority of students who attend school in Fullerton commute to the campuses located in northeast Fullerton. Table 1-1 depicts the institutions and estimated enrollment numbers.

\footnotetext{
${ }^{1}$ This image was retrieved from the City of Fullerton website at http://www.ci.fullerton.ca.us/visitors/downtown_fullerton/luxury_apartments.asp .
} 
Table 1-1 - Institutions of Higher Education Located in Fullerton, California

\begin{tabular}{|c|c|c|c|}
\hline SCHOOL NAME & $\begin{array}{l}\text { COMMUTER OR } \\
\text { RESIDENTIAL }\end{array}$ & ENROLLMENT & $\begin{array}{l}\text { SOURCE OF } \\
\text { ENROLLMENT }\end{array}$ \\
\hline $\begin{array}{c}\text { California State } \\
\text { University, Fullerton }\end{array}$ & Commuter & 36,000 & http://www.fullerton.edu/ \\
\hline Fullerton College & Commuter & 20,000 & http://www.fullcoll.edu/ \\
\hline $\begin{array}{c}\text { Hope International } \\
\text { University }\end{array}$ & Residential & 1,700 & http://www.hiu.edu/ \\
\hline $\begin{array}{c}\text { Western State University } \\
\text { College of Law }\end{array}$ & Commuter & 500 & http://www.wsulaw.edu/ \\
\hline $\begin{array}{c}\text { Southern California } \\
\text { College of Optometry }\end{array}$ & Residential & 100 & http://www.scco.edu/ \\
\hline
\end{tabular}

Three major freeways - Interstate 5 (Santa Ana Freeway), California State Route 91 (Riverside Freeway), and California State Route 57 (Orange Freeway) — pass through Fullerton, carrying an average of 733,250 vehicles per day (derived from traffic flow data given to the author by the City of Fullerton). The majority of commuters in the area utilize at least one of these freeways at some point during their travel to or beyond Fullerton. Figure 1-2 is a map of the City of Fullerton, California.

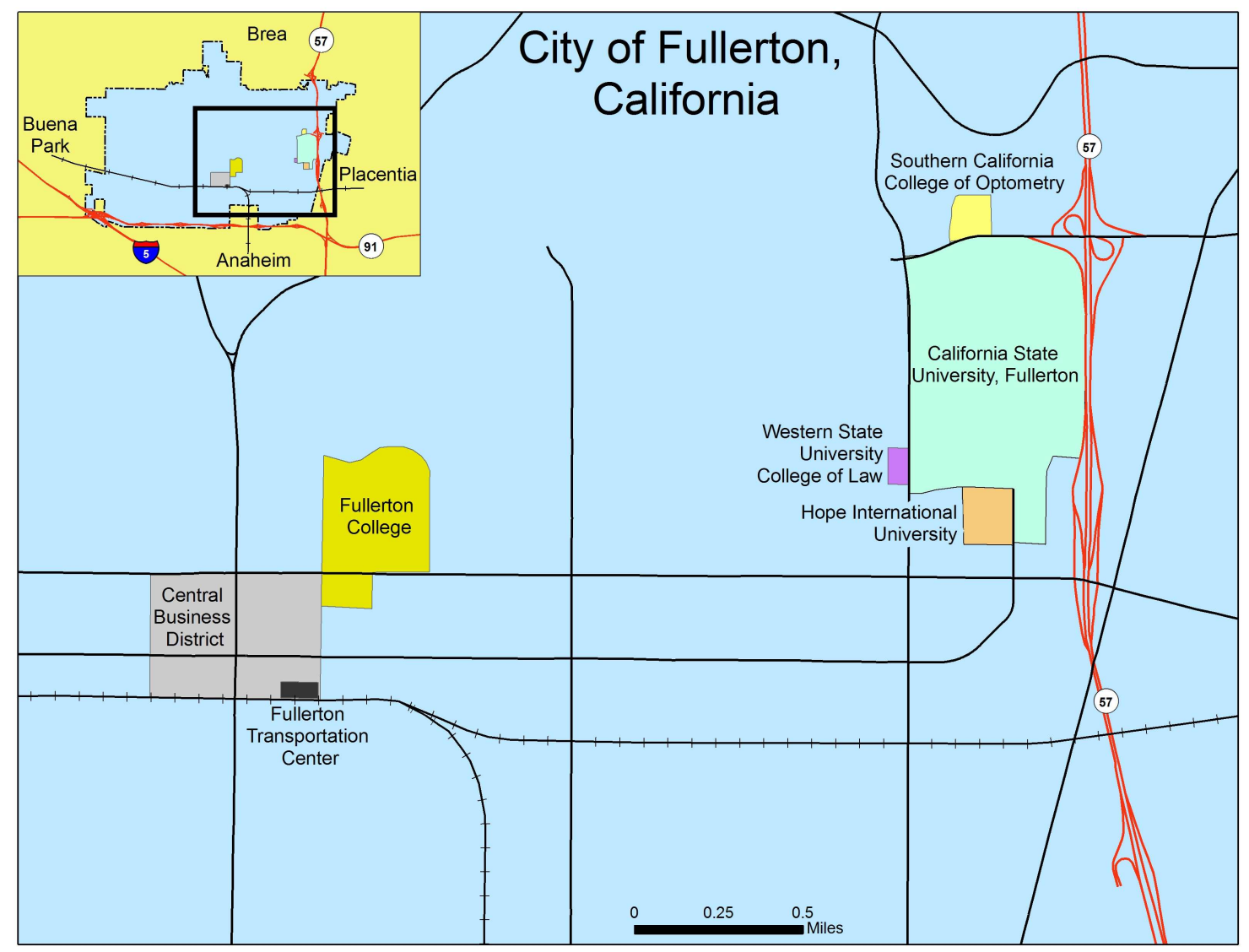

Figure 1-2 - City of Fullerton, California. 


\subsection{Problem Statement}

The City of Fullerton wishes to capitalize on the amount of people coming into the city everyday by promoting the CBD as a place of interest and leisure. This promotion can be efficiently achieved through the displaying of destinations geographically with a Geographic Information System (GIS). The city is currently using software created by the Environmental Systems Research Institute (ESRI) to run an ArcIMS (Internet Map Server) application on their website. However, with the new release of ESRI's ArcGIS Sever 9.2, the client, Jon Orndorff, wants to upgrade to an ArcGIS Server Web mapping application. The city's Traffic Division also has data that it would like to make available for residents to view. Currently, static traffic maps display this data on the city's website. By including this data within an interactive ArcGIS Server Web mapping application, a user will be able make informed decisions, such as where to avoid road projects, when traveling through the city.

\subsection{Client}

The client and contact for this project, Jon Orndorff, is the GIS Specialist for the City of Fullerton Engineering Department. Indirect clients include the numerous businesses located in the city's CBD, the Traffic Division, and the residents and visitors of Fullerton. The businesses located in and around the CBD will benefit from free advertising by having information such as address, phone number, website, and business type made available for the public to view within the application. Residents and visitors can access the application via the Internet to plan trips. Residents and visitors also have the option of entering a starting location address and a destination location address to obtain a driving route with written step-by-step directions. The Traffic Division will benefit by having all of the city's traffic and transportation data, including streets, traffic control points (i.e., street signals, stop signs, or flashing pedestrian crosswalks), road projects (i.e., street reconstruction or street widening) and parking structure locations, available for display in one location. The routing functionality of the application also gives the Traffic Division an additional tool to serve the community of Fullerton.

\subsection{Client Expectations}

The client has various expectations of this project. First, Orndorff requested that a geodatabase be built to hold the spatial and attribute data to be utilized. Additionally, the client requested that an ArcGIS Server Web mapping application be developed to replace the city's existing ArcIMS application. The current application allows residents to query for parks and businesses located within the CBD. Orndorff also wanted the data supplied by the Traffic Division, such as streets, traffic control points, road projects, and parking structures, to be included in the new application. Finally, the client indicated an interest in the application having routing functionality, however, routing functionality was not a requirement. 


\section{Background and Literature Review}

This chapter will present a few examples of destinations from around the world that have begun to advertise their attractions to a global audience via the Internet. These Web applications use maps to promote their destination so that tourists thousands of miles away can preview and plan their trips.

For this project, two application domains needed to be explored: Internet tourism promotion, and Internet vehicle routing and trip itinerary planning. Because vehicle routing and trip itinerary planning play significant roles in tourism, the two domains go hand-in-hand.

The tourism industry provides services, such as accommodations, transportation, and general information to travelers. Tourism continues to grow in popularity, and is considered to be one of the fastest growing economic sectors, with future projections of all international trip arrivals to surpass 1.5 billion in 2020 (World Tourism Organization, n.d.). Travelers increasingly resort to the Internet to find information about their next destination.

Tourists are making increasing use of the web for obtaining information prior to departure, including organizational information such as route planning, traffic news or accommodation, as well as information on the destination, e.g. topography, landscape and land use (Meng, Xipf, and Reichenbacher, 2005).

The first mapping application that was investigated was developed by The City of Fullerton, California (www.cityoffullerton.com). Fullerton currently has an ArcIMSbased website that allows users to search for restaurants, shops, historical sites, and parks within the city's CBD (Figure 2-1). The user can select a place of interest from a dropdown list to receive more information, such as phone number, address, and Website (City of Fullerton, n.d.). 


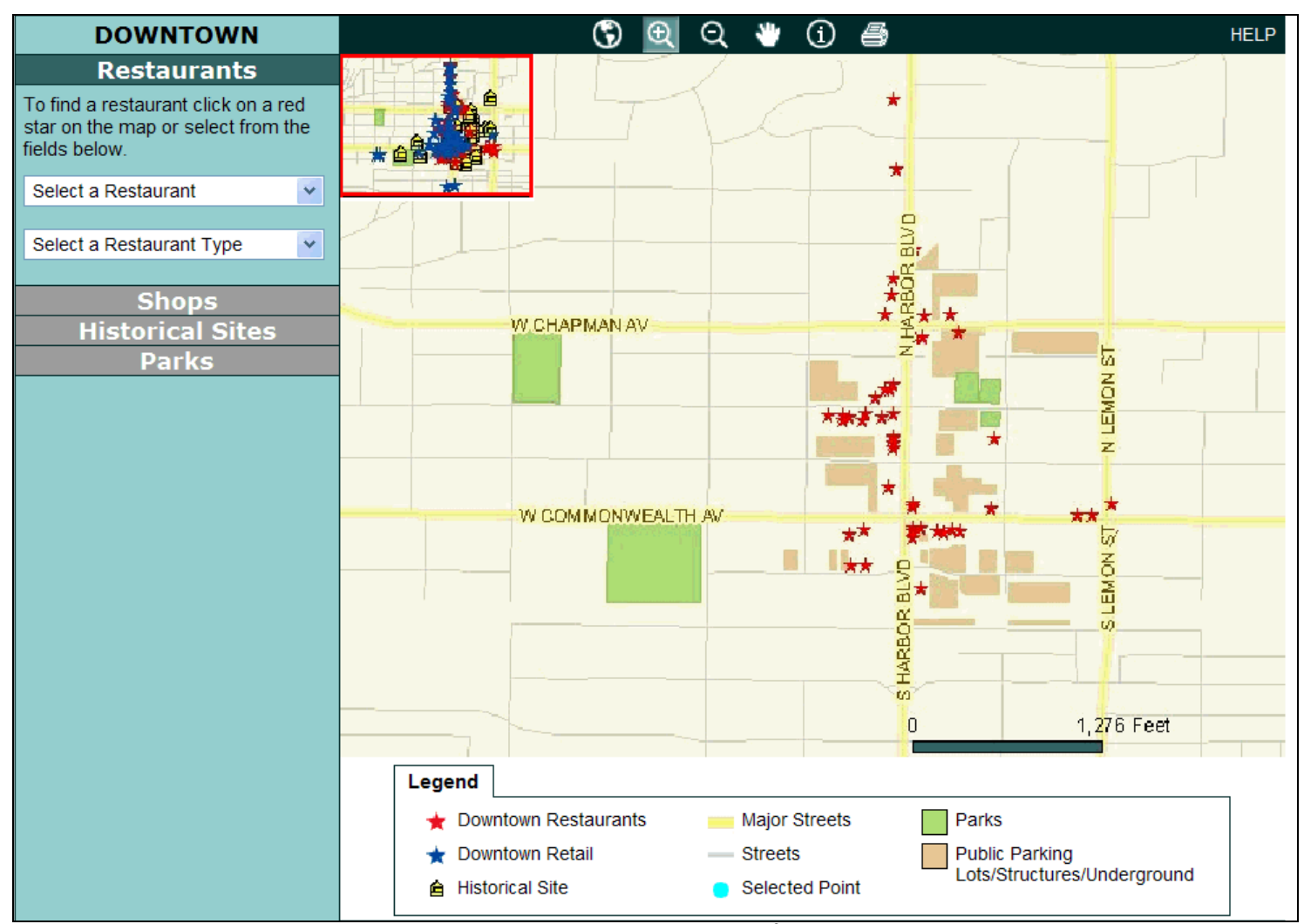

Figure 2-1 - City of Fullerton Downtown Interactive Map. ${ }^{2}$

The Municipality of Chania, Greece, has a Web mapping application that is a simple point-and-click user interface titled Facilities of the City of Chania (Christodoulakis et al., 1998). The application allows its users to retrieve information about locations within the city, such as a street or square. Once the user has chosen a point of interest, the application displays information associated with the chosen point. The Facilities of the City of Chania application is available for use by English-speaking tourists and local residents, as the application is provided in both English and Greek (Christodoulakis et al., 1998).

The Maine Office of Tourism provides a Web mapping application available to the public (www.visitmaine.com). This application has an interactive map that allows users to explore Maine's eight tourism regions (Figure 2-2).

\footnotetext{
${ }^{2}$ This image was retrieved from the City of Fullerton website at http://www.cityoffullerton.com/visitors/downtown_fullerton/map_of_downtown.asp .
} 


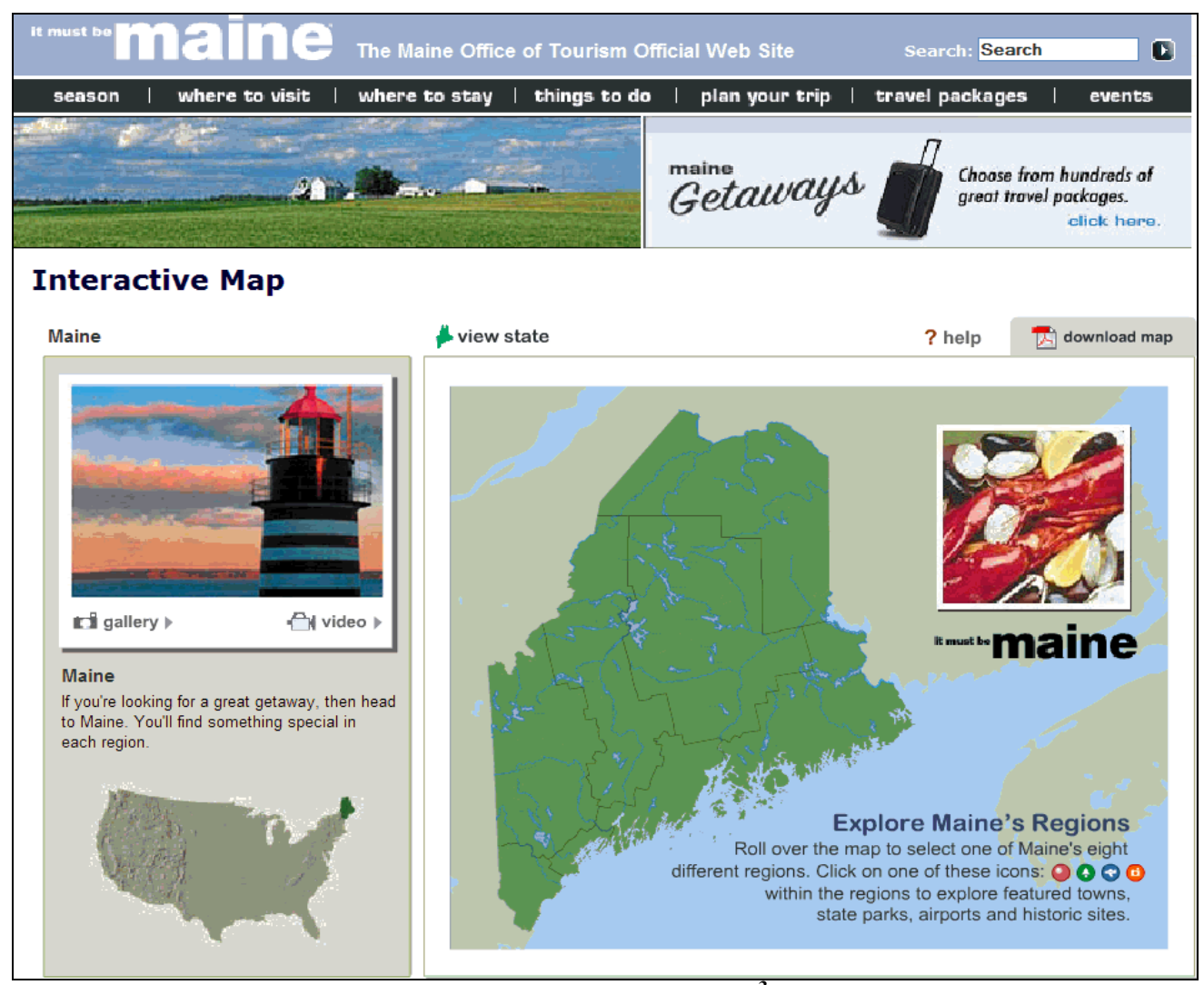

Figure 2-2 - Maine Office of Tourism Interactive Map. ${ }^{3}$

Once a region has been selected, additional information such as towns, state parks, airports, and historic sites can be retrieved. Each point of interest has associated pictures and additional websites where users can access information such as nearby accommodations and related activities (Maine Office of Tourism, n.d.).

The Province of Nova Scotia, Canada, has a mapping application titled Destination Nova Scotia (www.destination-ns.com). This is a tourism information interactive website that accesses tourist attractions, accommodation information, and restaurants via a database (Figure 2-3). MAPEZE, the company that developed Destination Nova Scotia, has added editorial content and geocoded photographs to allow users to view representative areas of the province from their home computer. An additional routing component of the application allows visitors to create multiple door-todoor driving routes and directions. The user can specify a route utilizing highways or side streets, and can select between the shortest distance or the quickest travel time route (Destination Nova Scotia, n.d.).

\footnotetext{
${ }^{3}$ This image was retrieved from the Maine Office of Tourism website at http://www.visitmaine.com/map/interactive/.
} 


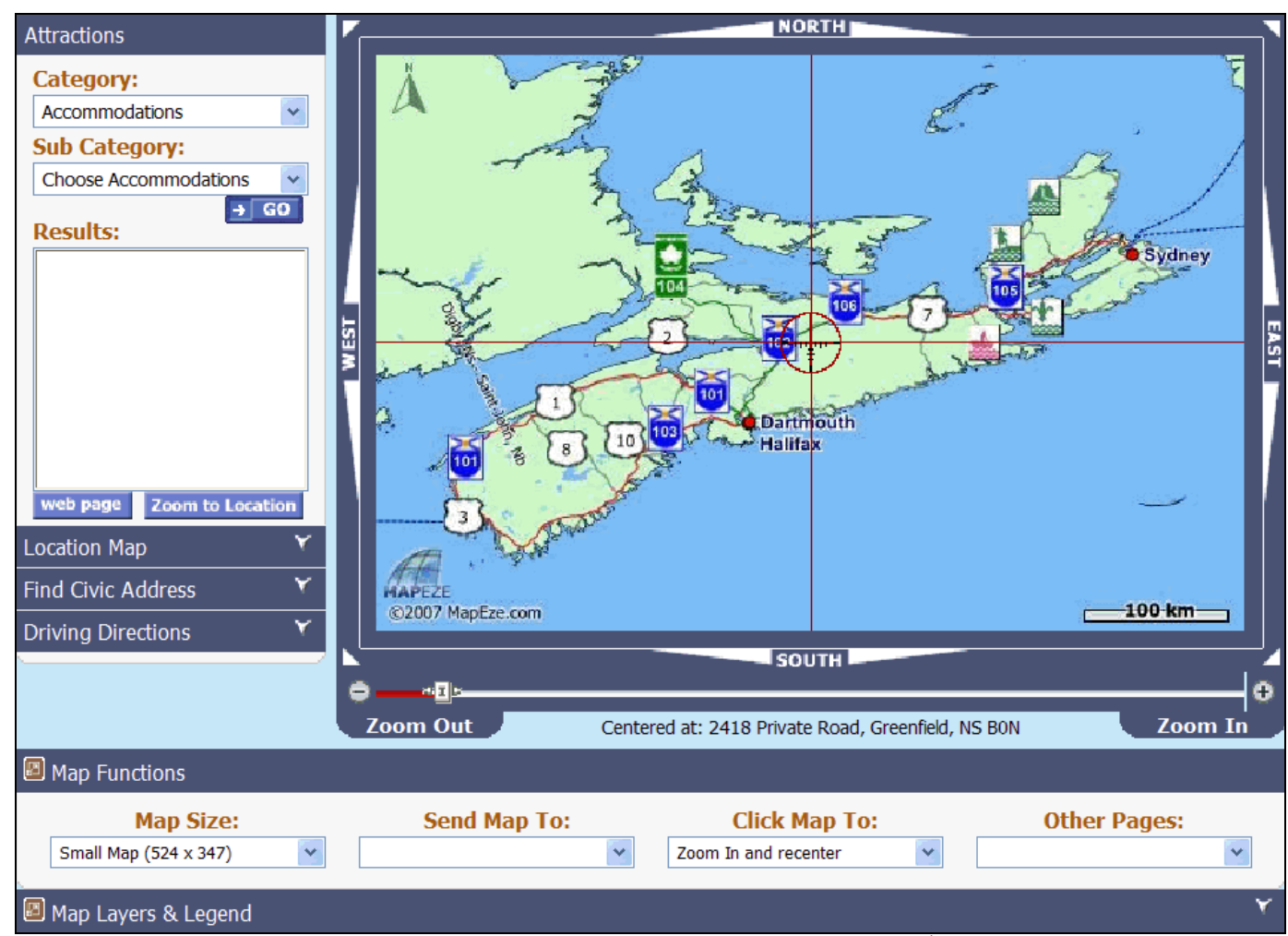

Figure 2-3 - Destination Nova Scotia Attractions Interactive Map. ${ }^{4}$

In addition to tourism, trip itinerary planning and vehicle routing are expanding services that many websites are now offering. The first routing application was developed by Michelin in 1982 and ran on the French Minitel Videotex system (Mitchell, 1998). Customers connected to the application via a telephone line and could request routes for a planned trip. The user would then pay for a hard copy text version of their routes (Shannon, 2005). It was not until March of 1997 that Michelin took their routing business to the Internet, where customers could use a credit card to pay for the itinerary (Collis, 1998). Today, the company, renamed ViaMichelin (www.viamichelin.co.uk), allows users to obtain maps and driving directions, as well as tourist information on restaurants, hotels, museums, and local attractions directly from their website (Figure 2-4).

\footnotetext{
${ }^{4}$ Image retrieved from the Destination Nova Scotia website at http://www.destinationns.com/common/map/Map.asp .
} 


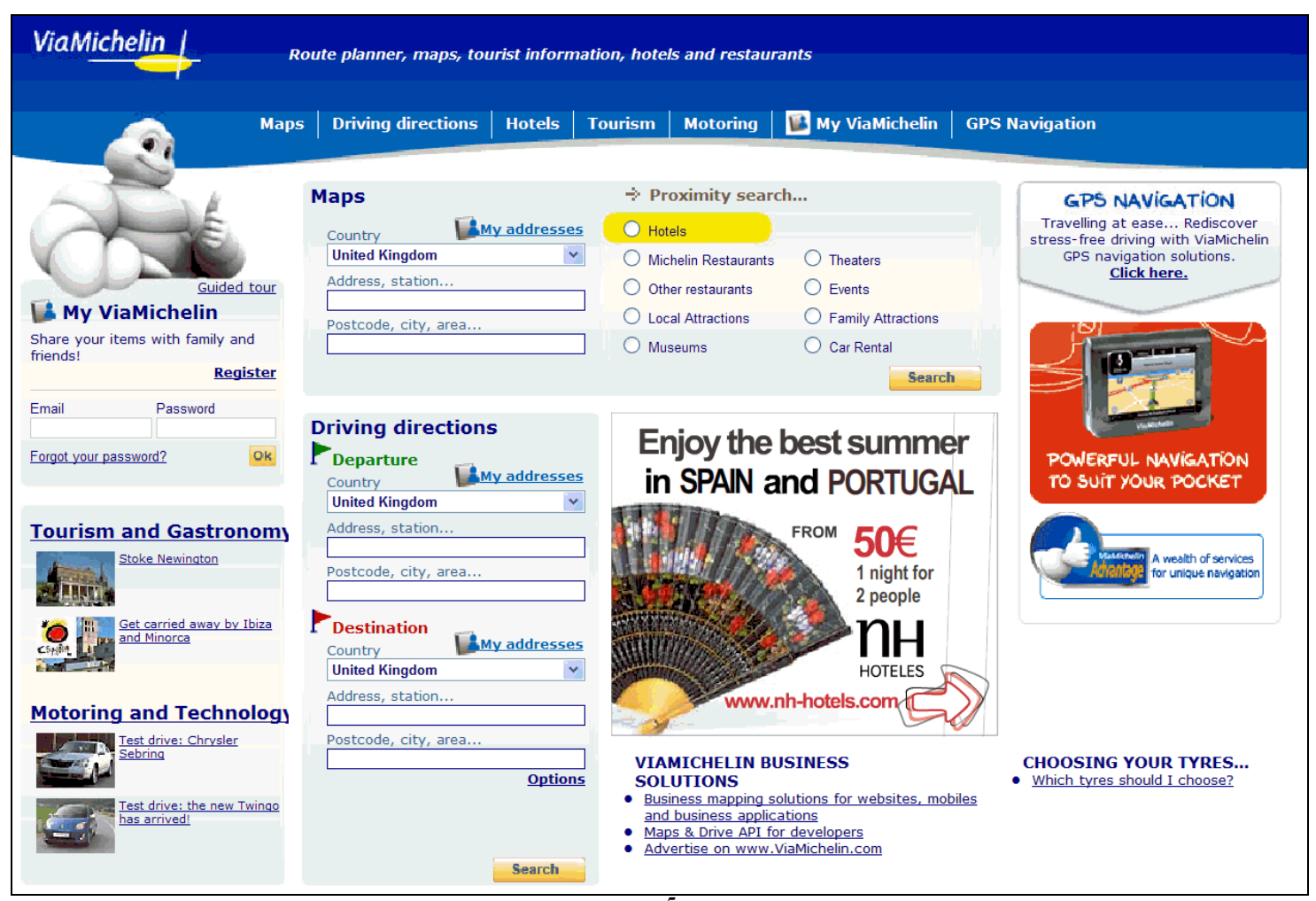

Figure 2-4 - ViaMichelin Route Planner Website. ${ }^{5}$

Internet transportation GISs were made popular by trip planning applications such as MapQuest (www.mapquest.com) and Yahoo! Maps (maps.yahoo.com) (Peng \& Tsou, 2003). MapQuest, now owned by America Online, Inc. (Figure 2-5), and Yahoo! Maps, owned by Yahoo! Inc. (Figure 2-6), allow the user to input a starting and ending street address.

\footnotetext{
${ }^{5}$ Image retrieved from the ViaMichelin website at http://www.viamichelin.co.uk/viamichelin/gbr/tpl/hme/MaHomePage.htm .
} 


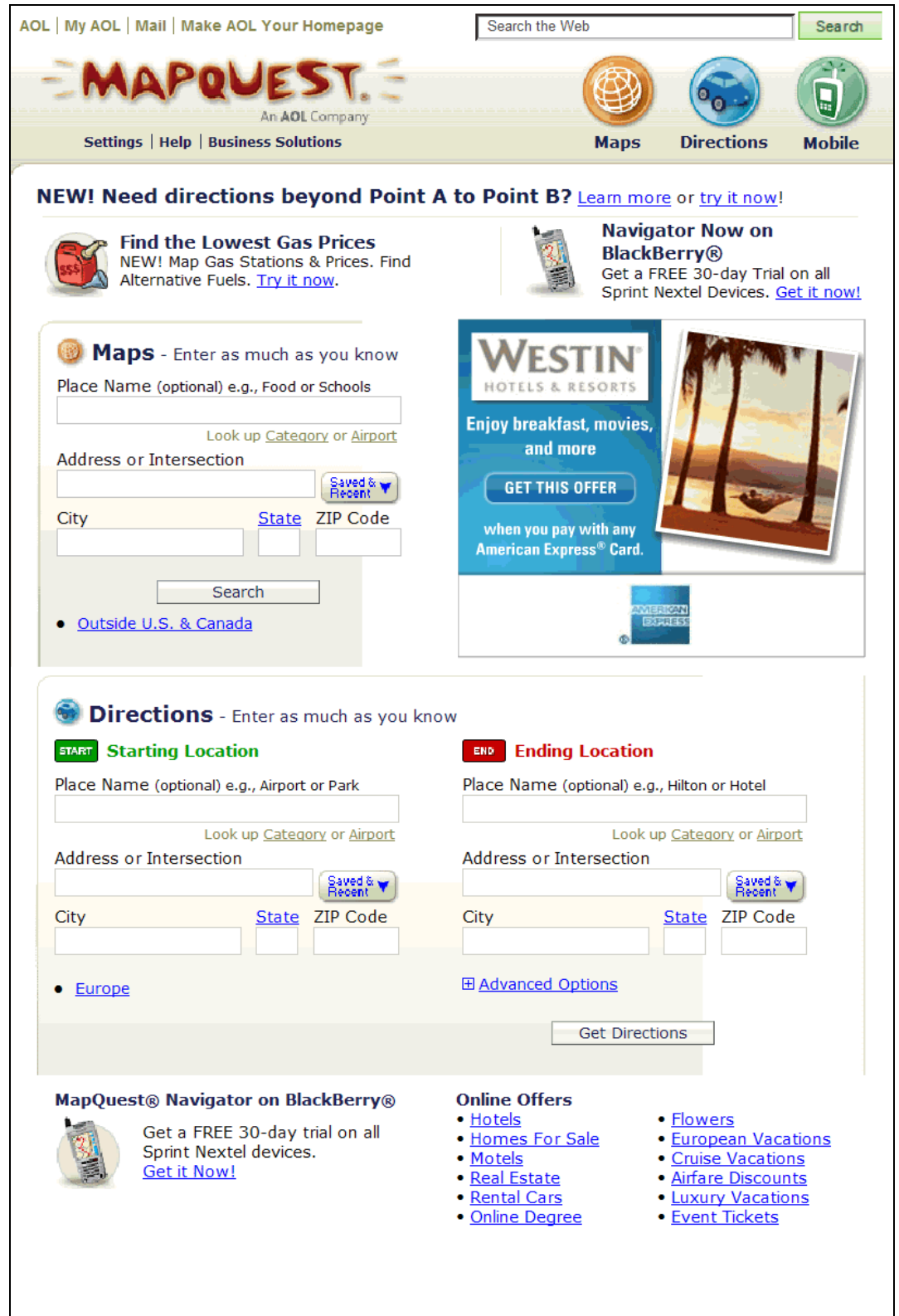

Figure 2-5 - MapQuest Route Planner Website. ${ }^{6}$

${ }^{6}$ Image retrieved from the MapQuest website at http://www.mapquest.com/ . 


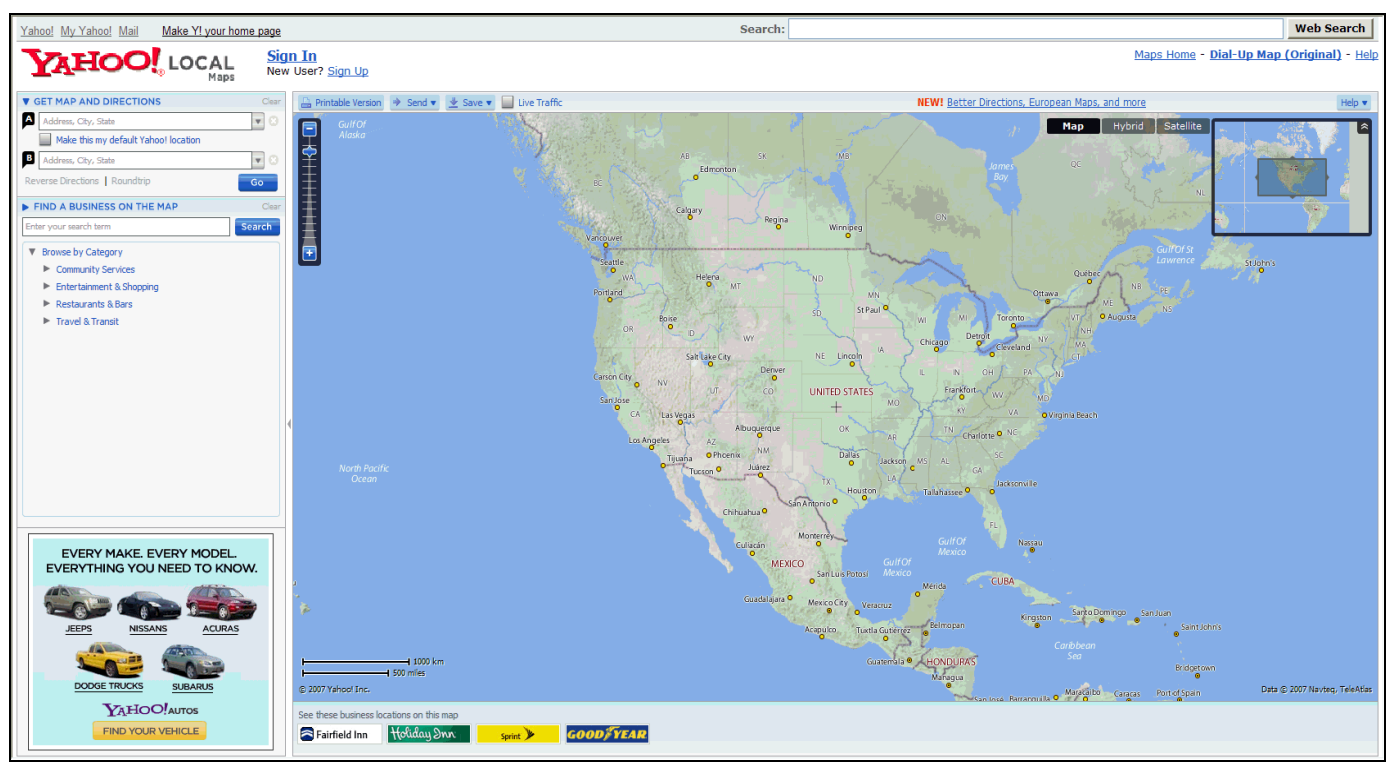

Figure 2-6 - Yahoo! Maps Route Planner Website. ${ }^{7}$

The applications then present a map window with turn-by-turn directions and a driving route on which the user can then zoom to different scales (Peng, 1998). Both websites give the user the option of viewing their route with an aerial image or street map. According to MapQuest.com, Inc., the website receives over 40 million visitors every month (MapQuest.com, 2005).

In December of 2005, another trip planning application was launched by Google (www.google.com) called Transit Trip Planner. The application was developed for the Tri-County Metropolitan Transportation District of Oregon as a beta test version (Passenger Transport, 2005). Since its initial release, Google has transformed its beta version into Google Transit (www.google.com/transit) (Figure 2-7) and is now a Google Labs product that allows trips to be planned in 12 U.S. cities and throughout all of Japan.

\footnotetext{
${ }^{7}$ Image retrieved from Yahoo website at http://maps.yahoo.com/broadband\#env=a .
} 


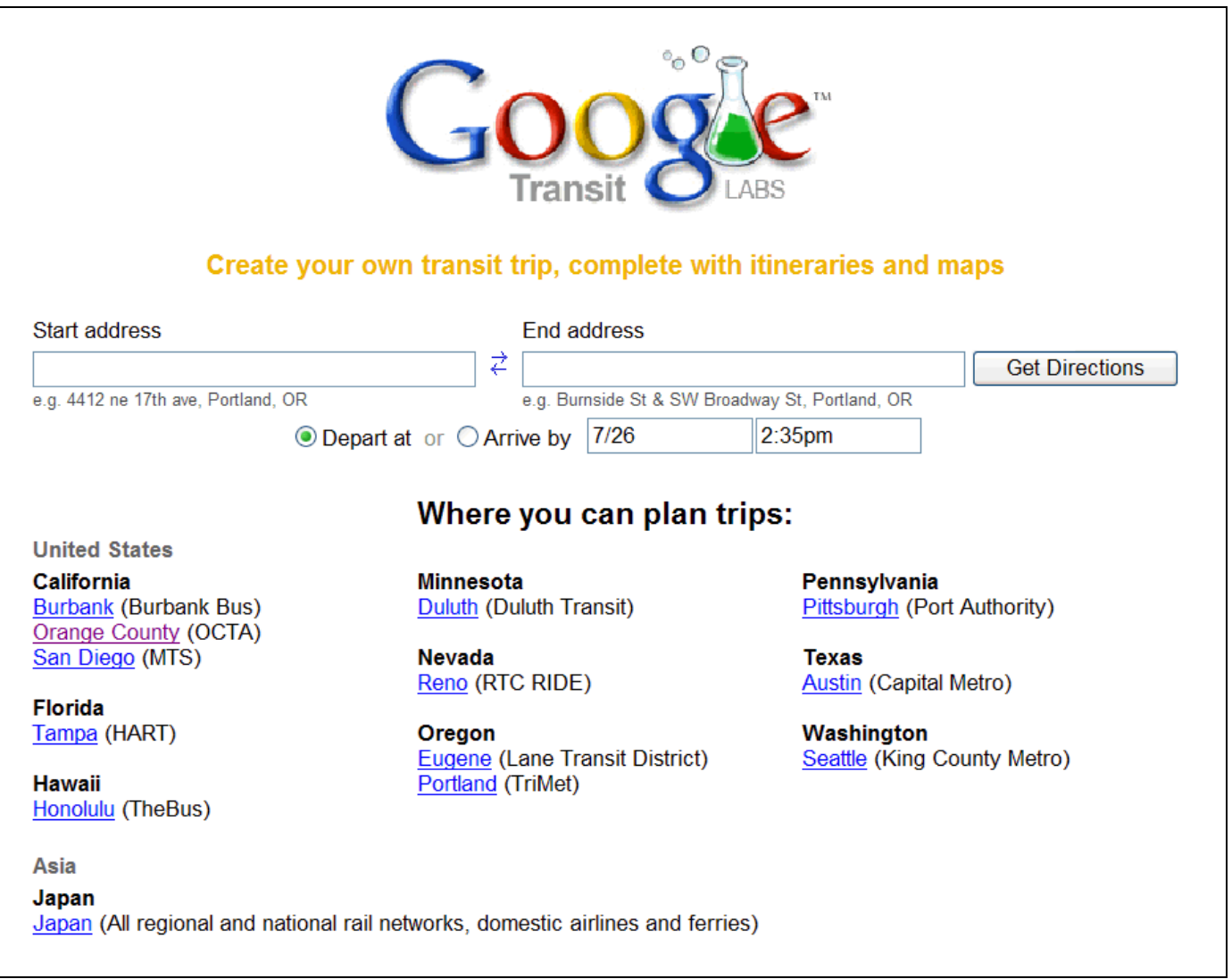

Figure 2-7 - Google Transit Trip Planner Website. ${ }^{8}$

Google Transit utilizes the user's place of origin and final destination information to produce the most efficient itinerary with available public transportation schedules for busses, trains, and ships (Passenger Transport, 2005).

\subsection{Proposed Solution}

The application proposed here is an ArcGIS Server Web mapping application. This application will educate the user on numerous businesses in Fullerton's CBD by allowing querying and geocoding functionality. In addition, the application will provide the user with traffic-related information, such as the location of current and proposed road projects, the location of all stop signs, street signals, pedestrian crosswalks, and parking structures. Through an additional linked Web mapping application, the users will be able to input and geocode their origin and destination addresses to receive driving routes and step-by-step directions to their destination.

\footnotetext{
${ }^{8}$ Image retrieved from Google website at http://www.google.com/transit .
} 


\section{Geodatabase Design and Development}

For this project an ArcSDE Database Server was assembled in ArcCatalog to store a Workgroup Edition geodatabase using SQL Server Express. The Workgroup geodatabase named Fullerton was built to hold the project's spatial data, geocoding address locator, network dataset, topology, and orthophotograph (Figure 3-1).

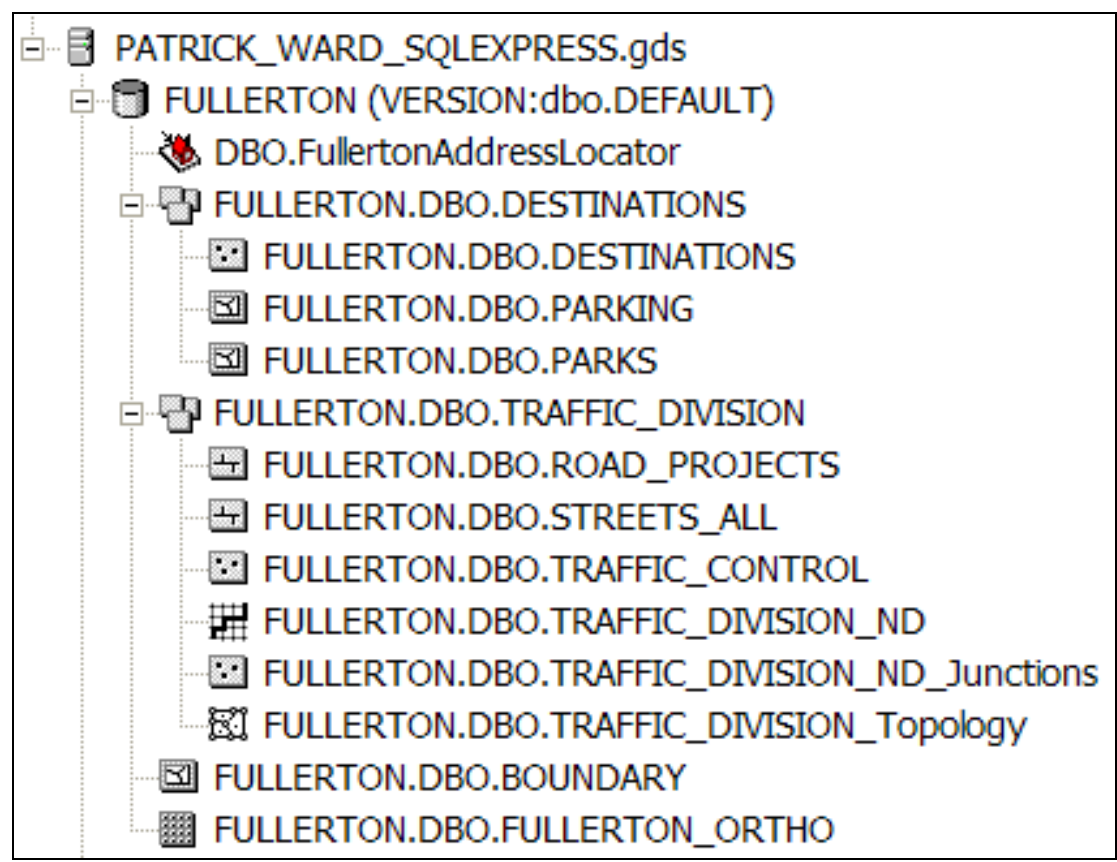

Figure 3-1 - Fullerton Workgroup Geodatabase.

The projected coordinate system that was used for both feature datasets and all standalone data within the geodatabase is the State Plane California zone VI (1983, FIPS 0406, Feet). For California, all of the state plane coordinate zones trend East-to-West and thus use a Lambert Conformal Conic projection with the 1983 North American Datum (NAD).

\subsection{Destinations Feature Dataset}

The Destinations feature dataset contains feature classes that represent a location that a visitor would want to explore as a place of interest. Included in the Destinations feature dataset is a point feature class titled Destinations and two polygon feature classes titled Parking and Parks.

\subsubsection{Destinations Feature Class}

The Destinations feature class contains point features for locations that visitors may consider as locations of interest. These destinations, which are listed in the Destination_Type attribute field, are Bar, Coffee or Tea House, Historical Site, Park, Parking, Restaurant, Shop, and Vegetarian. The feature class also contains attribute fields for Name, Address, Phone, and website. This feature class was created from multiple feature classes that were supplied by the City of Fullerton. The feature classes that were 
supplied are titled as follows: Restaurants, which contained bars, coffee or tea houses, restaurants, and vegetarian restaurants, Parking, and Parks. To create the Destinations feature class that was used for this project, the "Feature To Point" tool from ArcToolbox was used to obtain points from the Parking and Parks polygon feature classes that were supplied by the City of Fullerton. Next, the "Merge" tool from ArcToolbox was used to combine the Restaurants point feature class with the newly created Parking and Parks point feature class. This new feature class was titled Destinations.

\subsubsection{Parking Feature Class}

The Parking feature class contains polygon features for parking lots located in the city's CBD. The feature class has attribute fields for the parking area's Name, its Type, the number of parking Spaces, its Address, and any parking Restrictions. The feature class was imported as-is from data supplied by the City of Fullerton.

\subsubsection{Parks Feature Class}

The Parks feature class contains polygon features for parks located within the City of Fullerton. The feature class has attribute fields for a park's Name, Address, Size in Acres, as well as a field for all possible amenities with the attributes yes or no. Possible amenities include: Activity_Building, Activity_Slab, Barbecue, Baseball, Basketball, Benches, Bleacher_Seating, Fire_Rings, Gazebo, Gym, Handicap_Accessibility, Horseshoe_Rings, Par_Course, Parking, Picnic_Tables, Playground, Racquetball, Trail, Restroom, Seating, Shuffleboard, Skate_Park, Snack_Bar, Soccer, Softball, Swimming, Tennis, Volleyball, and Wading_Pool. The feature class was imported as-is from data supplied by the City of Fullerton.

\subsection{Traffic_Division Feature Dataset}

The Traffic_Division feature dataset contains feature classes that belong to the Traffic Division within the City of Fullerton's Engineering Department. Included in the Traffic_Division feature dataset are line feature classes titled Road_Projects and Streets_All. A point feature class titled Traffic_Control, a network $\overline{\text { dataset titled }}$ Traffic_Division_ND, the network dataset's junctions titled Traffic_Division_ND_Junctions, and a topology titled Traffic_Division_Topology are also included.

\subsubsection{Road_Projects Feature Class}

The location of road projects was supplied by the City of Fullerton in an Excel document with attributes such as the Name of the street where the project was being carried out, the Limits of the project, the projects Revised_Date, and the Type of road project. The Road_Projects feature class was created using heads up digitizing against the Streets_All feature class within the limits of the road project. The attributes were then entered into the feature class table during an ArcMap edit session.

\subsubsection{Streets_All Feature Class}

The Streets_All feature class contains line features that represent the city's street centerlines. The feature class was supplied by the City of Fullerton with the following attributes: ID, F_Node, T_Node, FCC, L_F_Add, L_T_Add, R_F_Add, R_T_Add, 
Prefix, Name, Type, Suffix, City, State, L_ZIP, R_ZIP, One_Way, F_ZLev, T_ZLev, Full_Name, Class, Distance, and Speed_Limit. An additional attribute titled Minutes was added to indicate the amount of time it would take to travel a street segment. To obtain this field, the following equation was used:

Minutes $=($ Distance in miles $/$ Speed in Miles per hour $) * 60$

The Streets_All feature class had been clipped to the city boundary by the City of Fullerton. This deleted the interchange between the 91 and 57 highways, which would cause problems during the construction of the network dataset. To remedy this problem, the interchange was heads-up digitized and attributed with a From Node (F_Node) and a To Node (T_Node). The interchange was then given the names "ramp to 57 freeway" and "ramp to 91 freeway". Additionally, all major roads were heads-up digitized to the outer edge of the orthophoto so that they would not appear to end abruptly at the Fullerton border.

\subsubsection{Traffic_Control Feature Class}

The Traffic_Control feature class was supplied by the City of Fullerton and displays point features such as stop signs, traffic signals, and flashing pedestrian crosswalks. These points were snapped to the vertices located at the intersections or to the edge of the Streets_All feature class during an ArcMap edit session using heads-up digitizing. The feature class has a type attribute field to specify the type of traffic control that is located at each point.

\subsubsection{Traffic_Division_ND Network Dataset}

A network dataset, created in ArcCatalog, is an interconnected set of lines (edges), points (junctions), and turns that represent a geographic feature that will allow undirected flows of movement such as transportation (ESRI, 2006). The Traffic_Division_ND was created using the Streets_All feature class as the source edge feature and the Traffic_Division_ND_Junctions feature class as the source junction feature. The network also allows for global turns. Global turns describes turns that are permitted anywhere when two street segments meet. The network dataset has three default attributes and two additional attributes. The default attributes are: Class, used as hierarchy, Distance, used as cost, and Oneway, used as a restriction. The additional two attributes are: Minutes, used as cost, and RoadClass, used as a descriptor (Figure 3-2). 


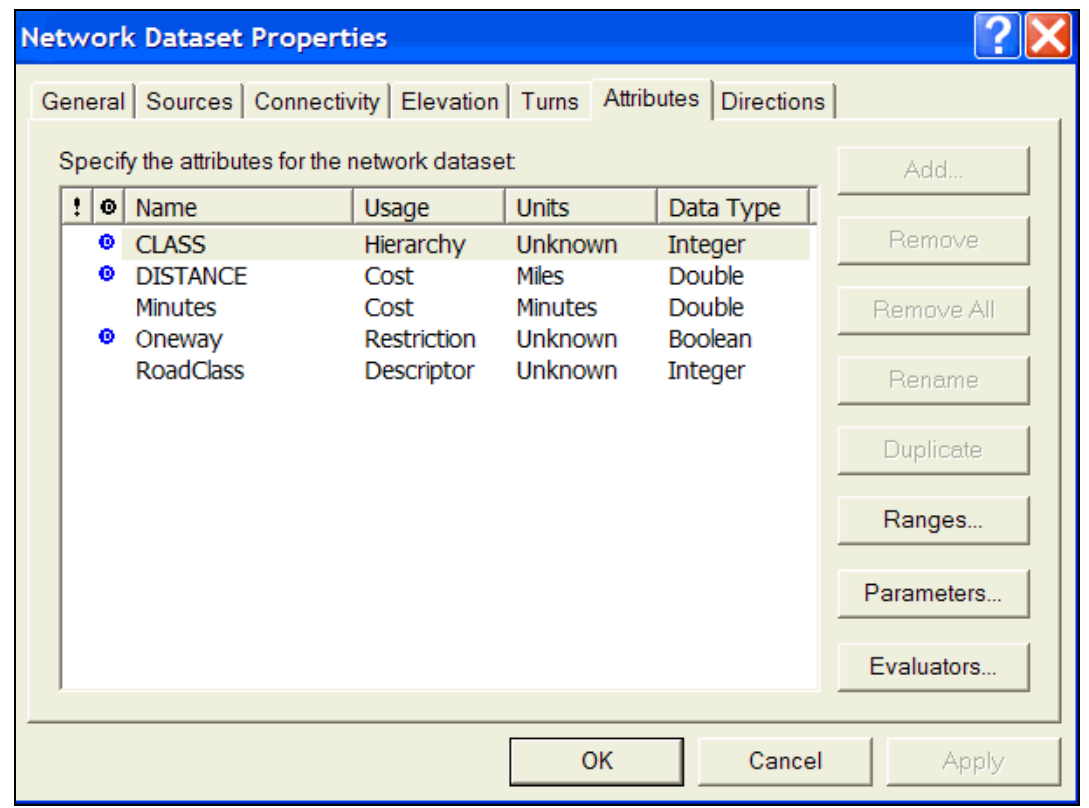

Figure 3-2 - Network Dataset Attribute Properties.

The network dataset also produces driving directions displaying length units as miles and utilizes Distance as the length attribute, Minutes as the time attribute, and RoadClass as the road class attribute (Figure 3-3).

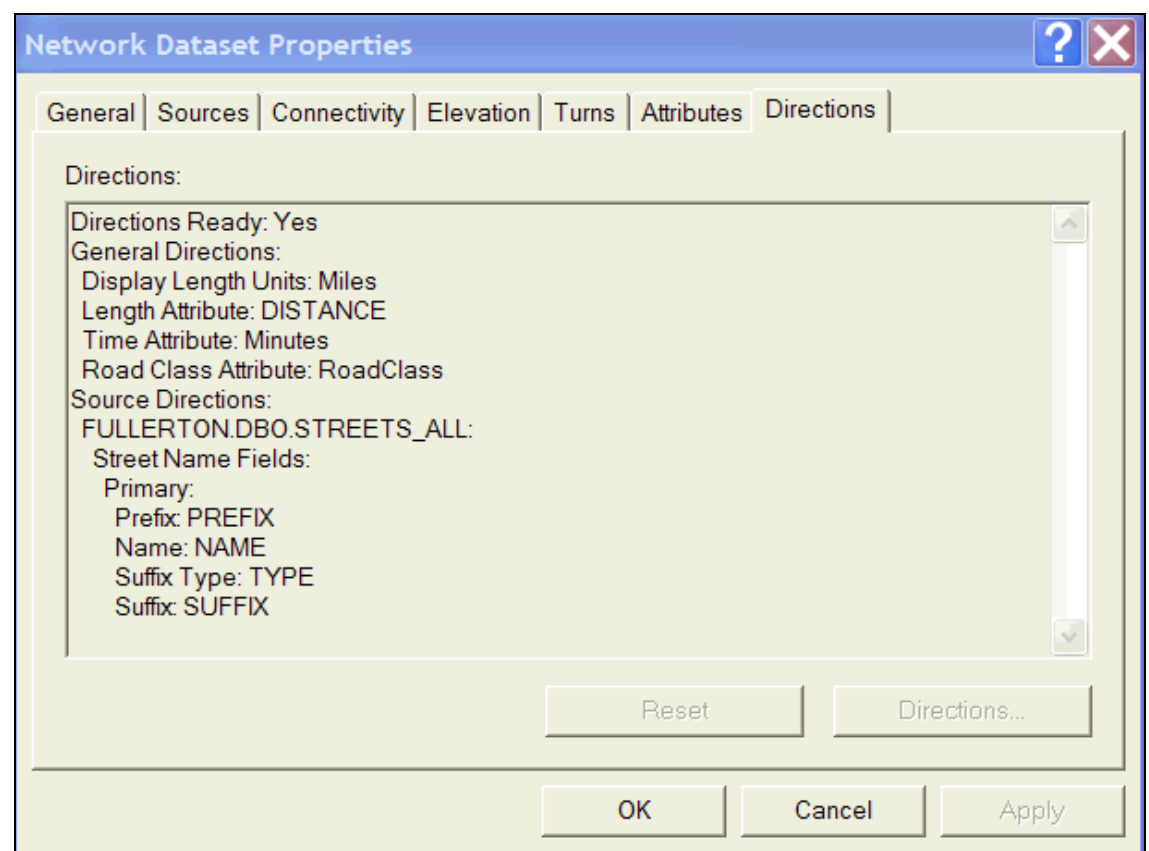

Figure 3-3 - Network Dataset Direction Properties.

3.2.5. Traffic_Division_ND_Junctions Feature Class

The Traffic_Division_ND_Junctions feature class is a source feature for the Traffic_Division_ND network dataset. Junctions or vertices are places at every 
intersection and street endpoint. The junctions feature class was created during the creation of the network dataset in ArcCatalog.

\subsubsection{Traffic_Division_Topology}

Topology in geodatabases manages how point, line, and polygon features share geometry and enforces data integrity rules defined by the user (ESRI, 2007). The

Traffic_Division_Topology manages the interaction between the Streets_All and

Traffic_Control feature classes. For vehicles to travel correctly on the network dataset, six rules were established to ensure that the two feature classes behaved properly (Figure 3-4). The six rules are as follows:

- Streets_All must not overlap, this means that no two streets can share the same exact spatial location.

- Streets_All must not have dangles, this translates into a street not ending without connecting to another street segment. Cul-de-sacs and dead end streets must be marked as exceptions.

- Streets_All must not self-overlap, this ensures that a street cannot back over itself and have two street segments in the same exact spatial location.

- Streets_All must not self-intersect, this prevents a street segment from turning and intersecting itself. Highway ramps that turn and pass over themselves as a bridge are marked as exceptions.

- Streets All must be a single part, this makes certain that a street cannot have two segments that are the same but in different locations. Each segment is required to have an individual ID.

- Traffic_Control point must be covered by line of Streets_All. This rule indicates that the Traffic_Control points must be snapped to the Streets_All feature class either at vertices or to the edge of the street segment.

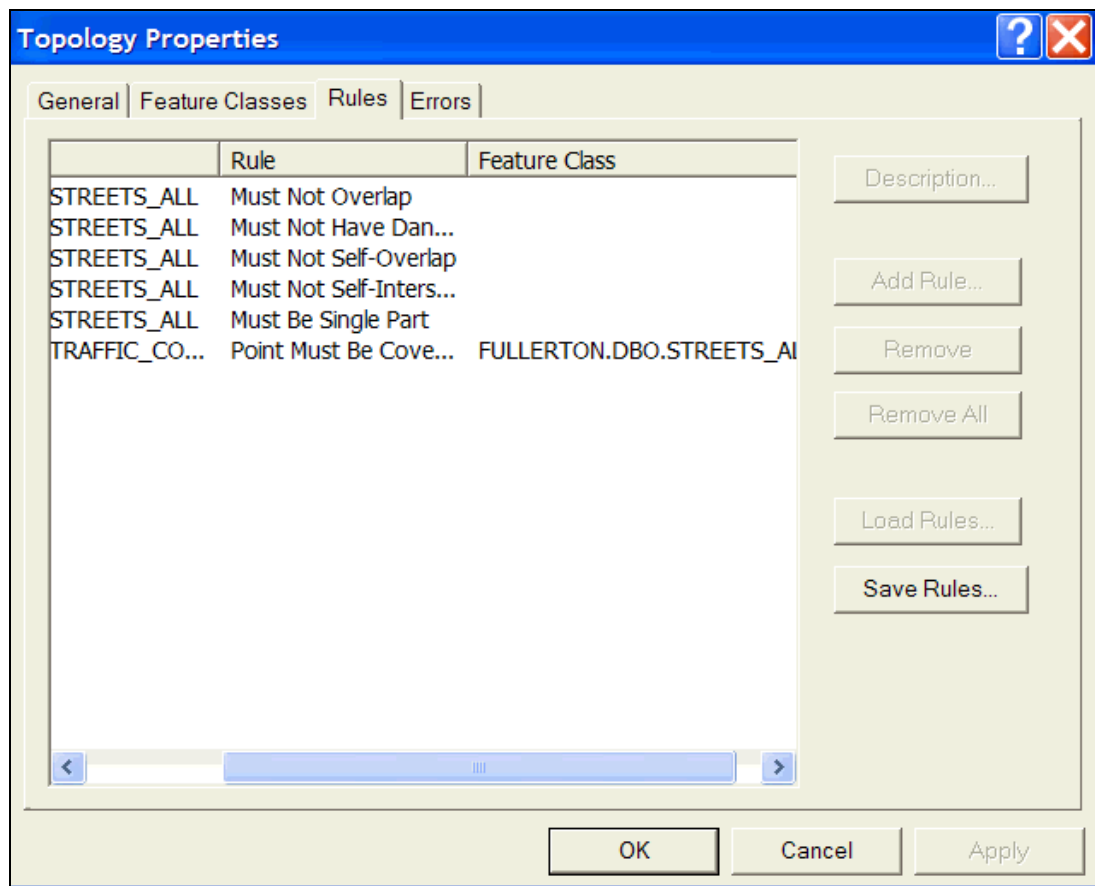

Figure 3-4 - Topology Rule Properties. 


\subsection{Boundary Feature Class}

The stand-alone feature class named Boundary does not belong to either feature dataset. The reason is because the city boundary is not a place of interest (Destination) nor does it belong to the City's Traffic Division. The Boundary feature class was imported as-is from data supplied by the City of Fullerton.

\subsection{Fullerton Ortho Raster}

The orthophoto named Fullerton_Ortho is a standalone raster dataset and cannot belong to a feature dataset. The raster was created from six United States Geological Survey (USGS) Digital Orthophoto Quarter-Quadrangles (DOQQ). The DOQQs have a ground resolution of 1 meter and are 3.75 minutes of latitude by 3.75 minutes of longitude in size. The six quarter-quadrangles used were: Orange Northwest, Anaheim Northeast, Anaheim Northwest, Yorba Linda Southwest, La Habra Southeast, and La Habra Southwest. After the orthophotos were downloaded from USGS, the six rasters were mosaiced using the "Mosaic To New Raster" tool from ArcToolbox to fit the spatial extent of the city.

\subsection{Domains and Subtypes}

To allow the client to easily edit existing data and enter new data, coded domains were created within Fullerton.dbo. Coded domains that were created are: Class, Control_Type_1, Destination_Type, Prefix, Speed_Limit, and Suffix. The Class domain specifies the magnitude of a street segment using the Census Bureau's Feature Class Code (FCC) (Table 3-1). Within the Traffic_Control feature class, the Control_Type_1 domain identifies the type of traffic control (i.e., stop sign, traffic signal, and crosswalk) at each point (Table 3-2). Within the Destinations feature class, the Destination_Type domain determines what type of establishment (i.e., restaurant, bar, shop, historical site, etc.) each destination point is (Table 3-3). Within the Streets_All feature class, the Prefix domain determines which directional indicator (i.e., North, South, East, or West) is placed in the title of a street name (Table 3-4). In the Streets_All feature class, the Speed_Limit domain specifies the speed limit of each street segment (Table 3-5). Within the Streets_All feature class, the Suffix domain identifies the type of street suffix (i.e., Avenue, Drive, Lane, Road, etc.) in a street's title (Table 3-6).

Table 3-1 - Class Domain

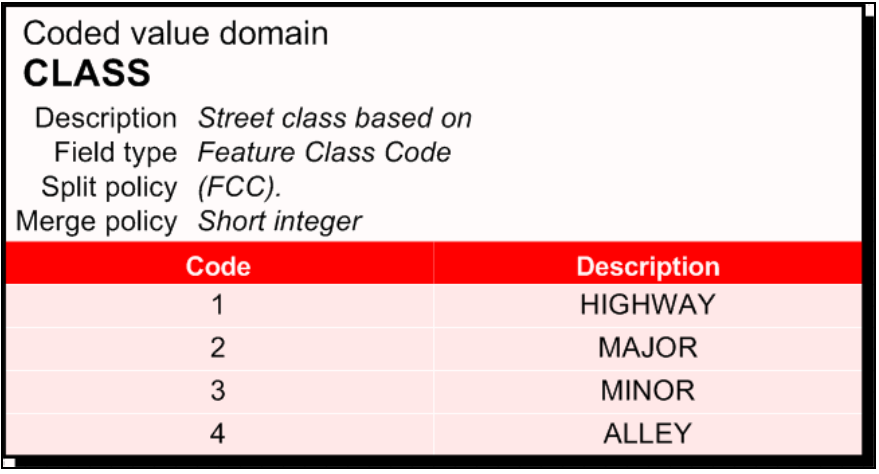


Table 3-2 - Control Type Domain

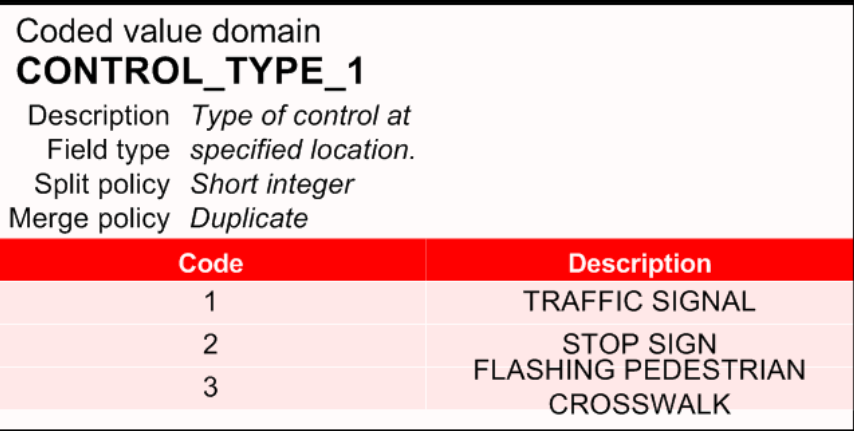

Table 3-3 - Destination Type Domain

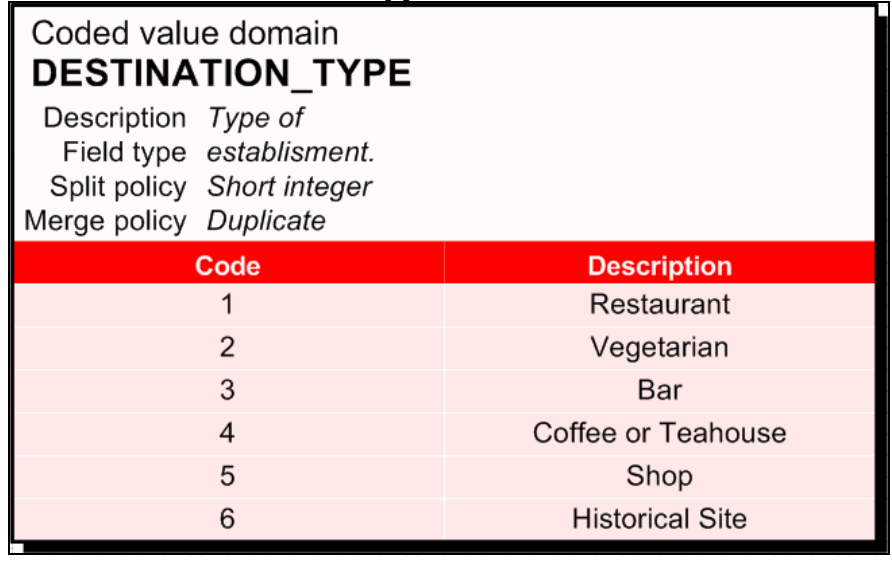

\section{Table 3-4 - Prefix Domain}

Coded value domain

\section{PREFIX}

Description Direction in street

Field type title.

Split policy String

Merge policy Default value

\begin{tabular}{|cc|}
\hline Code & Description \\
N & NORTH \\
S & SOUTH \\
E & EAST \\
W & WEST \\
NE & NORTHEAST \\
NW & NORTHWEST \\
SE & SOUTHEAST \\
SW & SOUTHWEST \\
\hline
\end{tabular}


Table 3-5 - Speed Limit Domain

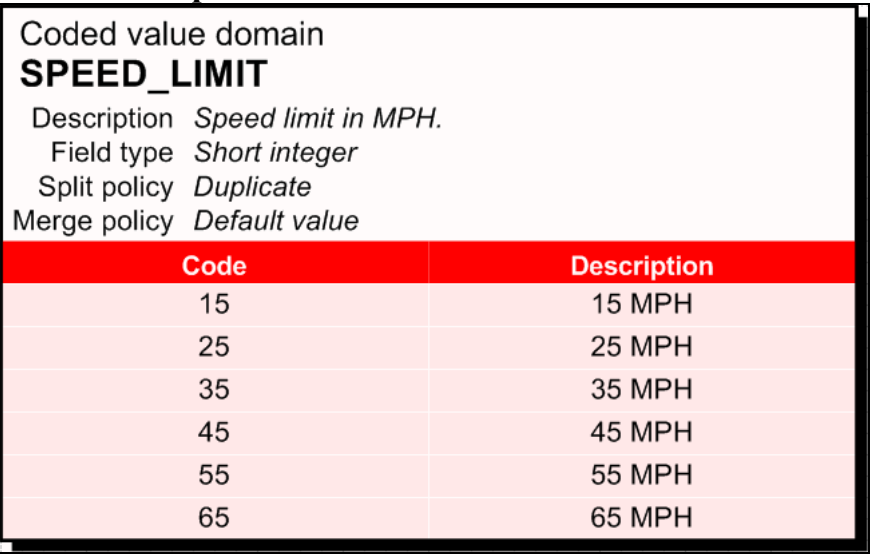

Table 3-6 - Suffix Domain

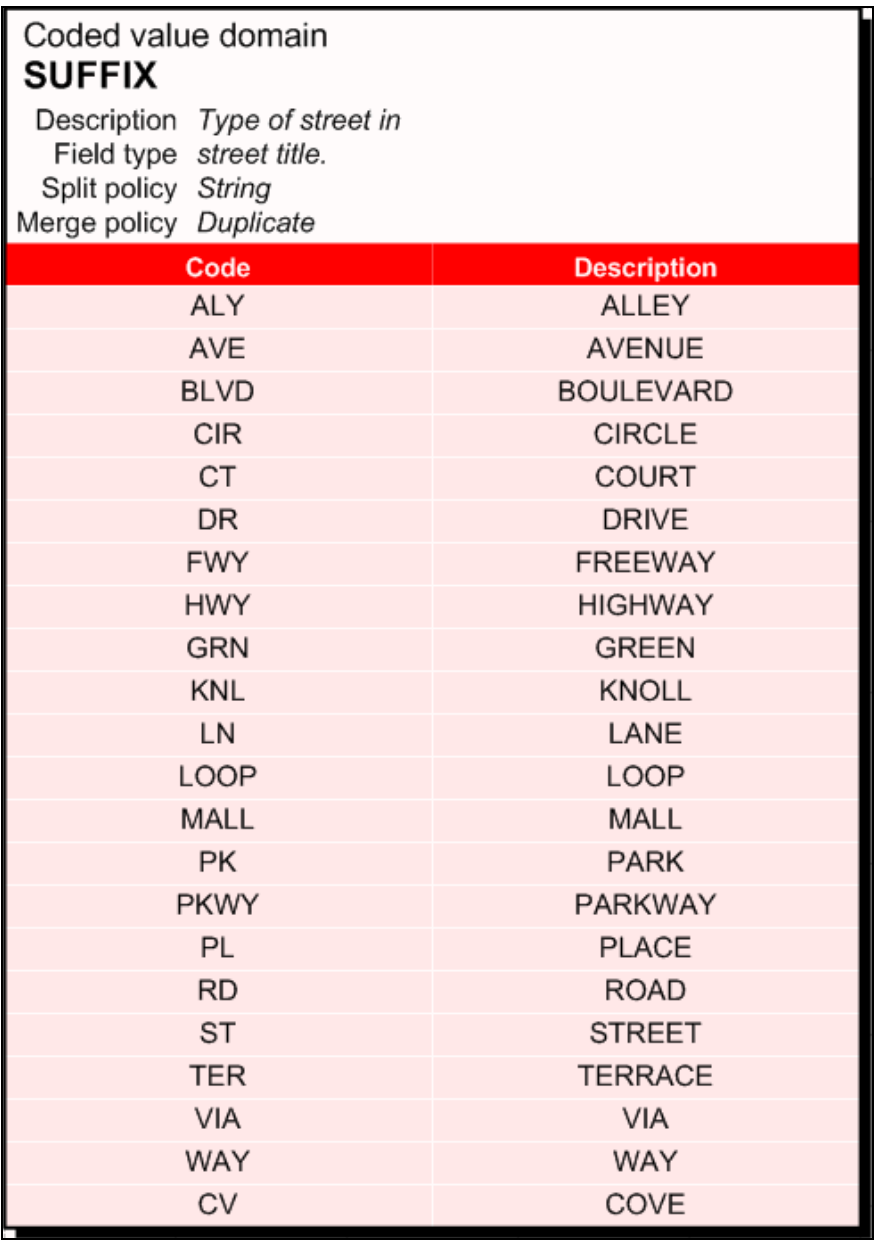

\subsection{Fullerton Address Locator}

The address locator, named FullertonAddressLocator, was built utilizing the US Streets locator as well as the Streets_All feature class as reference data (Figure 3-5). The address locator searches only for street name and street number since the Streets_All feature class 
only contains streets that belong to the City of Fullerton. An address locator that searches for anything more than a street name, such as city, state, and ZIP code was not necessary for the same reason.

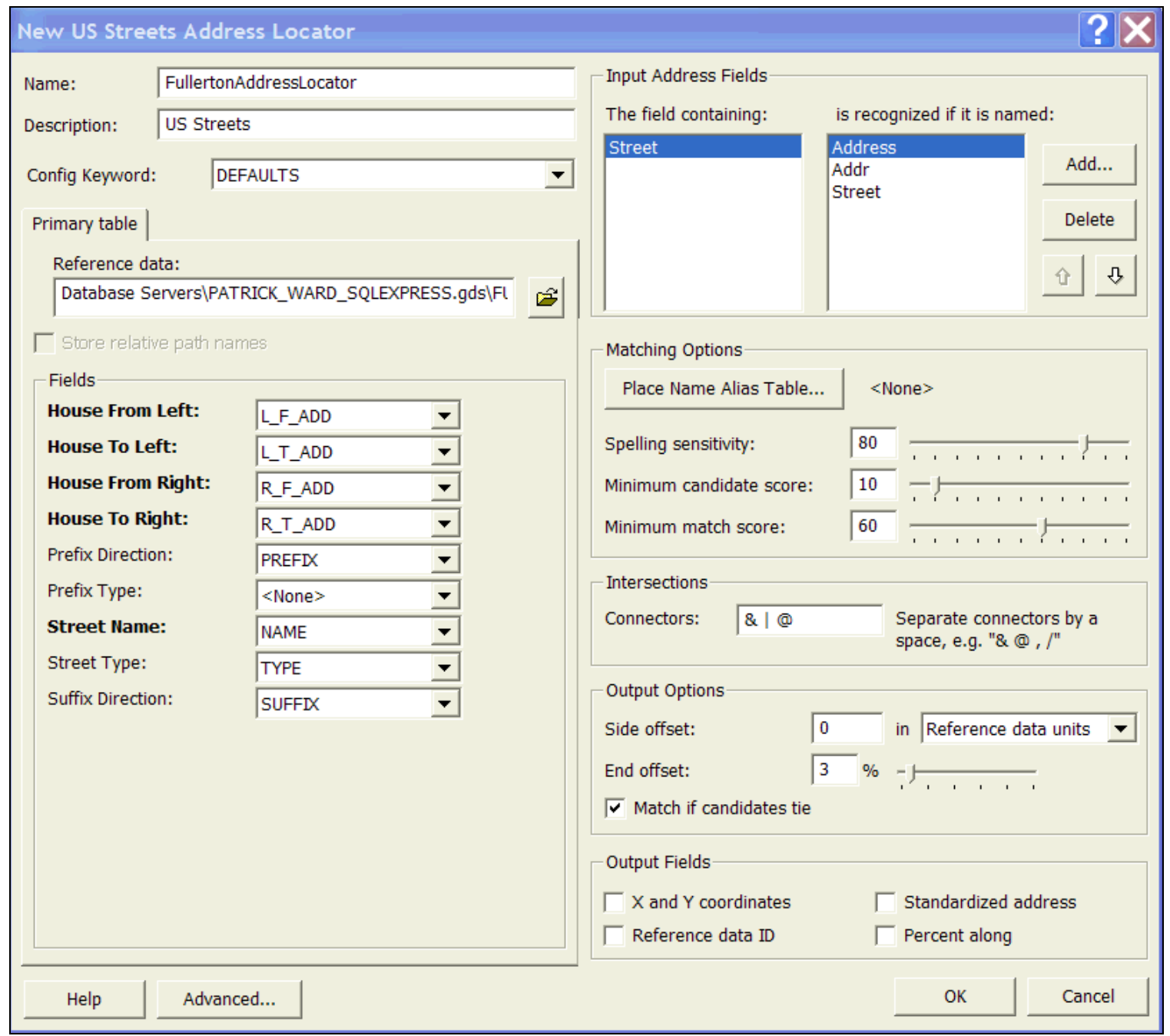

Figure 3-5 - US Streets Address Locator with Streets_All as Reference Data. 


\section{Application Design}

This section details the internal workings of the "Explore Fullerton" ArcGIS Server Web mapping application. The following sections explain how the application behaves and works to meet the needs of the proposed solution.

\subsection{Interface Description}

"Explore Fullerton" is a Web mapping application built for the City of Fullerton, California. The purpose of the application is to promote the city's CBD. Residents and visitors of Fullerton will be able to search for a business they wish to visit, and to obtain driving routes and directions. Residents and visitors will simply need to enter a starting and ending address within the city limits. The goal of this project is to inform Fullerton residents and visitors about the $\mathrm{CBD}$ and provide them with a way to explore the CBD.

The application was designed for end users who are not GIS savvy and have a limited knowledge of maps. For this reason, special considerations were kept in mind during the design phase. One consideration was the amount of data placed into the map combined with the level of the user's GIS knowledge. As a result, certain data layers were set to be scale dependent. When the application opens, the only data layers visible are the street layer and the city's boundary. Once the user zooms to a scale larger than $1: 5,000$, the other data layers that are scale dependent become visible. Since the map is then displayed on the Internet, another consideration was to show businesses with colorcoded symbols. Each symbol is also a different shape based on business type ensuring that a user will be able to recognize the symbols even if the map is ultimately printed in grayscale on a home printer.

\subsection{System Architecture}

The application, powered by ArcGIS 9.2 Server, was built using ArcGIS Server Manager. The authored map content was itself created using ArcGIS 9.2 Desktop applications, such as ArcMap and ArcCatalog. Once the map content is authored and the administrator has published this content on the Web, the user can connect to the Web application via the Internet over a wide area network (WAN) to explore the data, query for destinations or road projects, and print the map. The authored data is stored on the server computer in a Database Server using SQL Express. When the user explores the data or creates a driving route, the GIS Server returns the result to the client. The GIS Server has two parts: the Server Object Manager (SOM), and the Server Object Container (SOC). The SOM manages all the services on the server. The SOC reads and processes the data and returns maps and information to the user. The SOM manages SOC processes and creates new SOC processes as needed to service requests. Figure 4-1 depicts the systems architecture. 


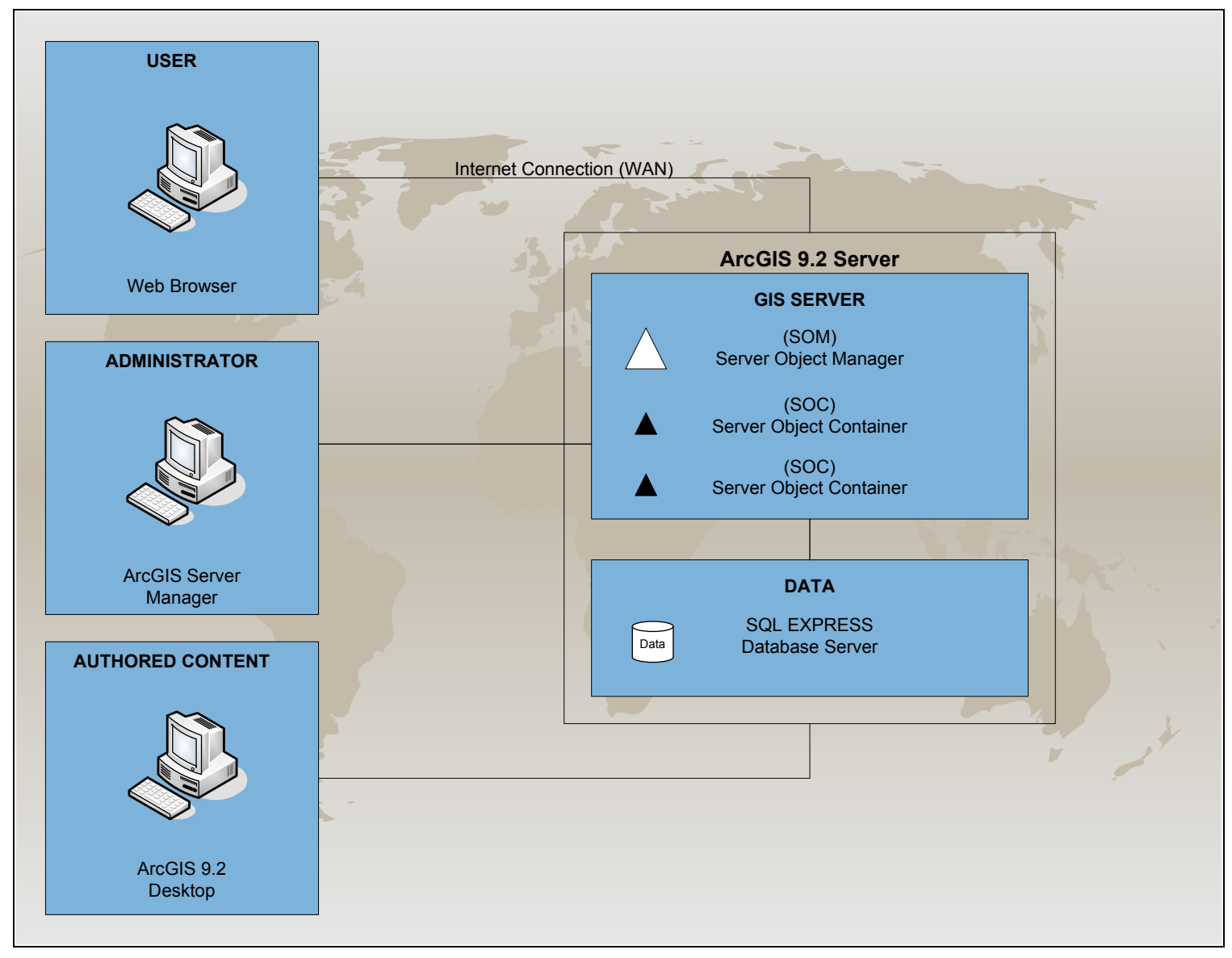

Figure 4-1 - "Explore Fullerton" System Architecture.

\subsection{Server Object Container Permissions}

In order to allow the SOC to access the data within the Fullerton geodatabase, the ArcGIS Server SOC account needed to be granted permissions to do so. To give the ArcGIS Server SOC account permissions, it was first added as a user of the ArcSDE Database Server (Figure 4-2). 


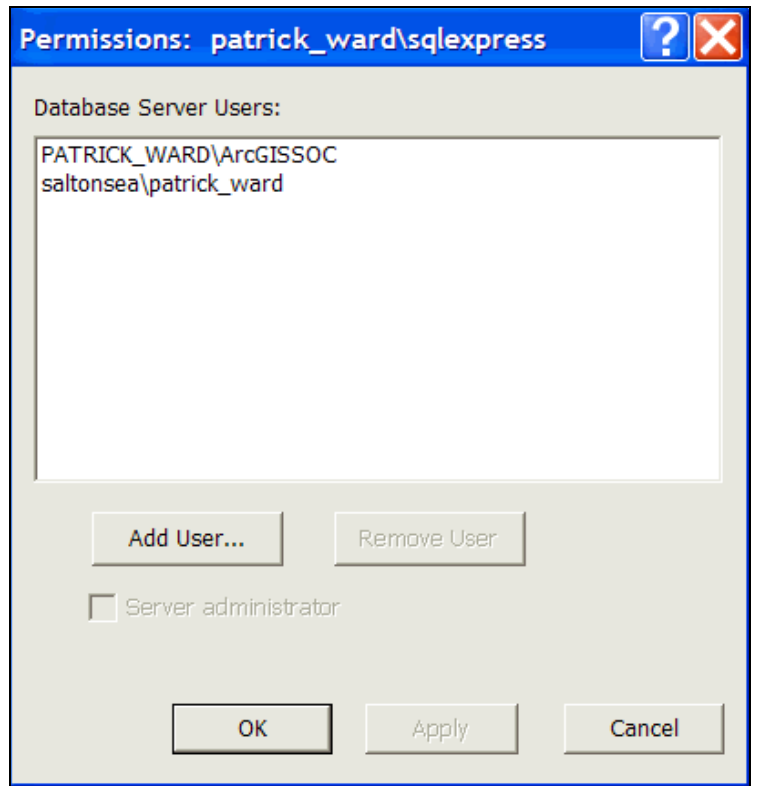

Figure 4-2 - SOC Permissions on the Database Server.

Once this was completed, the ArcGIS Server SOC account was given read and write access by adding the ArcGIS Server SOC account to the Geodatabase Permissions and selecting the Read/Write option (Figure 4-3). Read access is necessary because it allows the application to read and display the data in the Fullerton geodatabase.

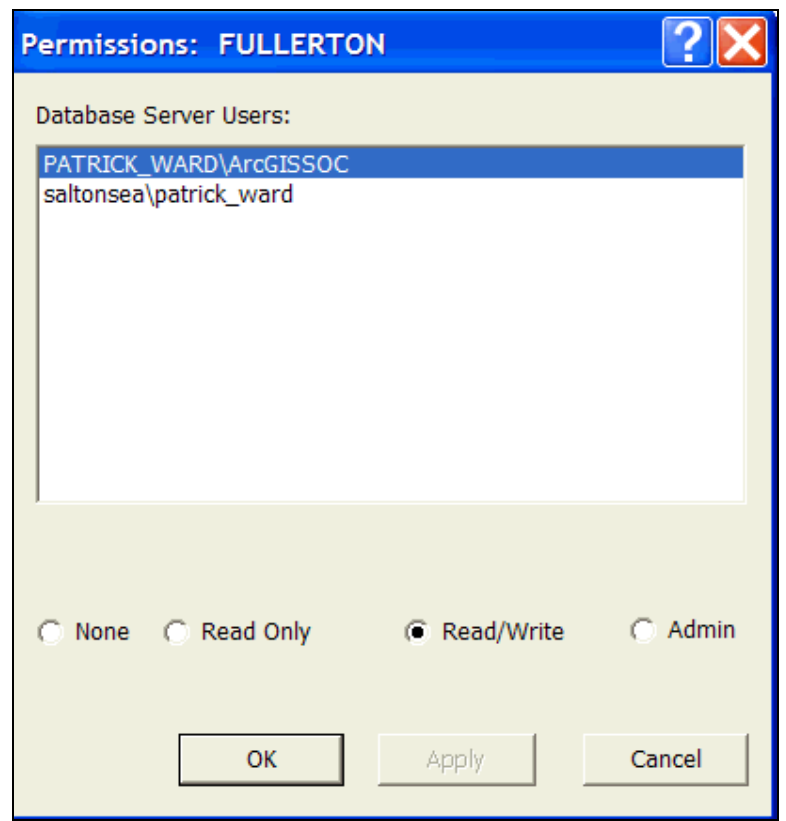

Figure 4-3 - SOC Read/Write Permissions on the Fullerton Geodatabase. 


\section{Application Development}

The development of the "Explore Fullerton" ArcGIS Server Web mapping application had four stages. In the first stage, a map document (MXD) titled Fullerton.mxd was created in ArcMap. In the second stage, the Fullerton MXD and the FullertonAddressLocator, created in the Fullerton Geodatabase, were published as services in ArcCatalog. The application was then designed in ArcGIS Server Manager in the third stage. Finally, the application was customized in Microsoft Visual Studio 2005.

\subsection{Fullerton Map Document}

The MXD was created in a manner that allows users to easily locate themselves within the city using the initial view extent of the map. The initial view extent contains only the Fullerton_Ortho, Streets_All, and Boundary layers. Limiting the layers that the user sees makes the map simple and easy to read. Other data layers, such as the Destinations, Traffic_Controls, Road_Projects, Parks, and Parking, do not need to be shown, as they would clutter the map at this scale. As a result, the layers that are easier to view at a larger scale were set to a scale dependency of 1:5,000 (Figure 5-1). Upon zooming into this larger scale, the layers turn on and display their symbology.

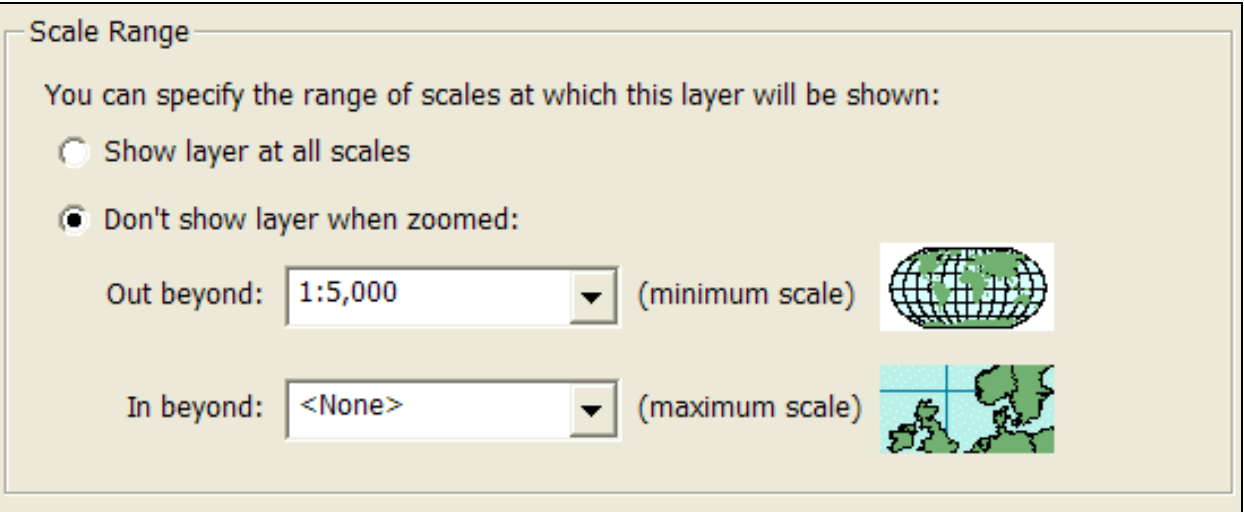

Figure 5-1 - Fullerton Map Document Layer Scale Dependency.

The symbology for the Destinations and Traffic Control layers use mimetic symbols that mimic or imitate the feature being symbolized (Figures 5-2 \& 5-3).

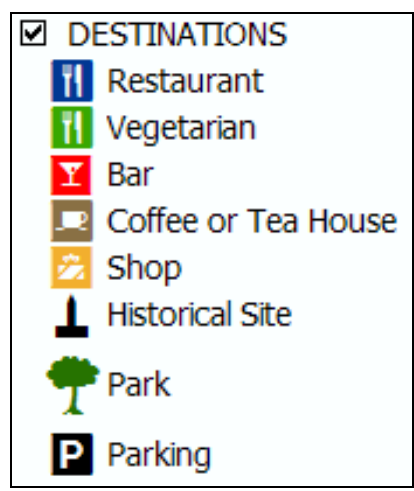

Figure 5-2 - Destinations Symbology. 


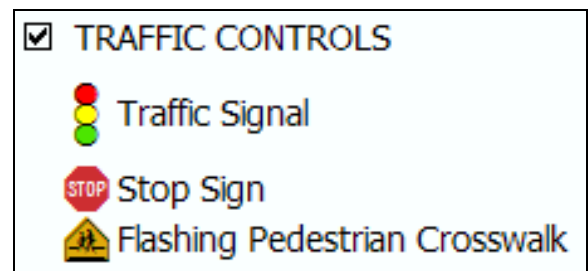

Figure 5-3 - Traffic Controls Symbology.

This helps the user identify what the feature is as the icon is visually related to what it represents. These layers also use hue to aid the mimetic symbol to more accurately represent the feature that it is mimicking. For example, the Vegetarian and Park symbols are green, like green vegetables or vegetation; the Coffee or Tea House symbol is brown, like the color of coffee; and the Parking symbol is black, like asphalt. The Traffic_Control layer has a customized traffic signal symbol that mimics a street signal, three circles with a black border stacked vertically with red on top, yellow in the middle, and green on the bottom. The custom symbol was designed in ArcMap using the Symbol Selector Editor (Figure 5-4).

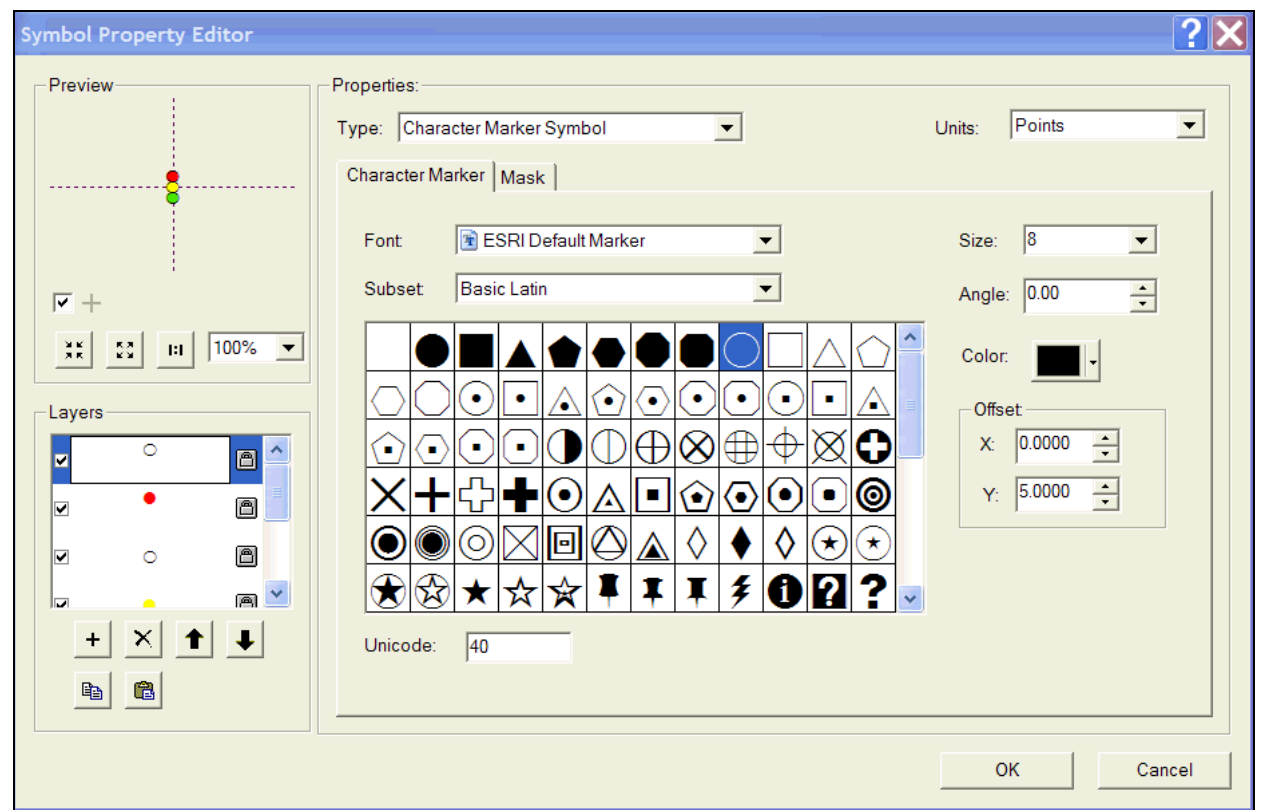

Figure 5-4 - Traffic Signal Symbol Property Editor.

The Streets All layer uses line size and hue to show the user that some streets are more important than others (Figure 5-5).

\begin{tabular}{|l}
$\square$ STREETS \\
- Highway \\
- Major \\
- Minor \\
- Alley
\end{tabular}

Figure 5-5 - Streets_All Symbology. 
For example, major streets are symbolized with thick black lines, whereas minor streets are symbolized with thin gray lines. The black lines for the major streets were drawn thick to give more significance. For this same reason, highways were symbolized with a red line so that they would be more noticeable than the major roads, allowing them to appear more significant.

\subsection{Publishing Services in ArcCatalog}

ArcGIS Server Manager allows five different types of services to be published. The five types of services are as follows: an MXD can be published as a map service; an address locator can be published as a geocode service; a geodatabase can be published as a geodata service; scripts, models, and tools can be published as geoprocessing services; and a globe document created in ArcGlobe can be published as a globe service.

To publish services in ArcCatalog, an administrative connection to an ArcGIS Server was added to manage GIS Services. Once this connection was made, the GIS resources were published to this server and were made available to the associated applications. For this project, two services needed to be published. The Fullerton MXD was published as the application's map service and the DBO.FullertonAddressLocator was published as the application's geocode service. The GIS resources were published in ArcCatalog. Since the Fullerton MXD service is used to obtain driving routes with the Network Analysis extension, the Network Analysis capability was set to an enabled state (Figure 5-6).

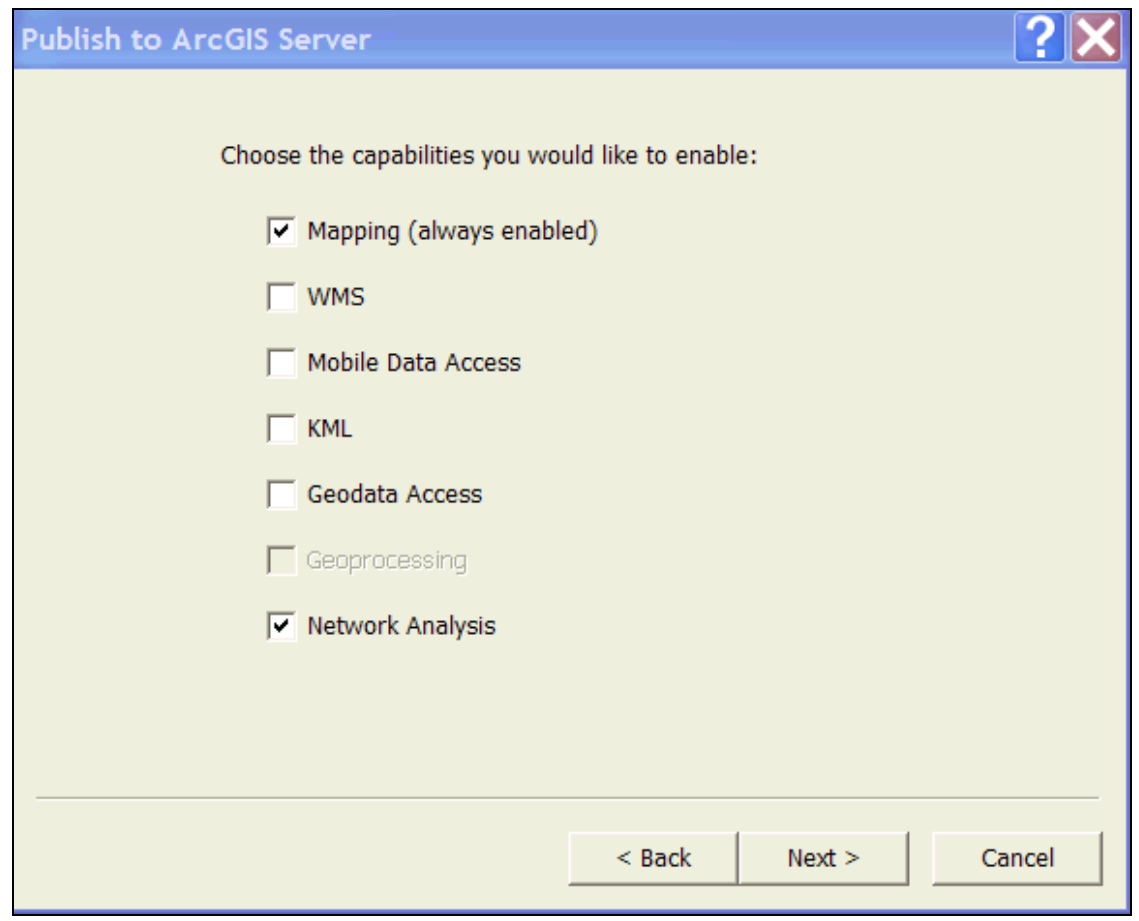

Figure 5-6 - Enabling Network Analysis while Publishing to ArcGIS Server. 


\subsection{Designing Explore Fullerton with ArcGIS Server Manager}

ArcGIS Server Manager is a web application that allows the administrator to publish services to the Web, create and design Web applications, and to manage the GIS Server.

\subsubsection{Adding Service Layers}

When creating Web applications with ArcGIS Server Manager, the map services that the application will use were added. The graphic below displays the process of adding the Fullerton map service to the "Explore Fullerton" Web mapping application (Figure 5-7).

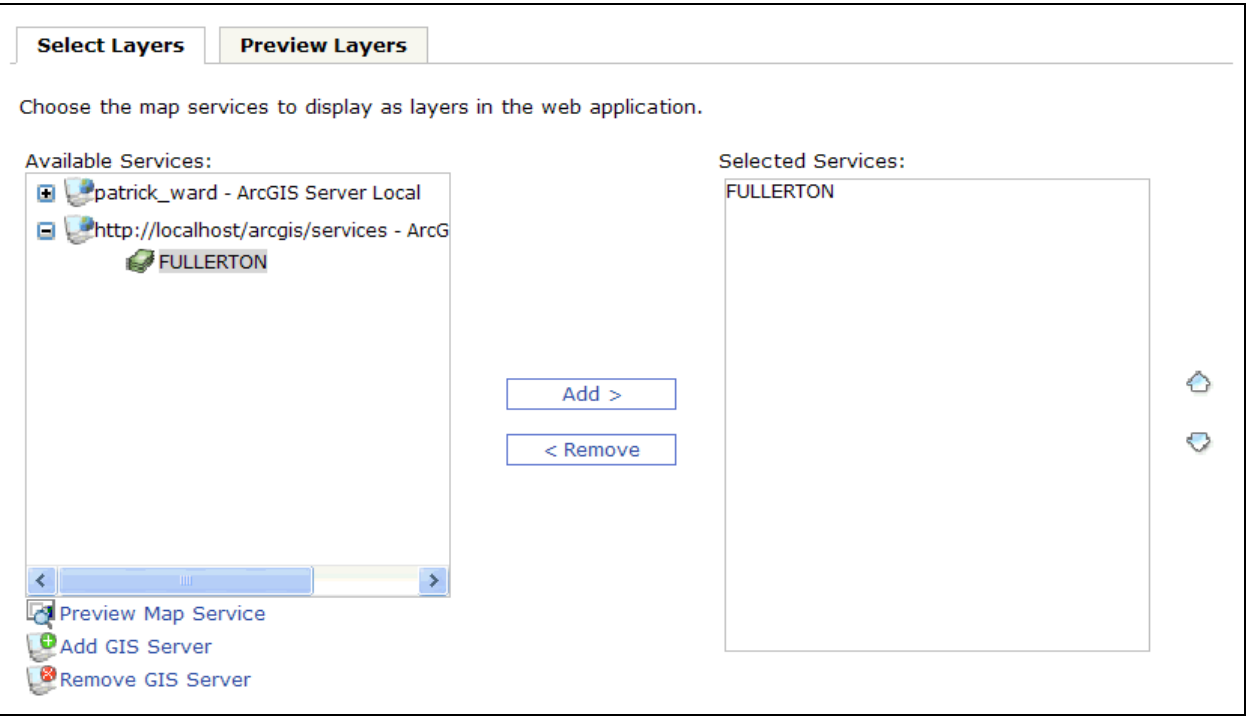

Figure 5-7 - Adding the Fullerton Map Service in ArcGIS Server Manager.

\subsubsection{Adding Tasks}

Once the desired services were added to the application, a set of tasks were added. Tasks act like tools and allow a user to interact with the map. Standard tasks available in ArcGIS Server are: editing, find address, find place, geoprocessing, query attributes, and search attributes. "Explore Fullerton" uses three query attribute tasks titled: Find Destination by Name, Find Destination by Type, and Find Road Project by Type. There is also a find address task, titled Find Fullerton Address. An additional print task, titled Print Your Map, developed by Bryan Baker at ESRI in Redlands, California, was also added to the "Explore Fullerton" Web mapping application (Baker, 2007). Although this task is not out-of-the-box functional in ArcGIS Server 9.2, it is available as an official sample for the Web ADF/ArcGIS Server and is scheduled to be included with the ArcGIS Server 9.3 release.

After the desired tasks for the application were selected and added, further configuration was needed to ensure they functioned properly. Each task was individually selected and configured in the Task Configuration window. In the window, the task name and button text were edited and the query settings were customized. Figure 5-8 depicts the Find Destination by Name task during configuration. 


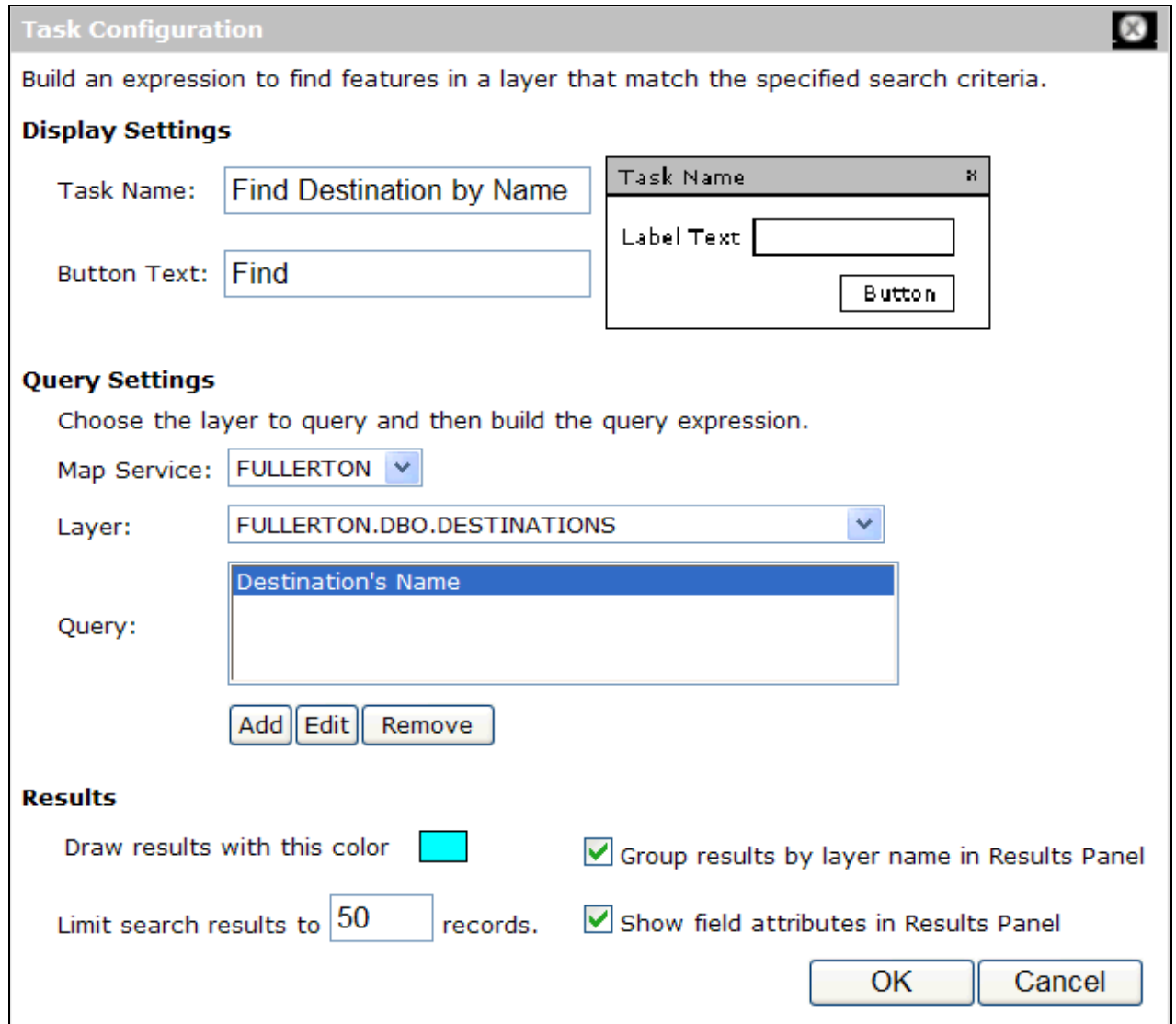

Figure 5-8 - Find Destination by Name Task Configuration.

To add or edit the query settings for the query task, the layer to be queried within the Fullerton map service was selected. In "Explore Fullerton" a query for Destinations was desired, and the Destinations layer was chosen. In the Form Entry window, Destination's Name was chosen as the label text and specified that the query search within the Name field. In order to have all the names shown to the user from a list, Select from List was chosen and all sample values within the name field were stored as the list of possible Destination names. This example can be seen in Figure 5-9. The Find Destination by Type and Find Road Project by Type query attribute tasks were configured using the same method. 


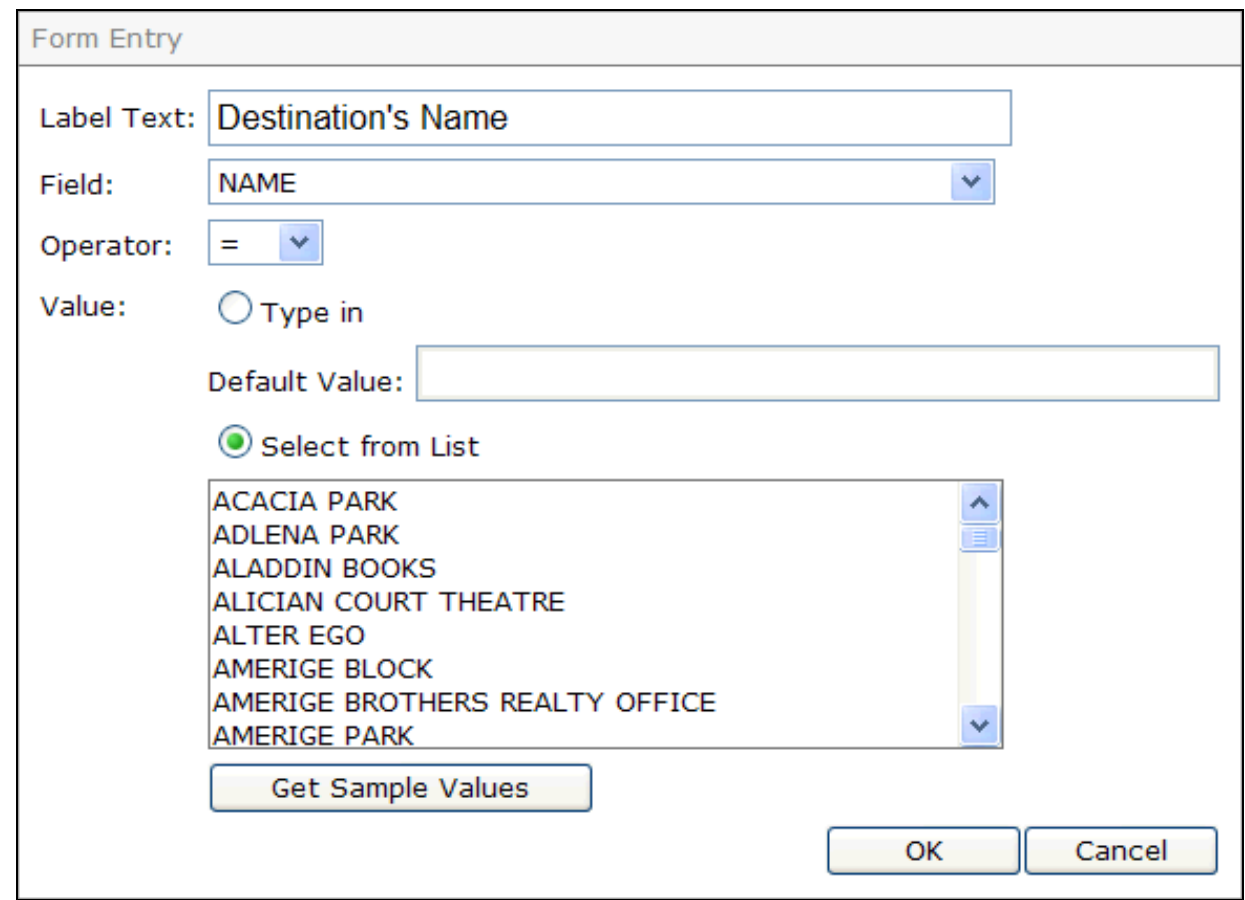

Figure 5-9 - Find Destination by Name Form Entry.

To add and configure the find address task, the FullertonAddressLocator geocode service was added as a supporting service. Once the geocode service was selected, the find address task was added to the application. After adding the task to the application, the task was configured using the Task Configuration window. The name of the task, a help tip, button text, and geocode service were configured. In Figure 5-10, the Find Fullerton Address task has been configured (Figure 5-10).

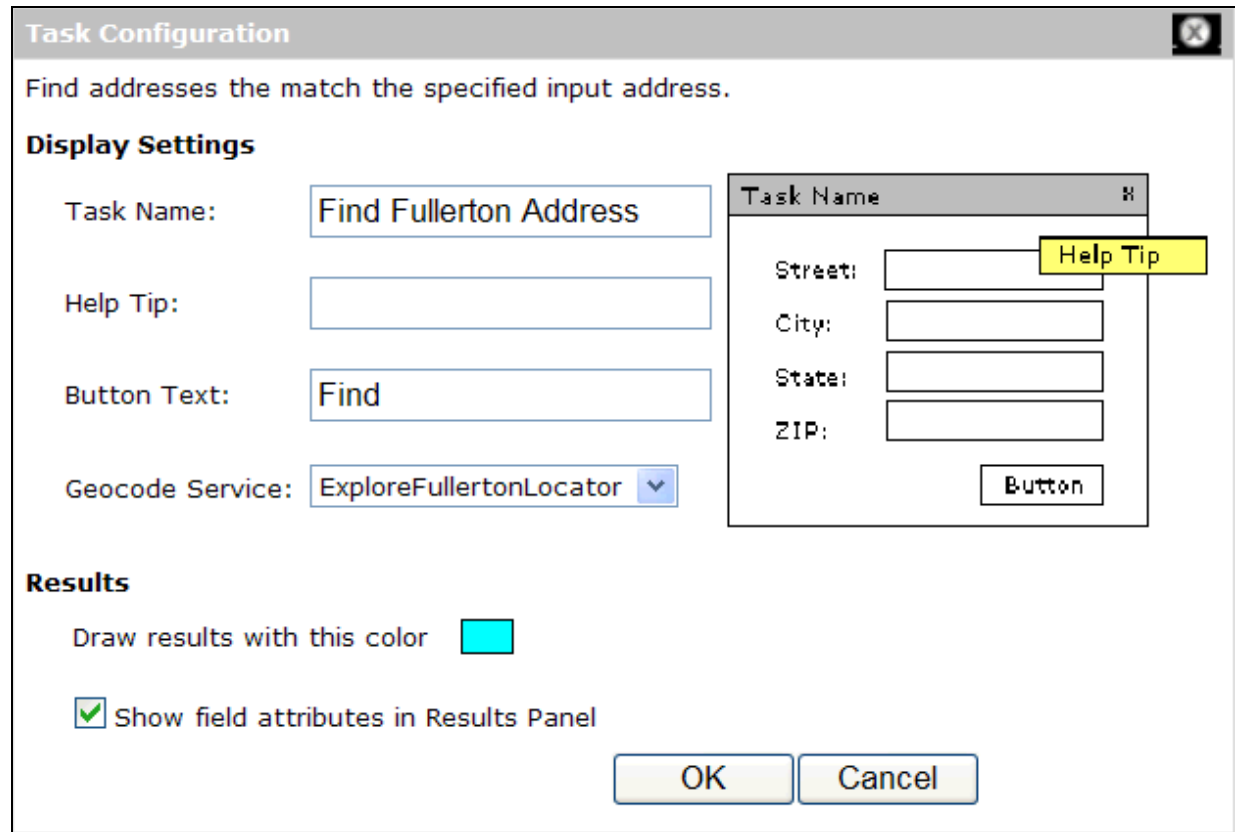

Figure 5-10 - Find Fullerton Address Task Configuration. 
After selecting the Print Task and adding it to the application, it was configured in the Task Configuration window. In this window, the tasks name, print page title, map width, map resolution, and attribute details were configured. The Print Your Map tasks configuration can be seen in Figure 5-11.

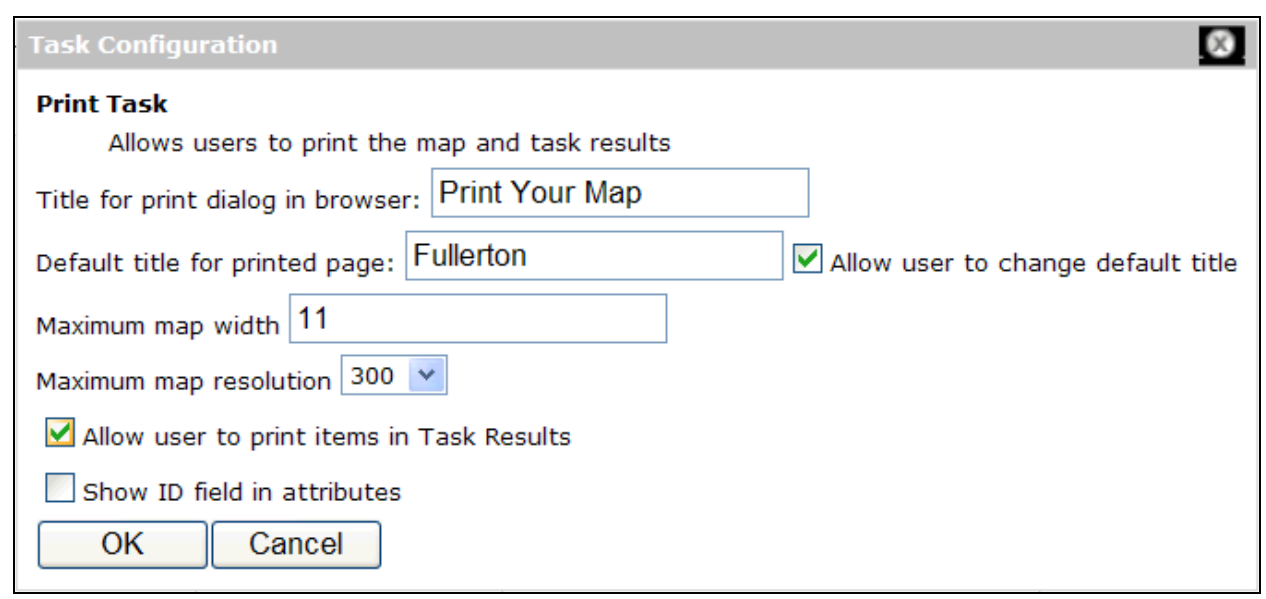

Figure 5-11 - Print Your Map Task Configuration.

\subsubsection{Setting Page Properties}

After selecting and configuring the application's tasks, the page properties were established using the Set Page Properties wizard. Properties that were customized were the title of the page, theme or color of the application, and Web page links. The "Explore Fullerton" title was set to be Explore Fullerton, and a light blue color was selected as the application's theme. Four Web page links were also added to the application. The Web page links are as follows: (a) http://localhost/DriveFullerton/default.aspx, which is a link to another ArcGIS Server Web mapping application titled Drive Fullerton that is part of this project and displays driving routes and directions, (b) http://www.institute.redlands.edu/msgis/ which is a link to the University of Redlands MS GIS Program, (c) http://www.cityoffullerton.com/, which is a link to the City of Fullerton Homepage, and (d) Help/Default.htm, which is a link to an ArcGIS Server Website Help page. The "Explore Fullerton" page properties can be seen in Figure 5-12. 


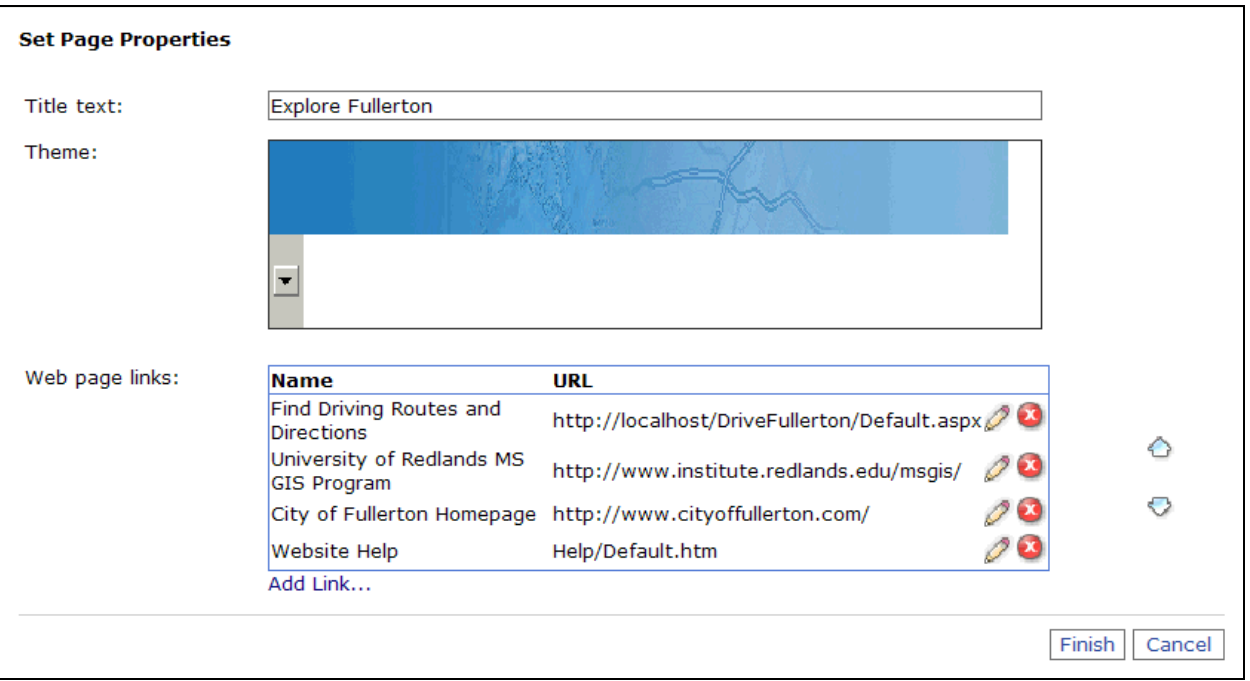

Figure 5-12 - Explore Fullerton's Page Properties.

\subsubsection{Enabling Map Elements}

Once the page properties were established, the last step in creating the "Explore Fullerton" Web mapping application was to enable the map elements on the page. Using the Enable Map Elements Wizard, elements such as the Table of Contents (TOC), Overview Map, Toolbar, North Arrow, and Scale Bar can be enabled or disabled by selecting the check box for the corresponding element. The elements enabled for the "Explore Fullerton" application were the TOC and Toolbar. Since the application opens with a simple overview map of the city, an additional overview map was not necessary. Also, because the target users are residents from the City of Fullerton and visitors from surrounding local areas, a north arrow was not included, as users will be able to spatially visualize the area. Within the Toolbar elements, a distance measuring tool is included so this eliminated the need for a scale bar. It was also determined that the scale bar provided with ArcGIS Server would draw the users' attention away from the map. After checking and enabling the elements for the application, additional settings needed to be set for the TOC. The TOC was set to display layer symbology and to be active upon application startup. Figure 5-13 displays the settings selected for the TOC element. 


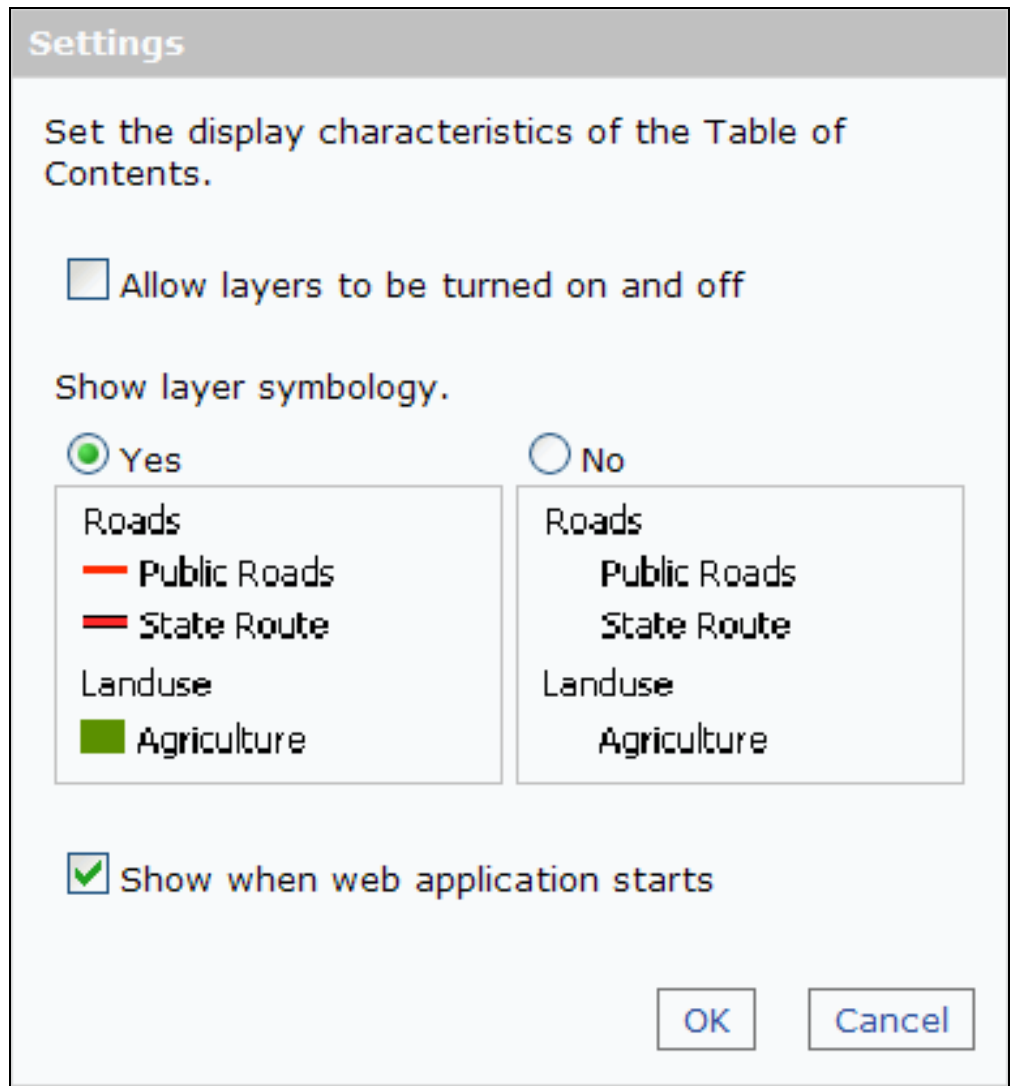

Figure 5-13 - Table of Contents Element Settings.

\subsection{Application Customization in Microsoft Visual Studio 2005}

In order to create a friendly environment for non-GIS users, customization to the Web application was completed in Microsoft Visual Studio 2005. Expand Depths were changed from the default " 0 ", which is not expanded, to an Expand Depth of " 2 ", which is expanded two layers deep, in order to allow users to view the results in the Task Results window more easily. (Figure 5-14, 5-15 \& 5-16).

๘ FULLERTON

Figure 5-14 -Expand Depth "0".

E FULLERTON

๘ DESTINATIONS

Figure 5-15-Expand Depth "1". 


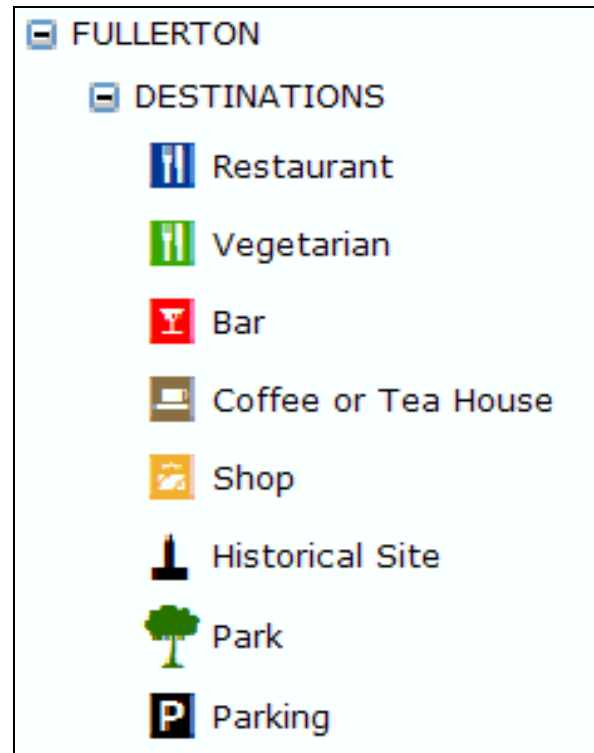

Figure 5-16 -Expand Depth "2".

Since the application was developed not to display the elements overview map, north arrow, and scale bar, a space was left unfilled by the left panel. To resolve this empty space, the TOC panel was enlarged to fill the vertical length of the page. When users visit the application, the TOC extends down along the left vertical side of the page and fills the empty space to provide better visual balance (Figure 5-17).

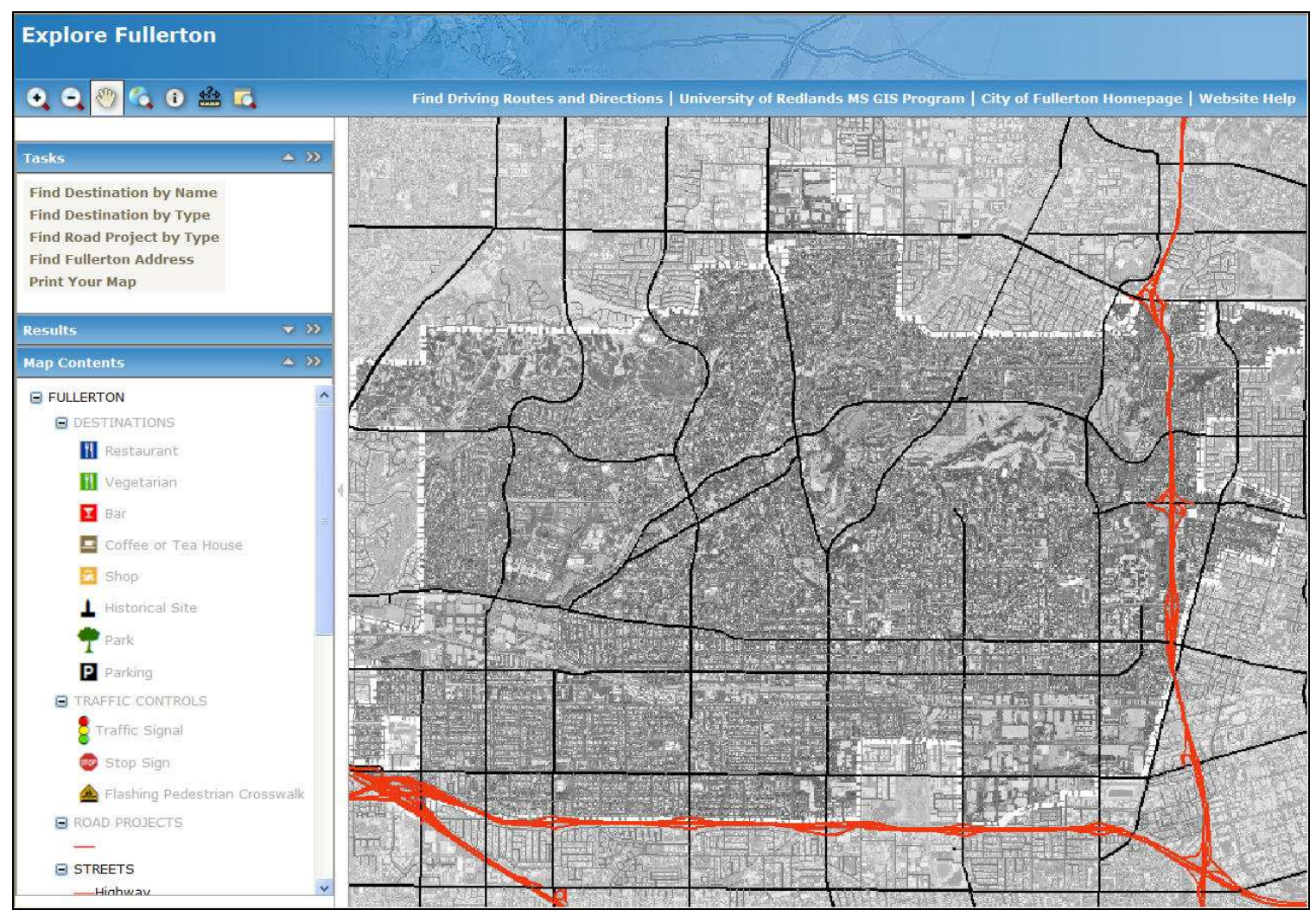

Figure 5-17 - "Explore Fullerton” Web Mapping Application. 
The default Help window was also customized to fit the needs of users accessing the "Explore Fullerton" Web mapping application. A section of the default help page provides information on editing the data within the application. Since the users of "Explore Fullerton" are unable to edit data, this section of the help page was removed. The title on the help page was changed from Web Mapping Application Help Page to Explore Fullerton Help Page (Figure 5-18).

\section{Explore Fullerton Help Page}

\section{Getting started \\ Quick tour}

Find Explore the map

- Identify features on the map

- Search for features

- Measure distance and area

- Using Results

- Using the mouse

- Using the keyboard

- Using the Overview and Magnifier

- Using the Toolbar

Personalize

- Working with layers and map contents

More information

- System requirements

- Frequently asked questions and troubleshooting

- Getting more help and information

Figure 5-18 - "Explore Fullerton” Customized Help Page.

\subsection{Routing Functionality}

The applications routing functionality was developed using an example called NAServer (Network Analyst Server) obtained from the ESRI Developer Network (EDN) website. The sample can also be found in the Developer Kit installed on the server. With help from Nathan Strout of the Redlands Institute, at the University of Redlands, this example was customized to work using the Fullerton map service and FullertonAddressLocator geocode service. The NAServer example was set up to use an address locator that searches for street number, street name, city, state, and ZIP code. Since the "Explore Fullerton" Web mapping application is focused on the City of Fullerton, the FullertonAddressLocator geocode service was set up to search only for street number and street name. In order to restrict the search by street number and name, the code was changed from multiple If statements to a single If statement that searches for street name (Figure 5-19 \& 5-20). 


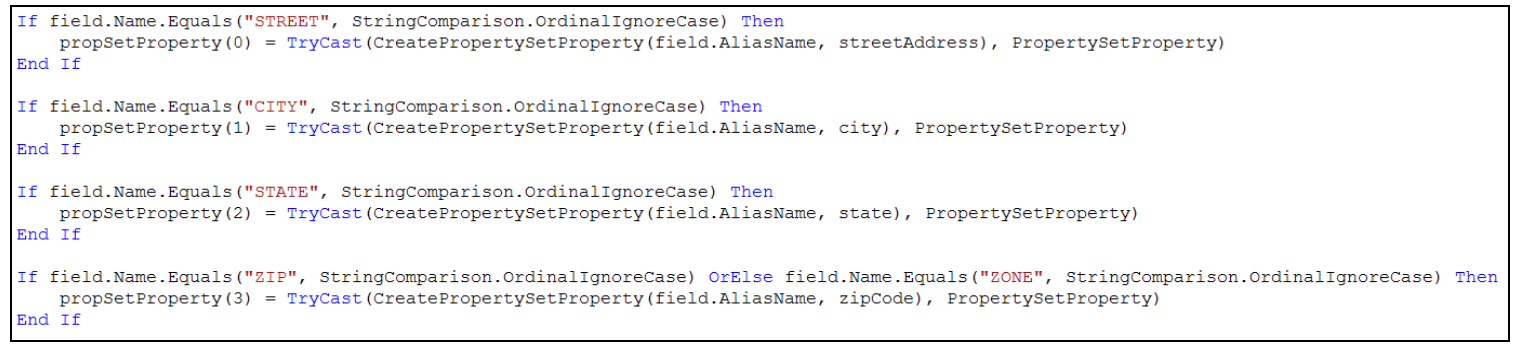

Figure 5-19 - NAServer Example Geocoding with Multiple If Statements.

If field.Name.Equals("STREET", StringComparison.OrdinalignoreCase) Then

propsetProperty $(0)=$ TryCast (CreatePropertySetProperty (field.AliasName, streetAddress), PropertysetProperty) End If

Figure 5-20 - Explore Fullerton Geocoding with Single If Statement.

The design of NAServer was also changed to eliminate the need for a user to enter a city, state, and ZIP code. If the user was to enter this information, the application would not be impacted, as the code would not search for it; however, it was changed to make the form appear simpler. The text boxes for city, state, and ZIP code were deleted and an example label was added to demonstrate how to enter an address (Figures 5-21 \& 5-22).

\begin{tabular}{|c|c|c|}
\hline \multicolumn{3}{|c|}{ Starting from: } \\
\hline \multicolumn{3}{|c|}{ Street Address } \\
\hline \multicolumn{3}{|c|}{ 925 Jackson Street } \\
\hline City & State & ZIP \\
\hline Albany & California & 94706 \\
\hline \multicolumn{3}{|c|}{ Arriving at: } \\
\hline \multicolumn{3}{|c|}{$\begin{array}{l}\text { Street Address } \\
\text { 213 Wilshire Avenue }\end{array}$} \\
\hline City & State & ZIP \\
\hline San Francisco & Ealifornia & Gode \\
\hline
\end{tabular}

Figure 5-21 - NAServer Address Form. 


\begin{tabular}{|l|}
\hline Starting from: \\
\hline Street Address \\
\hline ex. 303 W Commonwealth Ave \\
\hline Arriving at: \\
\hline Street Address \\
\hline ex. 303 West Commonwealth Avenue \\
\hline
\end{tabular}

Figure 5-22 - "Explore Fullerton" Address Form.

Once the code and forms were changed to allow the geocoding to work on the FullertonAddressLocator, the MapResourceManager and the GeocodeResourceManager were set so that the application would read the "Explore Fullerton" services. To set the MapResourceManager, the Map Resource Definition Editor was opened and the Fullerton map service was selected from ArcGIS Server (Figure 5-23).

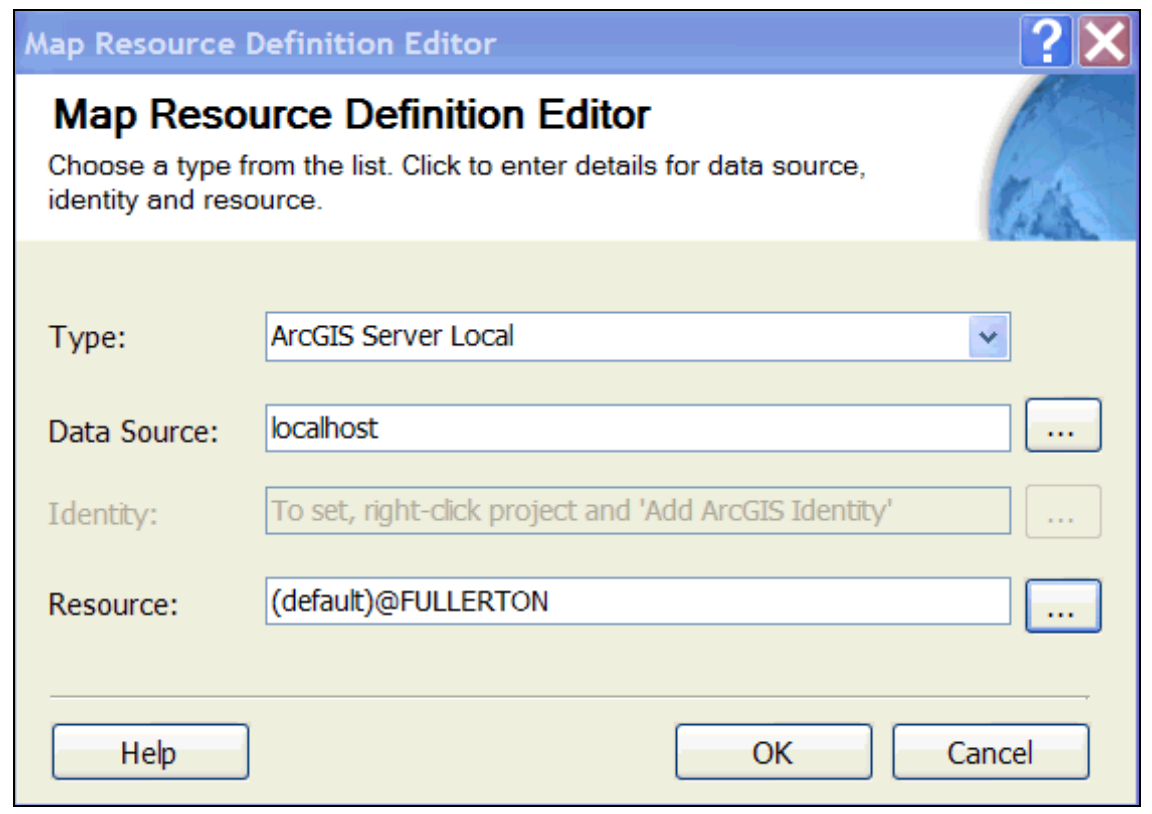

Figure 5-23 - Setting Map Service in the Map Resource Definition Editor. 
Since the NAServer example reads the geocode service behind the scenes, no actual GeocodeResourceManager needed to be set. Instead, the code was changed to read the FullertonAddressLocator geocode service (Figure 5-24).

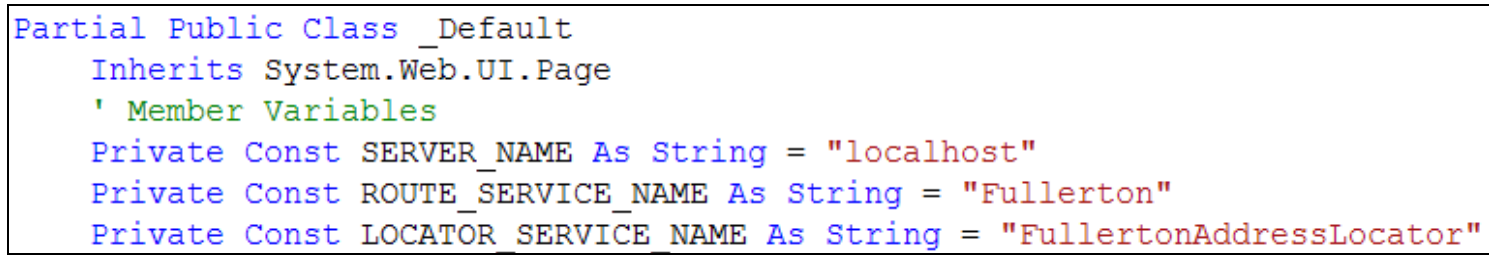

Figure 5-24 - Setting Locator Service within the NAServer Code. 


\section{Querying and Analysis}

"Explore Fullerton" supplies the user with five tasks for querying, geocoding, and printing. The querying functionality allows the user to query for a destination's name, destination type, or a road projects type. To query for a destination's name, a simple popup window allows the user to choose a business name from a list (Figure 6-1).

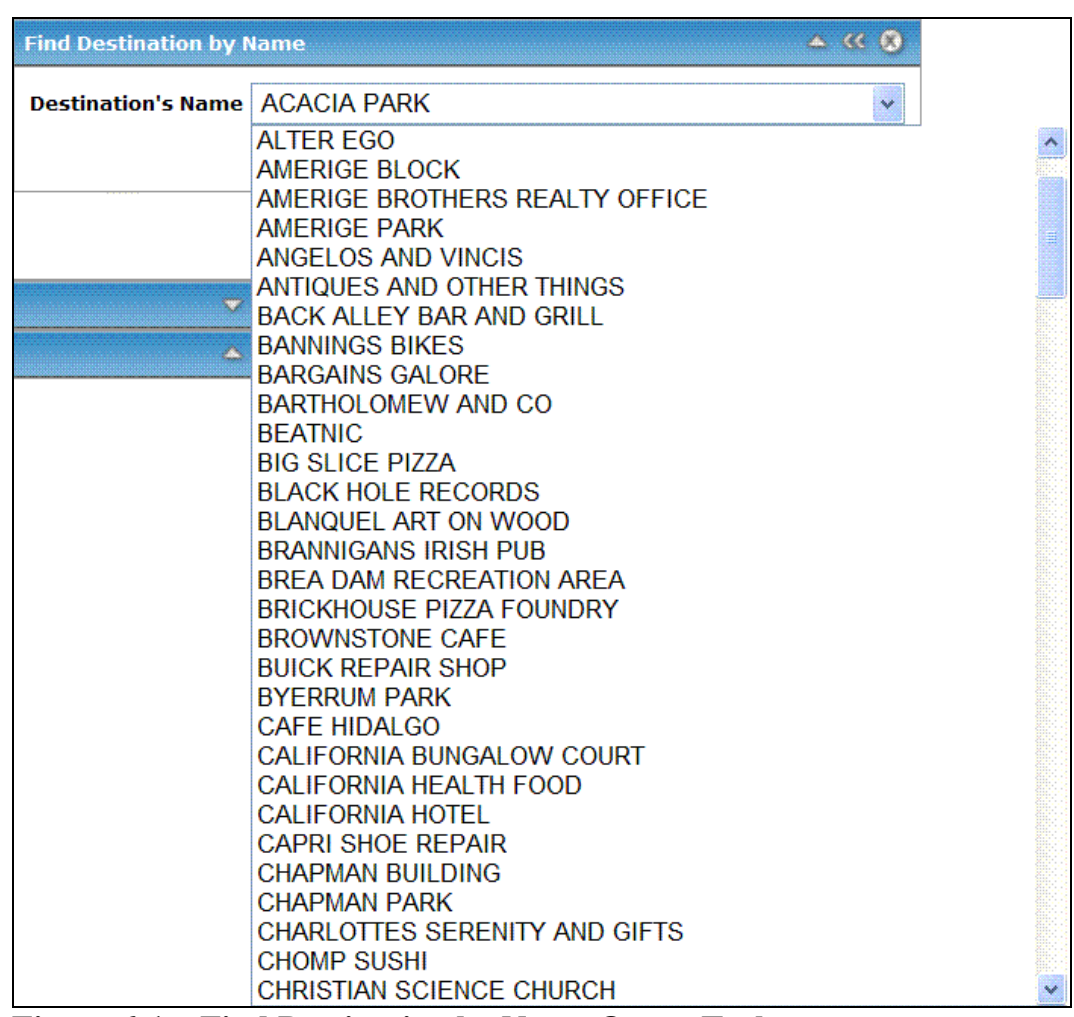

Figure 6-1 - Find Destination by Name Query Task.

To query for a destination type, another pop-up window allows the user to select a business from a list and, within the results panel, receive a list of all businesses that fall under that category (Figure 6-2).

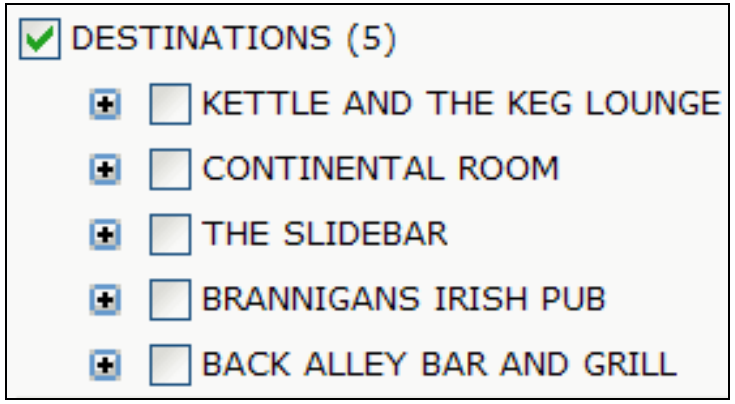

Figure 6-2 - Results of a Find Destination by Type Query Task for "BAR". 
From that point, users can make a selection in the results panel on which destination they wish to obtain information about. Once users decide which destination they wish to view, they can utilize the zoom icon to zoom to their destination. This allows users to see the exact location as well as other businesses surrounding their selection on the map display (Figure 6-3).

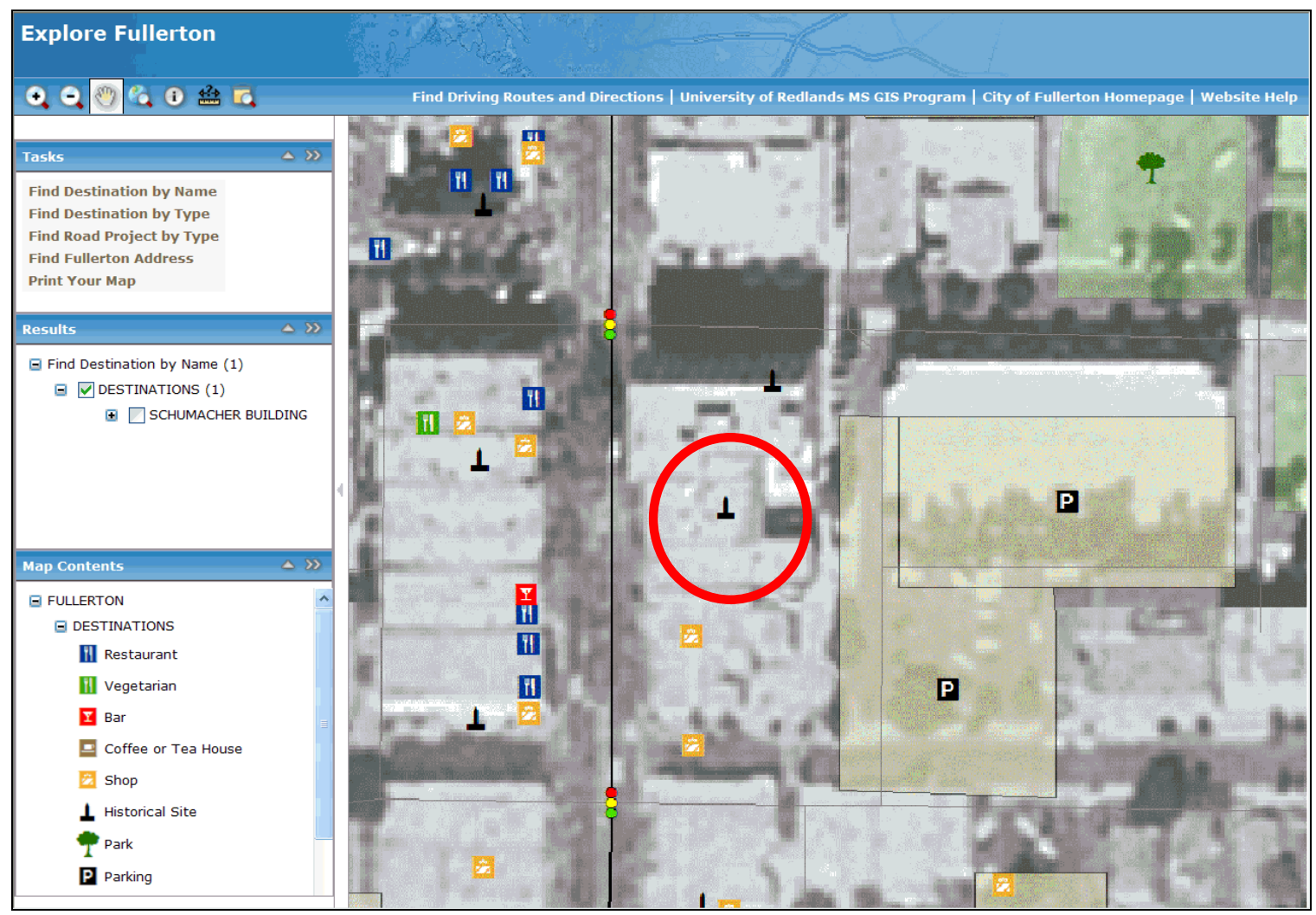

Figure 6-3 - Map Display Zoomed In on Destination.

The query for a road project by type allows users to select the type of road project they wish to find. A pop-up window gives users a list of road projects types that are available to choose from. Upon clicking on a road project type, a list of road projects that fall into the type of category selected appears in the results panel. Further selection will give users more information on the road project they select.

The geocoding task allows the user to enter a street number and street name, and then geocodes the address (Figure 6-4).

\begin{tabular}{|lr|}
\hline Find Fullerton Address & $\Delta \ll \otimes$ \\
\hline $\begin{array}{l}\text { Street or } \\
\text { Intersection } 303 \mathrm{~W} \text { Commonwealth Ave }\end{array}$ \\
\cline { 2 - 2 }
\end{tabular}

Figure 6-4 - Geocode Task. 
The results of the task are displayed in the results panel. If more than one address meets the user's request, then the user will have to make an additional selection within the results panel (Figure 6-5).

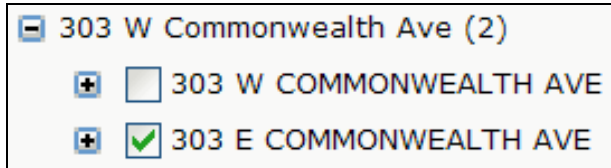

Figure 6-5 - Multiple Results from Geocode Task.

"Explore Fullerton" allows the user to print a static image of their map, a driving route, or driving directions. If users choose to print their map, they have the option of including a title and the attribute information from the results panel of the destination for which they queried (Figure 6-6).

\begin{tabular}{l}
\hline Print Your Map \\
Title: Fullerton \\
$\square$ Print Map \\
Task results to print: \\
$\square$ Find Destination by Name (1) \\
$\square 303$ W Commonwealth Ave (2) \\
Map width (in. (cm)): Default $\checkmark$ Resolution: $96 \quad \checkmark$ \\
Scale (optional) $1: \square$ \\
Create Print Page
\end{tabular}

Figure 6-6 - Print Task.

The application allows users to enter a Starting from and Arriving at address to obtain an optimal driving route with written step-by-step directions. Once users click the Find Route button, the application geocodes the two addresses and returns a new map display with a drawn route, directions, and an estimated time of arrival (Figure 6-7). 


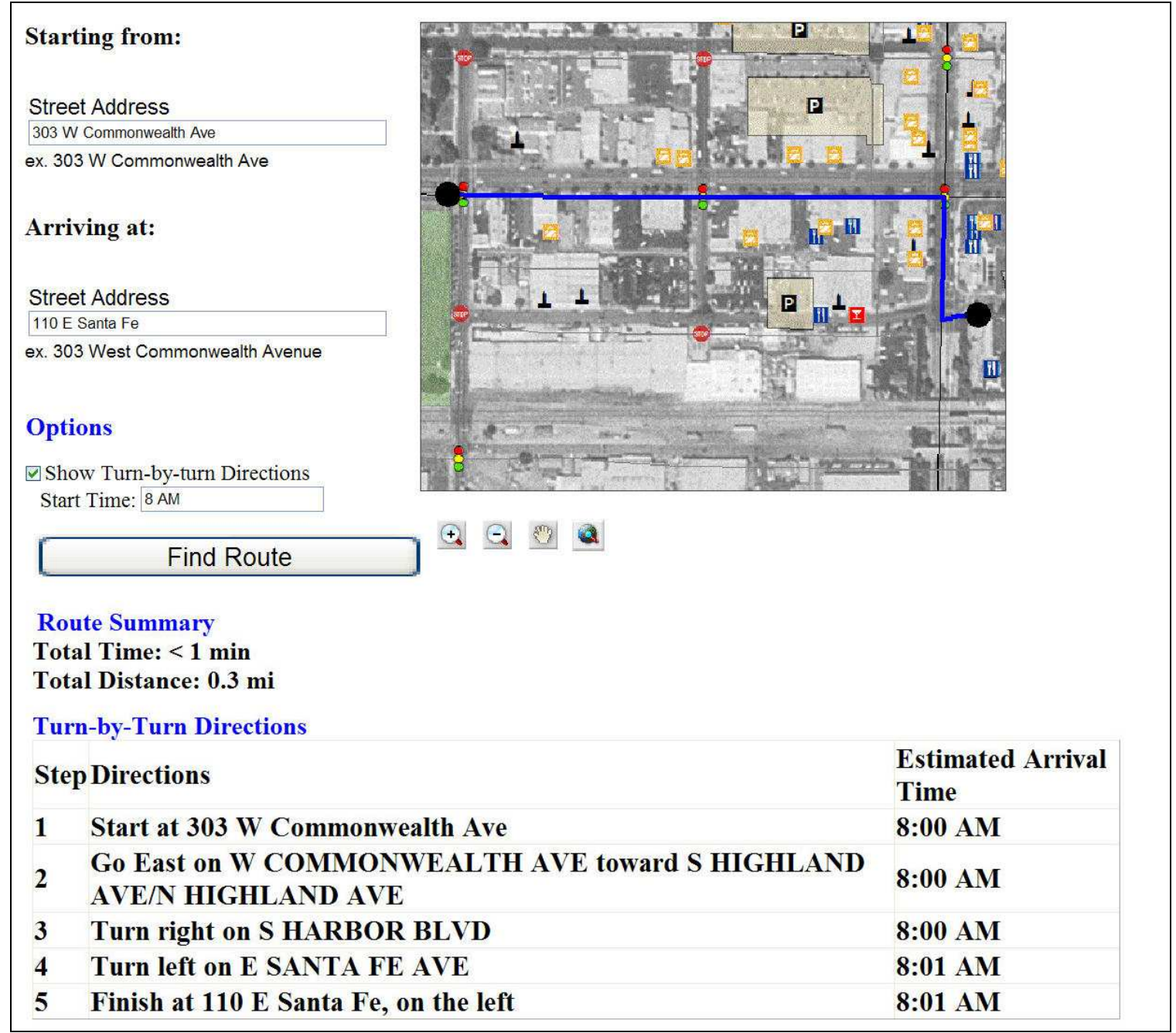

Figure 6-7 - Driving Route and Written Step-by-Step Directions. 


\section{Conclusion}

"Explore Fullerton" is a useful tool for the City of Fullerton to promote tourism to the CBD. Residents and visitors of Fullerton have access to knowledge about attractions within the city, and can easily get directions to these attractions through the use of "Explore Fullerton". What makes "Explore Fullerton" more valuable is that it can be accessed from any Internet-equipped computer at any time. Planning trips, finding efficient routes, and having knowledge of road construction projects are truly simplified with "Explore Fullerton". Businesses located in the CBD also benefit from "Explore Fullerton", as they obtain free advertising and listings. Consumers are able to access critical contact information for businesses and are also able to explore businesses that they were previously unaware of. With the service and information provided by "Explore Fullerton", the flourishing town has a place to continue to map its growth.

\subsection{Future Work}

Several components of the "Explore Fullerton" Web mapping application would benefit from further development. Further customization of the Web mapping application would create a friendlier environment for non-GIS users. The following are ways in which the Web mapping application could be made more efficient:

- In order to simplify the means of accessing a route and directions, text boxes could be programmed to be automatically filled in. Users of the application could click on a destination point and the route finder could automatically be filled with the destination address.

- If a street is known by two or more different names, the application could be programmed to recognize each name as the same street and deliver the route with directions rather than return an error message. For example, if the user enters in State Route 90, the application could recognize that Imperial Highway is the same street.

- When users search for a destination by type, they receive a list of possible destinations. Upon selecting a destination, the application could be programmed to automatically zoom to a large scale map of the destination. This would allow users to view the location of their choice without having to manually zoom.

- Websites located in the results panel could be hyperlinked to allow the user to click the link and have the website automatically open in a new window.

- The Road_Projects feature class could be integrated as barriers into the Traffic_Division_ND and this would give users the option of obtaining driving routes and directions that automatically avoid roads that contain construction.

\subsection{Website Usability and Design}

The "Explore Fullerton" Web mapping application was designed for people who have limited or no knowledge of GIS, however, the website still has some issues with usability and functionality. One concern is regarding the website template supplied with ArcGIS Server. This template complicates how users maneuver the site. For example, when querying for a destination the results are displayed within the results panel in a tree-view. In order to access different functions, users must click the check boxes to expand the tree 
and right click the destination for further options. The process of expanding the tree view and right clicking is not common knowledge and as a result, users who are unfamiliar with the way the website works may have a difficult time learning how to obtain the information available. Another issue deals with the toolbar elements and their symbols. Some non-GIS users may not be familiar with the magnifying glass zoom in and zoom out tools and this may cause confusion with how to use the tools. Without experience with these tools, users will not be able to explore the website at its full potential. It is critical that the design of a website meets the users' needs through trouble-free and simple design. In fact, poor interface design has been recognized as one of the leading causes of failure when it comes to websites (Buschke, 1997). Users are drawn to website applications that are easy to understand and easy to use. If users feel that the website application is difficult or confusing to use, they are less likely to return which could contribute to the website's failure. To eliminate the risk of failure, the website design must take into account the how users will perceive and experience the website. According to Palmer (2002), simple navigation on a website is a major design element which allows users to receive more of the information they are seeking. "Explore Fullerton" provides very useful information in one central location however, a simple website design with better navigation could contribute to the success of "Explore Fullerton". 


\section{References}

Baker, B. (2007). Print task sample. ArcGIS Server Development Blog. Retrieved June 21, 2007 from http://blogs.esri.com/Dev/blogs/arcgisserver/archive/2007/05/16/Print-Task$\underline{\text { Sample.aspx }}$

Buschke, L. (1997). The basics of building a great web site. Training and Development, 51(7), 46-48.

California State University, Fullerton. (2006). Official website. Retrieved August 9, 2007, from http://campusapps.fullerton.edu/news/2006/75 fallenrollment.html

Christodoulakis, S., Anastasiadis, M., Margazas, T., Moumoutzis, N., Kontogiannis, P., Terezakis, G., et al. (1998). A Modular approach to support GIS functionality in tourism applications. Laboratory of Distributed Multimedia Information Systems \& Applications: Technical University of Crete. Chania, Greece. Retrieved July 24, 2007 from http://www.ced.tuc.gr/Staff/Director/Publications/publ files/C CAMM ENTER 1998.pdf

City of Fullerton. (n.d.). Official website. Retrieved October 19, 2006, from http://www.cityoffullerton.com/

Collis, R. (1998, October 23). Michelin's electronic byways. International Herald Tribune. Retrieved February 13, 2007, from http://www.iht.com/articles/1998/10/23/freq.t_0.php

Destination Nova Scotia. (n.d.). Official website. Retrieved July 24, 2007, from http://www.destination-ns.com/content/arcnorthnews.pdf

Dictionary.com Unabridged (v 1.1). (n.d.). Tourism. Retrieved July 24, 2007, from Dictionary.com website: http://dictionary.reference.com/browse/tourism

ESRI. (2006). Working with ArcGIS network analyst. ESRI Press, USA.

ESRI. (2007). GIS dictionary. Retrieved June 21, 2007, from http://support.esri.com/index.cfm?fa=knowledgebase.gisDictionary.search\&searc $\underline{\mathrm{h}=\text { true \&searchTerm }=\text { topology }}$

Fullerton College. (2003). Official website. Retrieved October 30, 2006, from http://publicinfo.fullcoll.edu/about/history.htm

Hope International University. (n.d.). Official website. Retrieved October 30, 2006, from http://www.hiu.edu/about/strategicplan.pdf 
Maine Office of Tourism. (n.d.). Official website. Retrieved July 24, 2007, from http://www.visitmaine.com/map/interactive/?uri=map/interactive

MapQuest.com. (n.d.). Official website. Retrieved February 13, 2007, from http://company.mapquest.com/internet/1.html

Meng, L., Zipf, A., \& Reichenbacher, T. (2005). Map-based mobile services. Berlin, Germany: Springer. Abstract retrieved July 24, 2007, from http://training.esri.com/campus/library/Bibliography/RecordDetail.cfm?ID=47276 \&startrow $=1$ \&hidpage $=1 \&$ browseonly $=0$

Mitchell, K. F. (1998). Critical considerations when implementing Internet based mapping and routing services. Proceedings of the $13^{\text {th }}$ ESRI European User Conference, Florence, Italy. Retrieved January 23, 2007, from http://gis2.esri.com/library/userconf/europroc98/proc/idp113.html

Passenger Transport. (2005, December 19). Public Transportation Industry. Retrieved July 24, 2007, from http://apta100.apta.com/dbtwwpd/exec/dbtwpub.dll?AC=GET RECORD\&XC=http://apta100.apta.com/dbtw$\mathrm{wpd} / \mathrm{exec} / \mathrm{dbtwpub} . \mathrm{dll} \& \mathrm{BU}=\mathrm{http} \% 3 \mathrm{~A} \% 2 \mathrm{~F} \% 2 \mathrm{Fwww}$. apta.com $\% 2 \mathrm{Fpassenger}$ tran sport $\% 2$ Fthisweek $\% 2$ Farchive search.cfm\&TN=passtran\&SN=AUTO16477\&SE $=426 \& \mathrm{RN}=0 \& \mathrm{MR}=20 \& \mathrm{TR}=0 \& \mathrm{TX}=1000 \& \mathrm{ES}=0 \& \mathrm{CS}=2 \& \mathrm{XP}=\& \mathrm{RF}=$ Brief + List $\& \mathrm{EF}=\& \mathrm{DF}=\mathrm{Full}+\mathrm{Text} \& \mathrm{RL}=0 \& \mathrm{EL}=0 \& \mathrm{DL}=0 \& \mathrm{NP}=3 \& \mathrm{ID}=\& \mathrm{MF}=$ ptengmsg.ini $\&$ $\mathrm{MQ}=\& \mathrm{TI}=0 \& \mathrm{DT}=\& \mathrm{ST}=0 \& \mathrm{IR}=2282 \& \mathrm{NR}=0 \& \mathrm{NB}=0 \& \mathrm{SV}=0 \& \mathrm{BG}=0 \& \mathrm{FG}=00000$ $\underline{0 \& Q S=\text { passtransearch }}$

Palmer, J. W. (2002). Web site usability, design, and performance metrics. Information Systems Research, 13(2), 151-167. Retrieved August 30, 2007 from http://www.cis.gsu.edu/ ghubona/info790/palmer.pdf

Peng, Z. R., \& Tsou, M. H. (2003). Internet GIS: Distributed geographic information services for the Internet and wireless network. John Wiley \& Sons, Inc. Hoboken, New Jersey.

Peng, Z. R. (1998). Internet GIS and its applications in transportation. Transportation Research Board: March-April. Retrieved February 13, 2007, from http://www.iht.com/articles/1998/10/23/freq.t 0.php

Shannon, V. (2005, August 27). The End user: On the map, digitally. International Herald Tribune. Retrieved February 13, 2007, from http:/www.iht.com/articles/2005/08/26/business/ptend27.php

Southern California College of Optometry. (n.d.). Official website. Retrieved October 30, 2006, from http://www.scco.edu/ 
U.S. Census Bureau. (n.d.). Official website. Retrieved October 19, 2006, from http://factfinder.census.gov/servlet/SAFFPopulation? event=ChangeGeoContext \&geo $\mathrm{id}=16000 \mathrm{US} 0628000 \&$ geoContext $=\&$ street $=\&$ county $=$ fullerton $\&$ city Town $=$ fullerton\& state $=\&$ zip $=\&$ lang $=$ en \& $\_$sse $=$on $\&$ ActiveGeoDiv $=\&$ useEV $=\&$ pctxt $=$ fph\&pgsl $=010 \&$ submenuId $=$ population $0 \& d$ s name $=$ null\& ci $\mathrm{nbr}=\mathrm{n}$ ull\&qr name $=$ null\&reg $=$ null $\% 3$ Anull $\&$ keyword $=\&$ industry $=$

Western State University. (n.d.). Official website. Retrieved October 30, 2006, from http://www.wsulaw.edu/about/

World Tourism Organization. (n.d.). Official website. Retrieved July 24, 2007, from http://www.world-tourism.org/facts/menu.html 


\section{Appendix A - "Explore Fullerton" Installation Manual}

This installation guide assumes that ArcGIS 9.2, ArcGIS Server 9.2, and Microsoft Visual Studio 2005 are installed in the machine that is being used to run the "Explore Fullerton" Web mapping application.

Take your time and read through each process carefully as the omission of any minor task could result in the application not functioning properly. Before proceeding to the installation manual, ensure that the Network Analyst extension is turned on in ArcCatalog and ArcMap. To do this, open each program and select Tools from the menu bar and click on Extensions. Select the check box next to Network Analyst and then click close.

\section{Process 1: Database Setup and Data Transfer}

1. Insert the "Explore Fullerton" installation $\mathrm{CD}$ into the machine's $\mathrm{CD}$ drive and copy the Explore Fullerton folder over to the local machine.

2. Open ArcCatalog.

3. Navigate to Database Servers and double click Add Database Server (Figure 1).

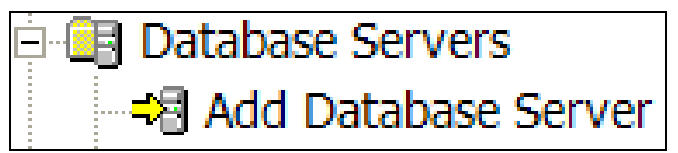

Appendix Figure 1 - Adding a Database Server.

4. In the pop-up window, enter the name of your local server followed by Isqlexpress (i.e., ExploreFullerton $/ s q l e x p r e s s)$ and click OK to have the Database Server will be added to ArcCatalog (Figure 2).

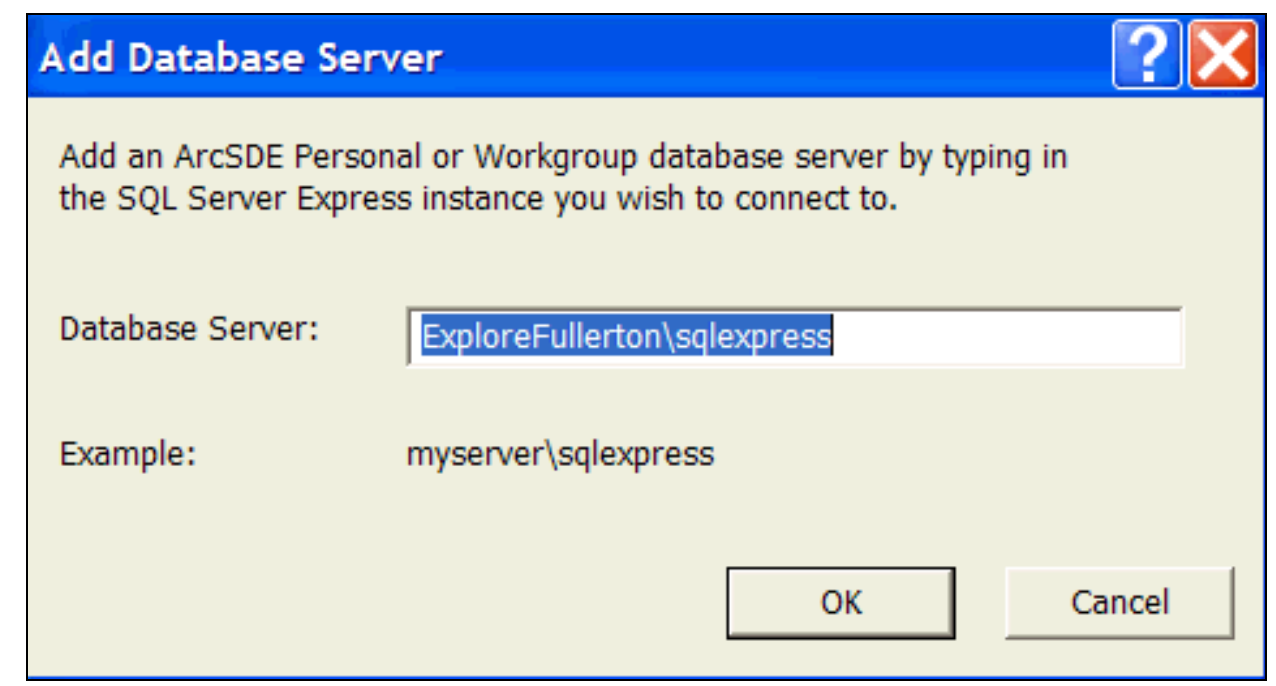

Appendix Figure 2 - Creating and Naming the Database Server. 
5. Now, right click the new Database Server and then click Permissions.

6. In the pop-up window, click Add User.

7. Enter the name of the ArcGIS SOC account user and click OK for the ArcGIS SOC account to be added as a user of the database server.

8. Next, right click the Database Server and click Connect.

9. After connecting, right click the Database Server and click New Geodatabase.

10. In the pop-up window, type Fullerton for the Geodatabase Name and accept the default location and size by clicking OK (Figure 3). A new SQL Express Geodatabase has now been added.

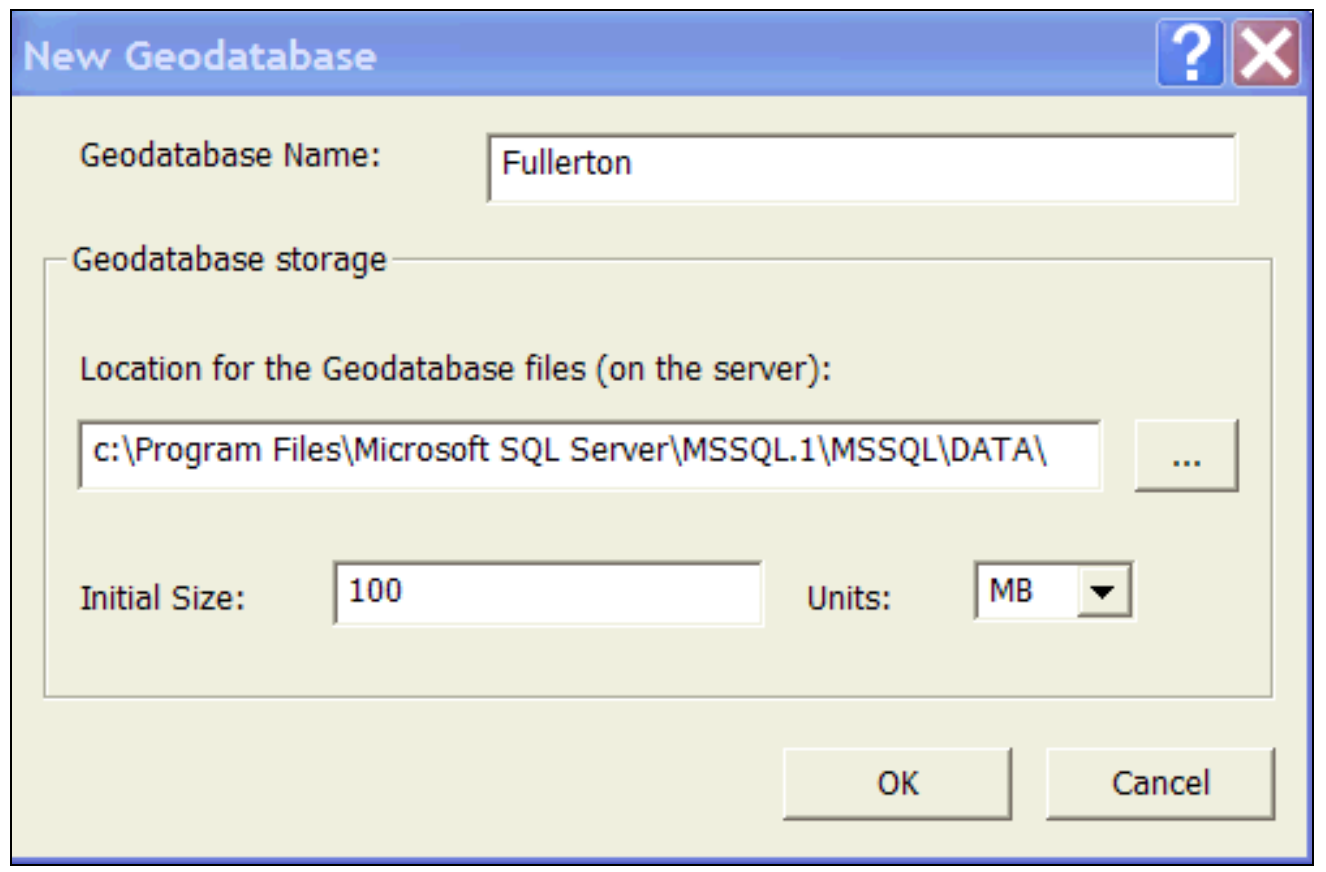

Appendix Figure 3 - Creating and Naming the New Geodatabase.

11. Navigate to the location you saved the contents of the "Explore Fullerton" installation CD and open the Explore Fullerton folder.

12. Next, open the Geodatabase folder and expand the Fullerton geodatabase to view its contents.

13. Right click on the FullertonAddressLocator and click Copy (Figure 4). 


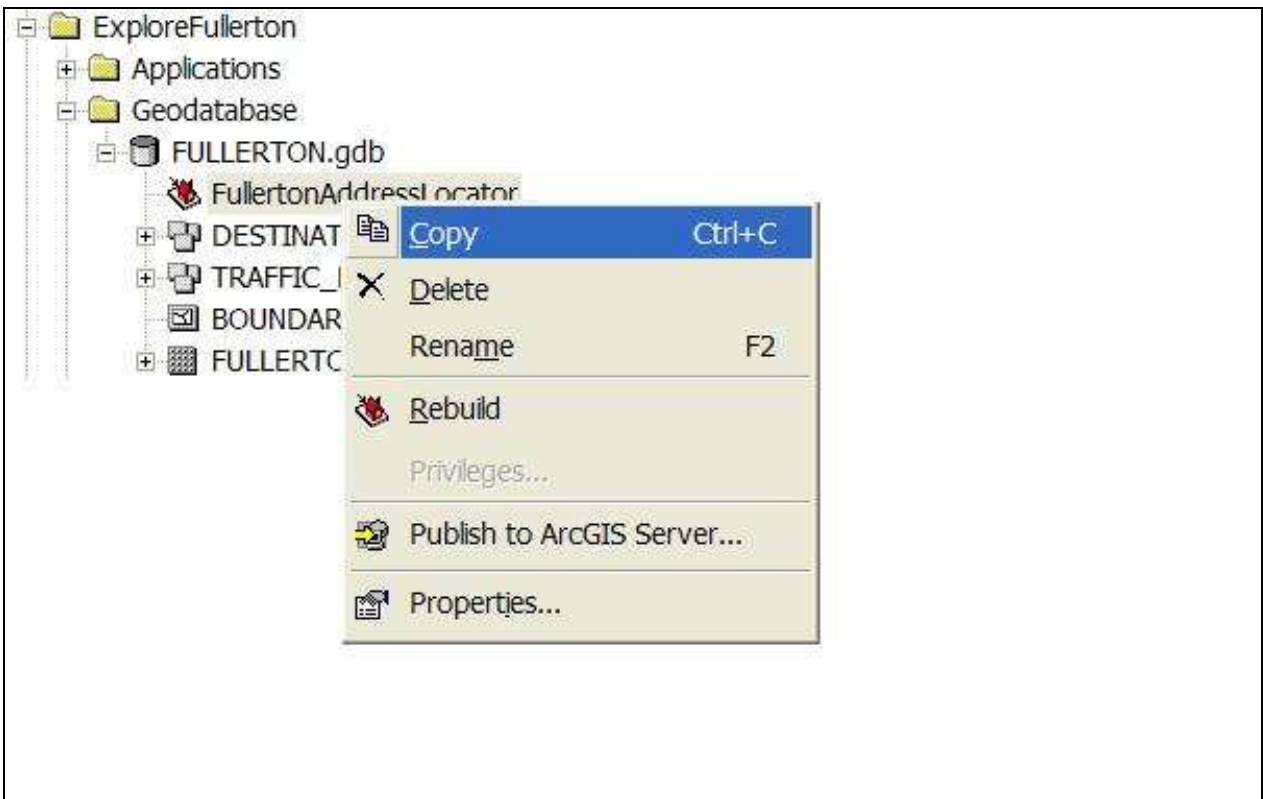

Appendix Figure 4 - Copying the Fullerton Address Locator.

14. Right click on the SQL Express Fullerton geodatabase and click paste. The FullertonAddressLocator has now been copied into the new SQL Express Fullerton geodatabase. Follow the same steps to copy over the DESTINATIONS feature dataset, the TRAFFIC_DIVISION feature dataset, the BOUNDARY feature class, and the FULLERTON_ORTHO raster. If prompted with a Data Transfer window, click OK.

15. Once all of the contents from the Fullerton geodatabase on the "Explore Fullerton" Installation CD have been transferred over to the new SQL Express Fullerton geodatabase, right click the SQL Express Fullerton geodatabase.

16. Next, hover over Administration and then click Permissions.

17. In the pop-up window, click on your ArcGIS SOC account user. At the bottom of the pop-up window change the permissions from None to Read/Write and click OK (Figure 5). The ArcGIS SOC account user now has Read/Write permissions to the SQL Express Fullerton geodatabase. 


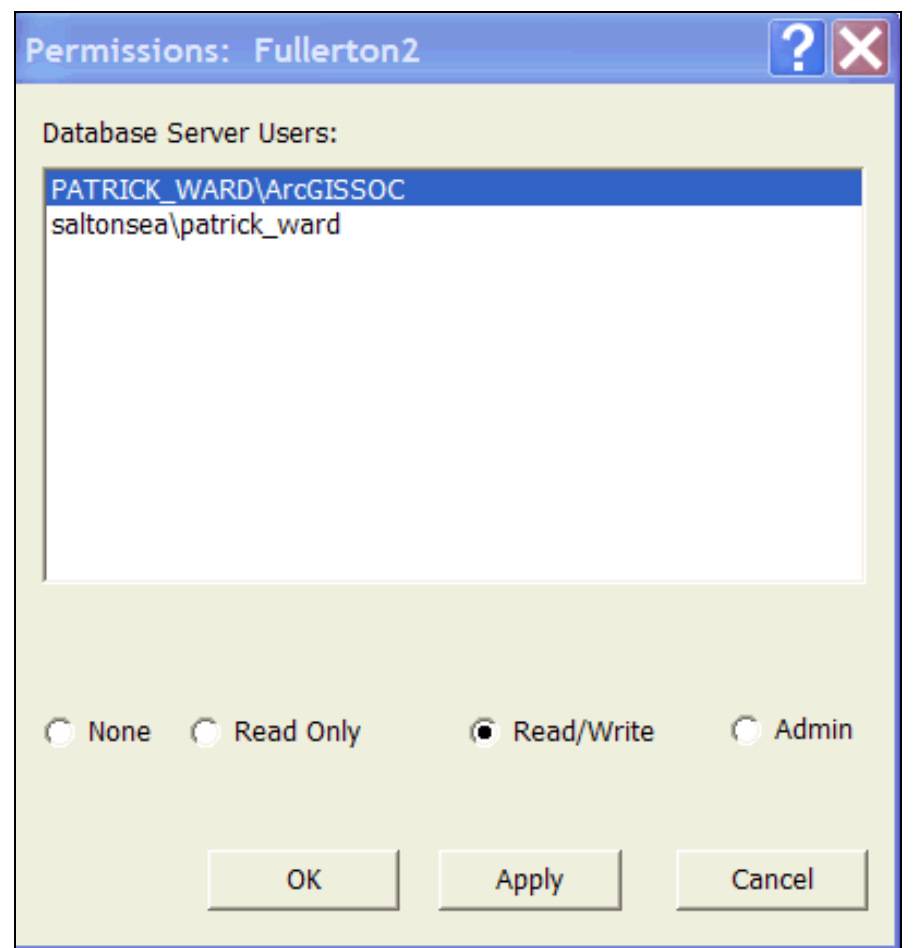

Appendix Figure 5 - Giving ArcGIS SOC Account User Read/Write Permissions.

The database server has now been successfully setup and a SQL Express Fullerton geodatabase has been successfully created. All of the data from the "Explore Fullerton" installation $\mathrm{CD}$ has also been transferred to this new geodatabase.

\section{Process 2: Setting and Publishing Services}

1. After completing Process 1, navigate to the location of the saved contents of the "Explore Fullerton" installation CD and open the Explore Fullerton folder.

2. Open the MapDocument folder and double click on the Fullerton.mxd to open the map document in ArcMap. When the map document opens, the layers will be drawn on the screen because the map document is reading the data from Fullerton geodatabase located on the "Explore Fullerton" installation CD. To have the map document read the data from the new SQL Express Fullerton geodatabase, the maps layers source data must be set to do so.

3. To set the layers source data, right click each layer and then select the Source tab in the Layer Properties window (Figure 6). 


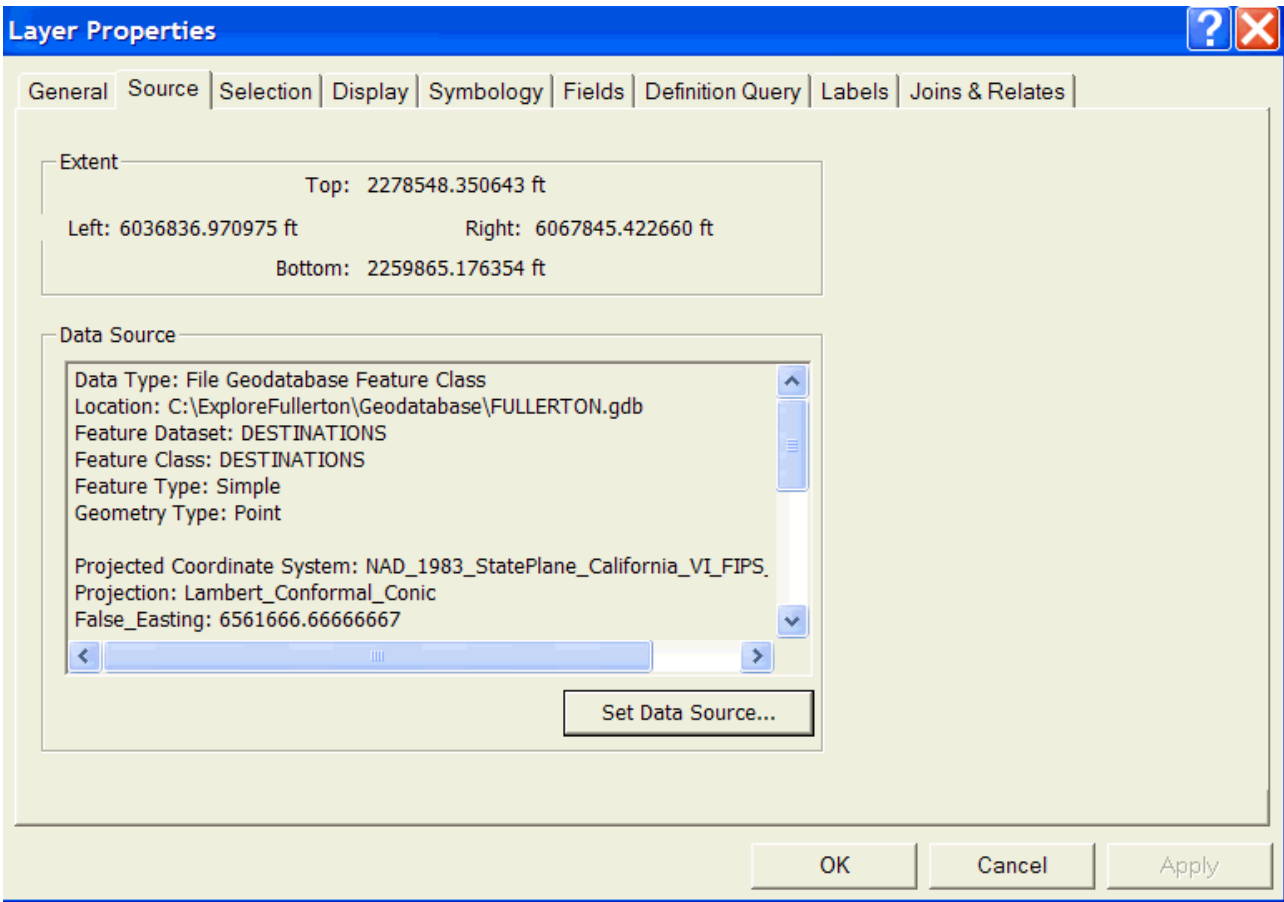

Appendix Figure 6 - Source Tab in Layer Properties.

4. Next, click the Set Data Source button.

5. In the Data Source pop-up window, navigate to the SQL Express Fullerton geodatabase and double click the feature class for the layer that the source data is currently being set for (Figure 7). Follow these same steps for all of the layers in the Table of Contents.

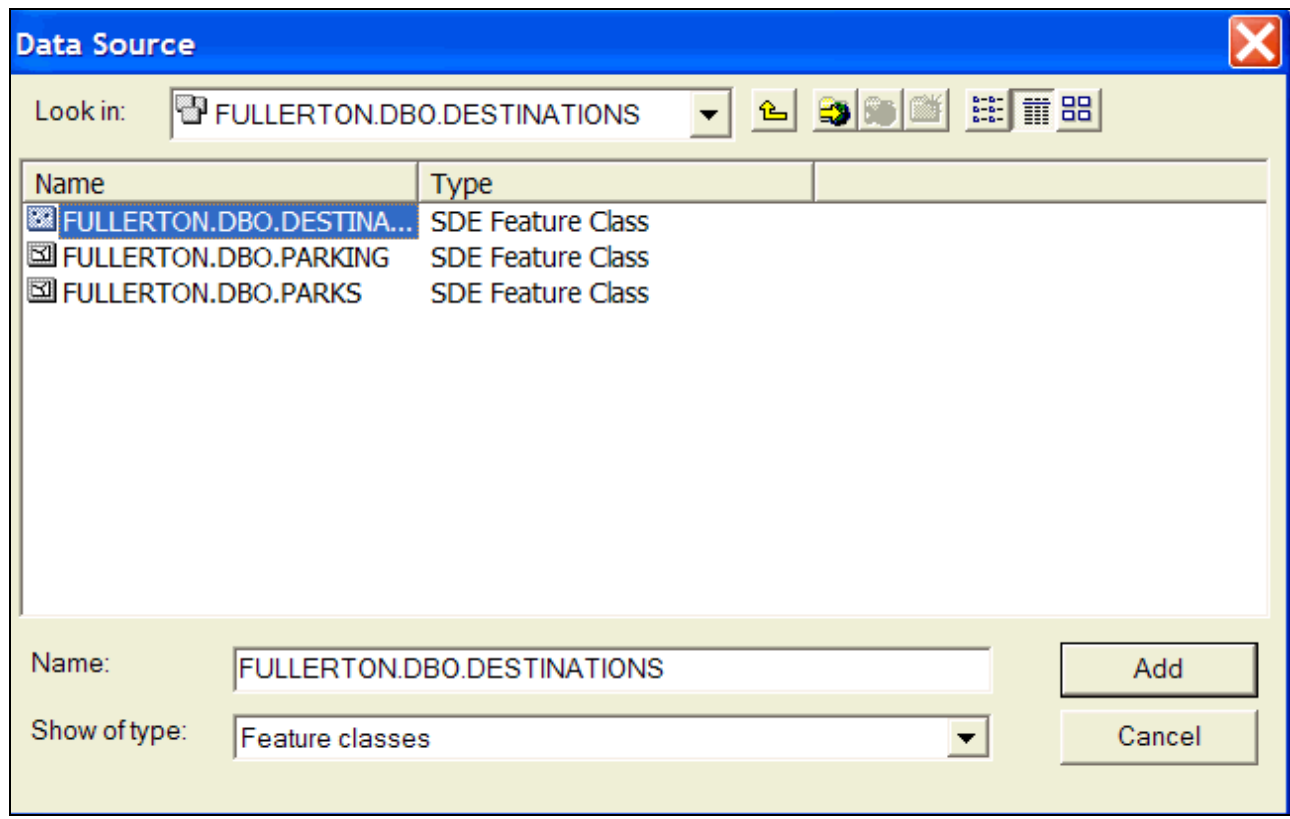

Appendix Figure 7 - Selecting Feature Class as Data Source. 
6. After the data has been set for every layer, click Save and close ArcMap.

7. Open ArcCatalog and navigate to GIS Servers. Double click Add ArcGIS Server (Figure 8).

\section{國 GIS Servers an Add ArcGIS Server}

Appendix Figure 8 - Adding an ArcGIS Server.

8. In the pop-up window, select the bubble for Manage GIS Services and then click Next (Figure 9).

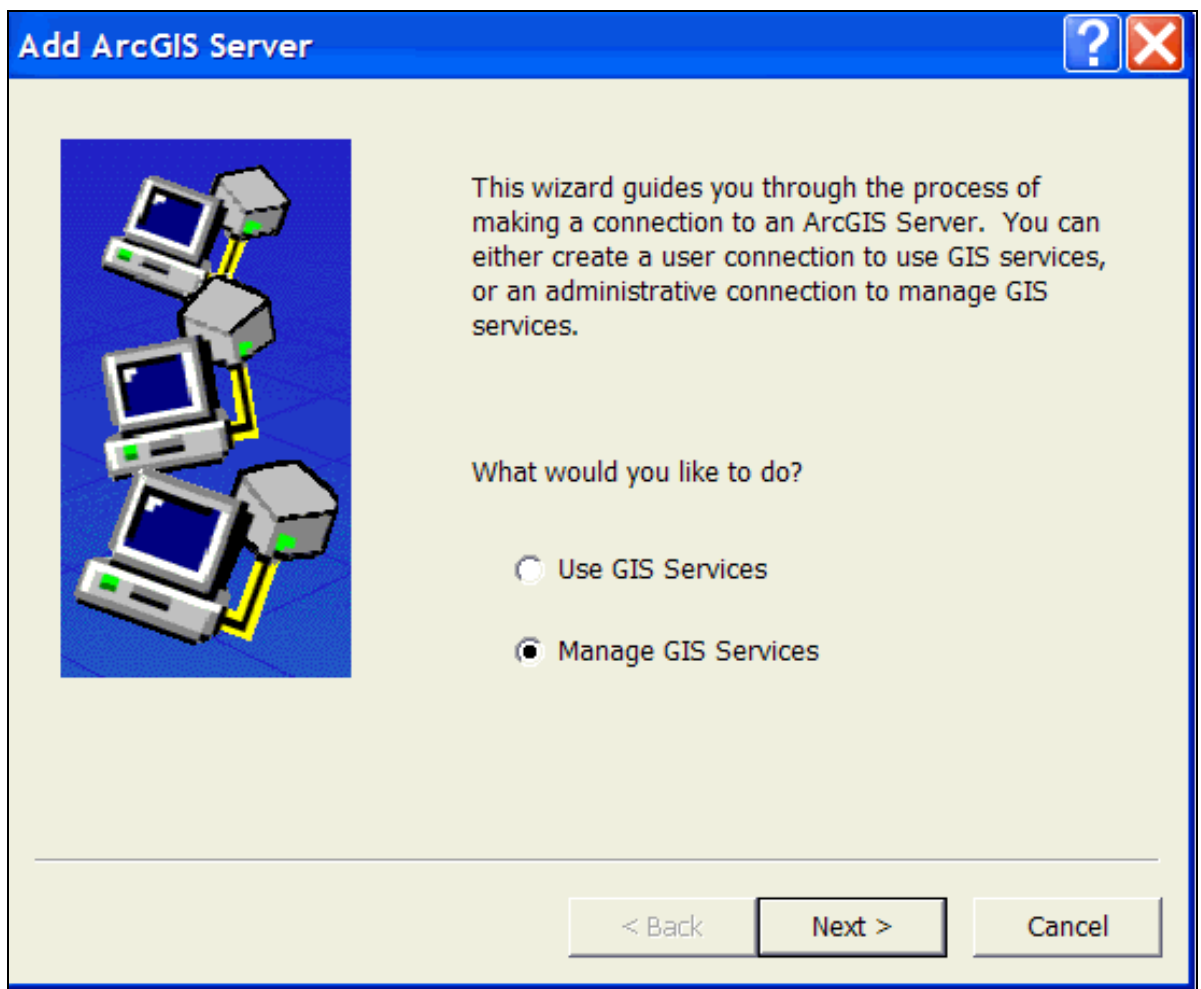

Appendix Figure 9 - Adding an ArcGIS Server to Manage GIS Services.

9. In the next window, enter in the Server URL and Host Name, then click Finish (i.e., http://www.cityoffullerton.com/arcgis/services as the Server URL and ExploreFullerton as the Host Name) (Figure 10). Check with your IT Administrator for the correct Server URL and Host Name. 


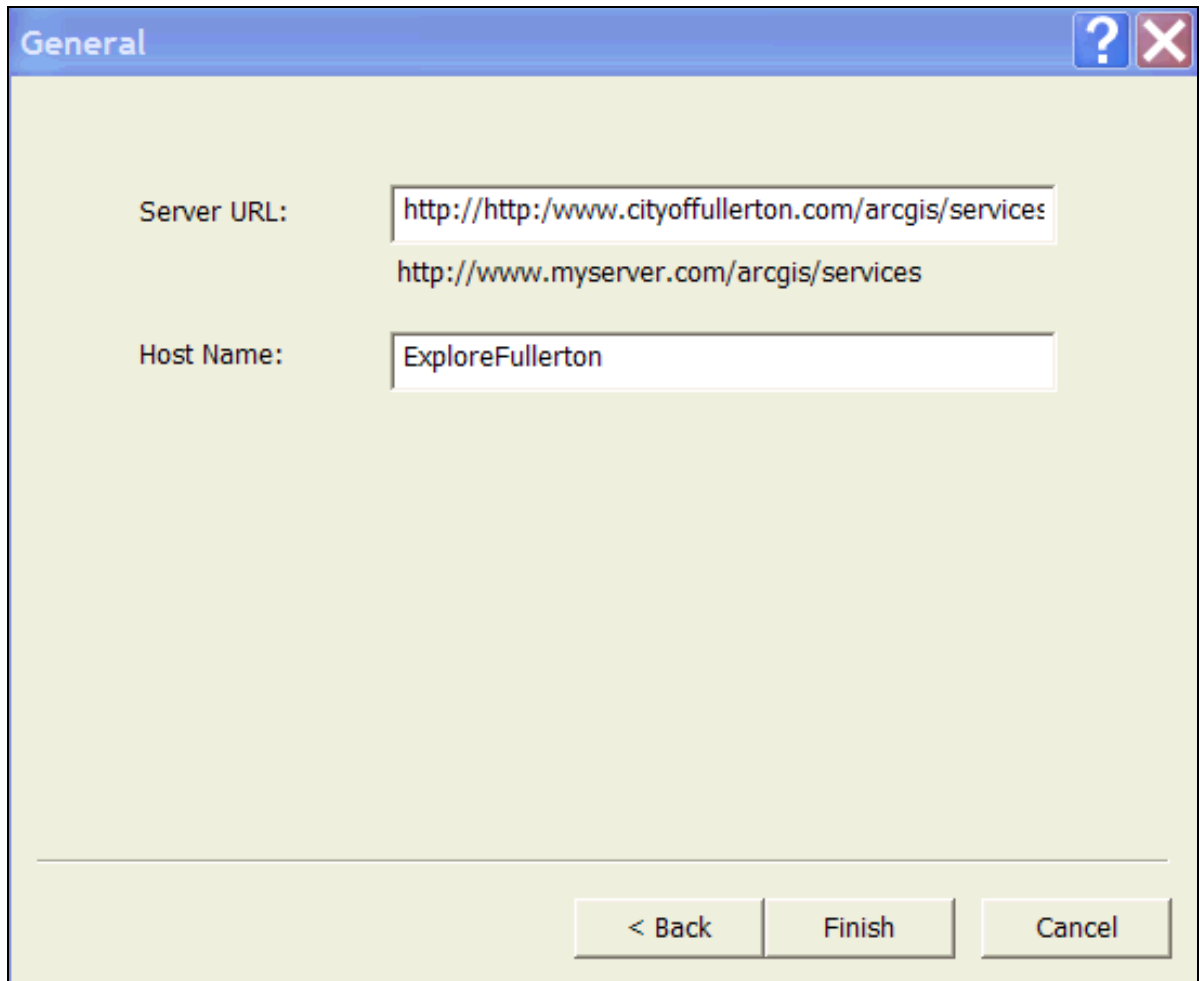

Appendix Figure 10 - Setting Server URL and Host Name.

10. Now that the ArcGIS Server has been set up and is ready to have services added for use in a Web mapping application, navigate to the SQL Express Fullerton geodatabase.

11. Right click on the FullertonAddressLocator and click Publish to ArcGIS Server (Figure 11).

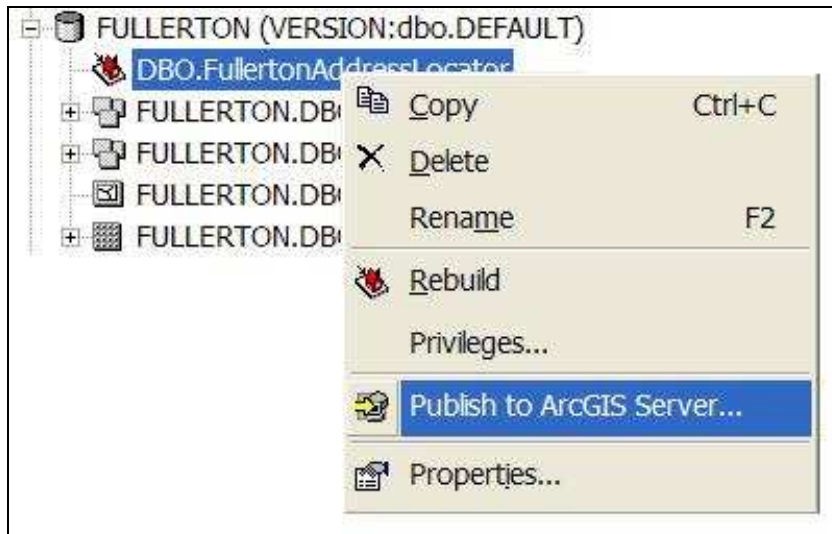

Appendix Figure 11 - Publishing FullertonAddressLocator to ArcGIS Server.

12. In the Publish to ArcGIS Server pop-up window, select the ArcGIS Server that was just created and then change the Service Name to FullertonAddressLocator. Click next for the FullertonAddressLocator to be added as a service to the ArcGIS 
Server (Figure 12). CAUTION: If the Service Name is anything other than FullertonAddressLocator, the "Explore Fullerton" Web mapping application will not function properly.

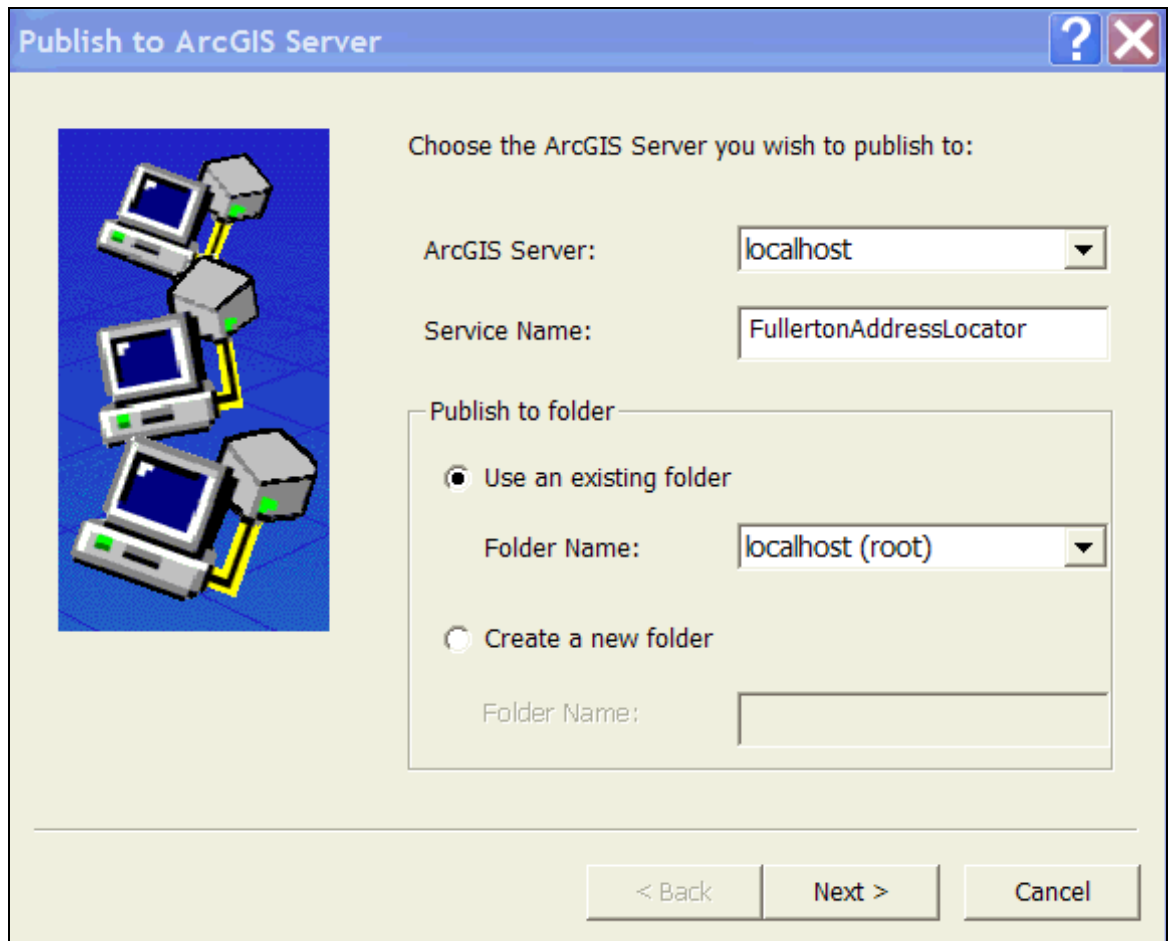

Appendix Figure 12 - Naming the FullertonAddressLocator Service.

13. Next, navigate to the Fullerton.mxd map document then right click and choose Publish to ArcGIS Server.

14. In the Publish to ArcGIS Server pop-up window, choose the ArcGIS Server that was created and change the Service Name to FULLERTON, then click next (Figure 13). CAUTION: If the Service Name is anything other than FULLERTON, the "Explore Fullerton" Web mapping application will not function properly. 


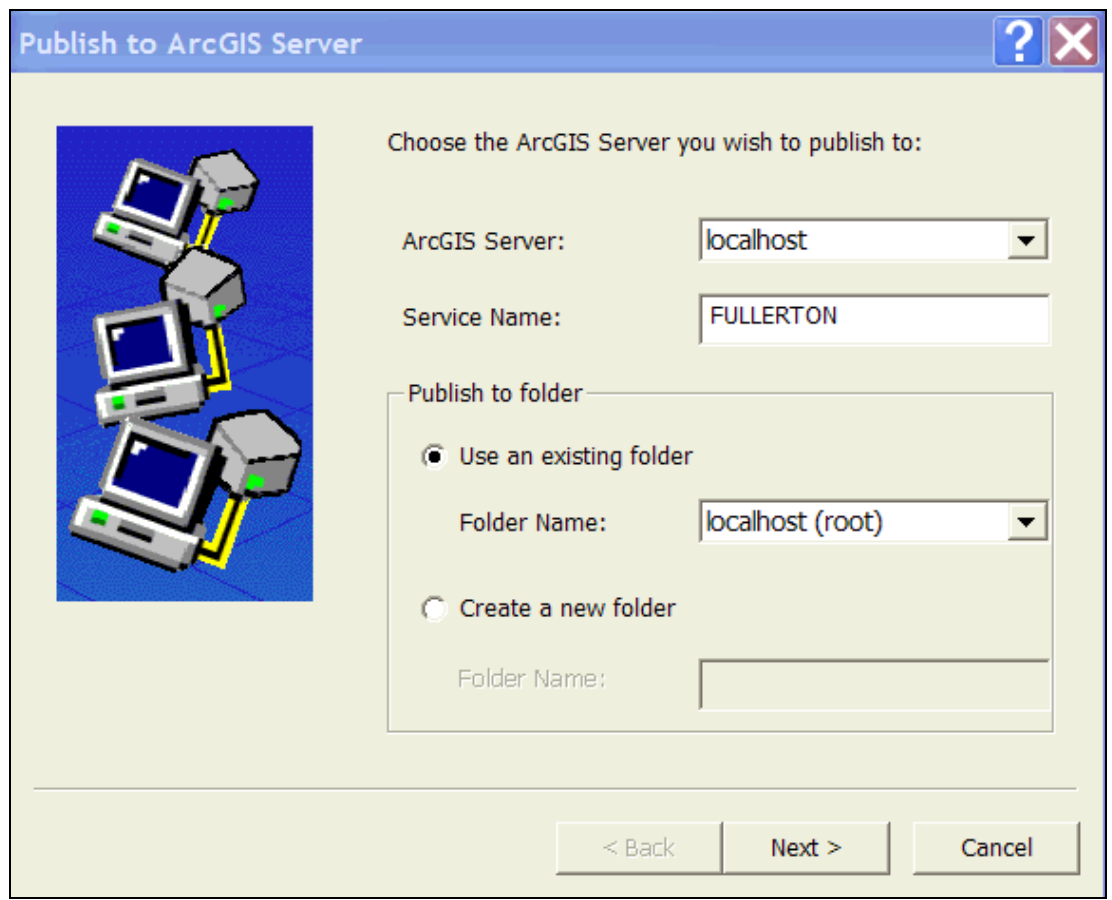

Appendix Figure 13 - Naming the FULLERTON Service.

15. In the next window, ensure that Mapping and Network Analysis are selected by clicking the corresponding capabilities check boxes and then clicking next (Figure 14). CAUTION: If the Mapping and Network Analysis capabilities are not selected, the "Explore Fullerton" Web mapping application will not function properly.

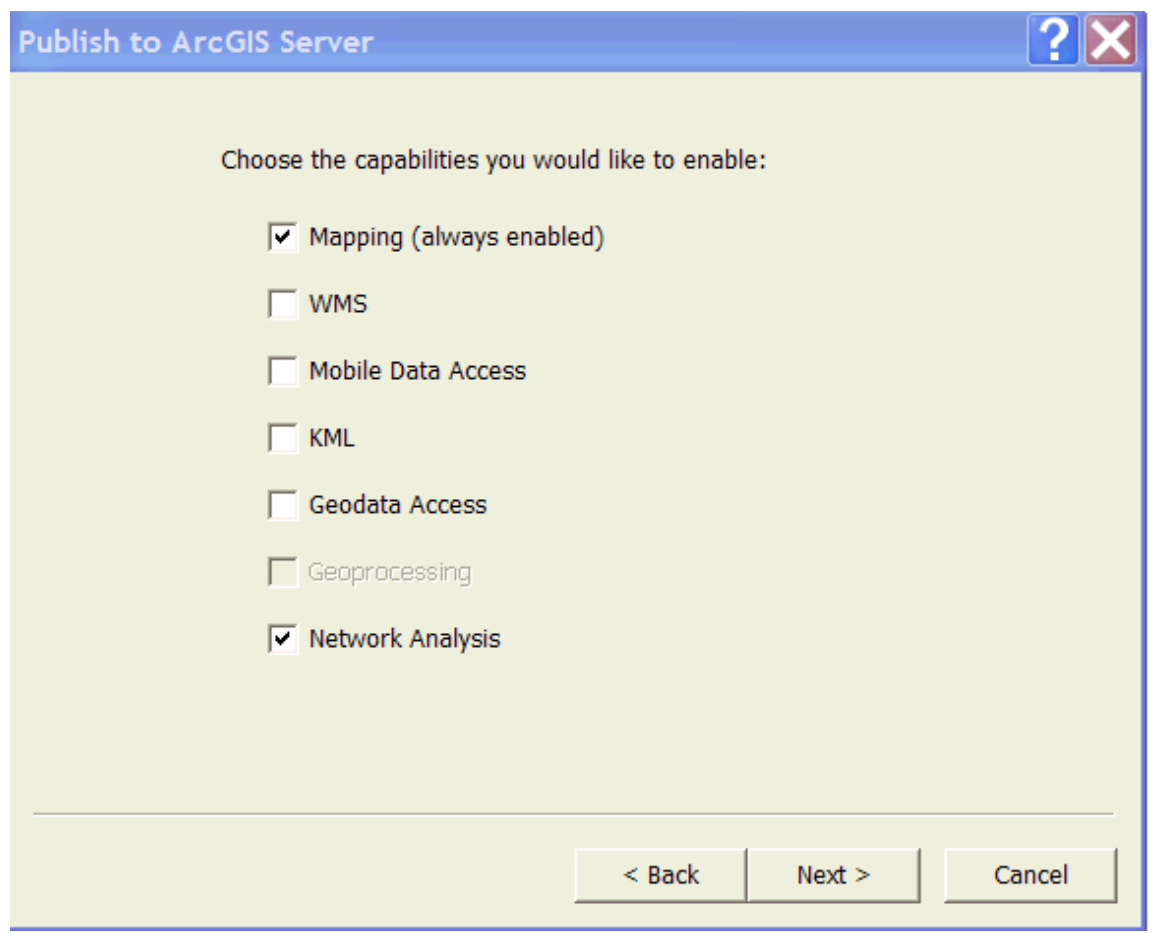

Appendix Figure 14 -Necessary Capabilities for the FULLERTON Service. 
16. Click Finish and FULLERTON will be added as a service to the ArcGIS Server.

The Fullerton.mxd map document file paths have now been set to read the data from the SQL Express Fullerton geodatabase. An ArcGIS Server was also added and the Fullerton.mxd map document and the FullertonAddressLocator were published as services to the local Server.

\section{Process 3: Transferring and Configuring "Explore Fullerton" Web Mapping Application}

1. After completing Process 2 , navigate to the location of the saved contents of the "Explore Fullerton" installation CD and open the Applications folder.

2. Double click the PrintTaskInstaller.msi file in order to open the File Download pop-up window.

3. In the File Download pop-up window click run. If a Security Window pops up, select run again.

4. In the Print Task Setup Wizard, read the Disclaimer and click the Next button.

5. In the Print Task Installation window, ensure that both boxes for Visual Studio integration and Manager integration are selected in the Installation Options and then click the Next (Figure 15).

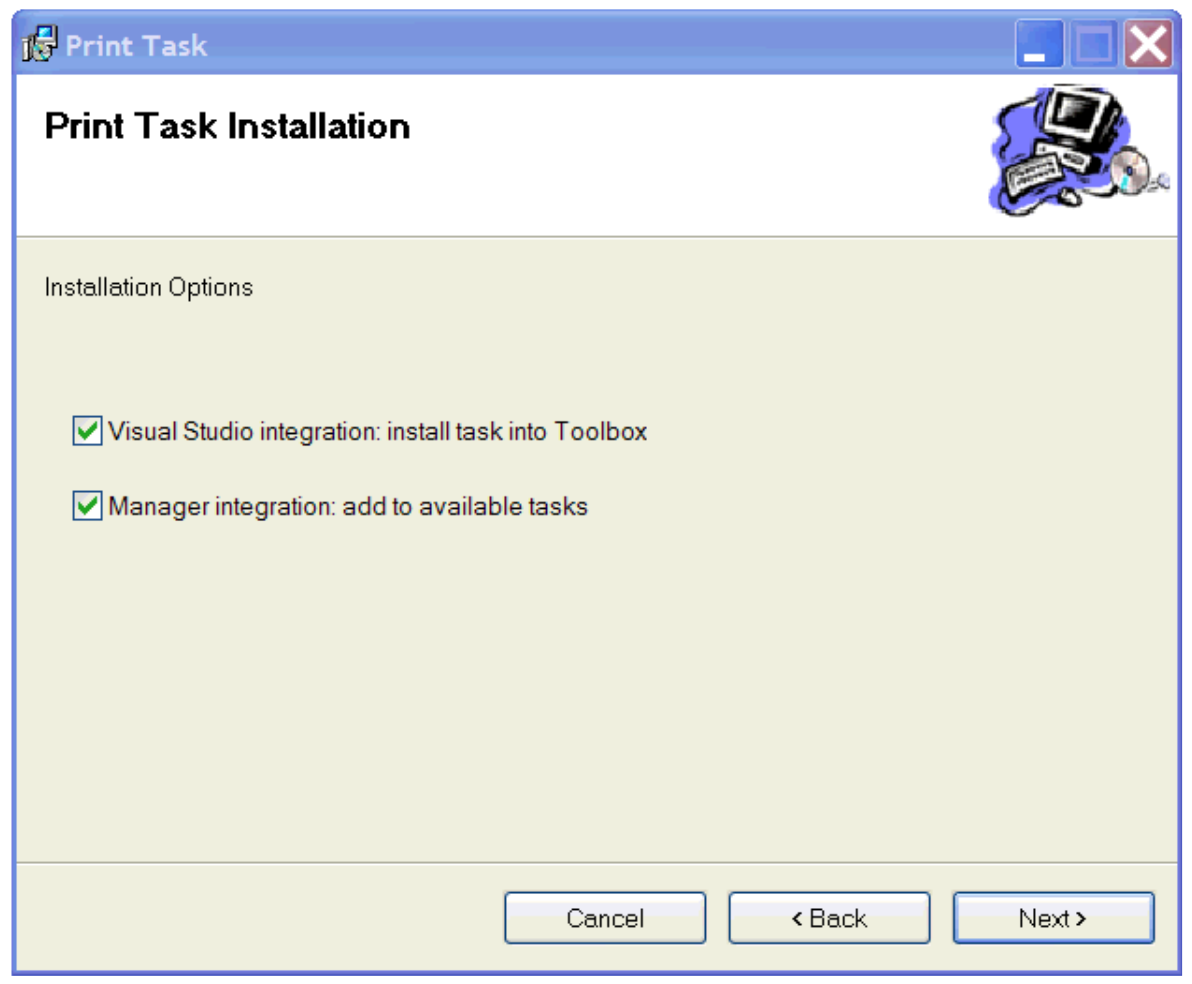

Appendix Figure 15 - Print Task intergration with Visual Studio and Manager. 
6. For the Select Installation Folder step, accept the default folder that is provided and click the Next button. A Confirm Installation window will follow, click the Next button.

7. Once the Print Task installation is complete, click the close button to exit.

8. Once again, navigate to the location of the saved contents of the "Explore Fullerton" installation CD and open the Applications folder.

9. Copy both the Explore Fullerton and Drive Fullerton folders to $\mathrm{C}:$ Inetpub $\backslash$ wwwroot

10. The application folders need to be declared as applications in IIS. To do this, click on the Start menu and go to Control Panel.

11. In the Control Panel window, double click Administrative Tools.

12. In the new window, double click Internet Information Services.

13. In the Internet Information Services window, expand the local computer, Web Sites and Default Web Site by clicking on the plus signs next to their titles (Figure 16).

$$
\begin{aligned}
& \text { Internet Information Services } \\
& \text { PATRICK_WARD (local computer) } \\
& \text { Web Sites } \\
& \text { Default Web Site }
\end{aligned}
$$

Appendix Figure 16 - Navigating to Default Web Site in IIS.

14. Next, right click on the Explore Fullerton folder and click Properties.

15. In the Properties window click the Create button under the Application Settings section and then click OK (Figure 17). 


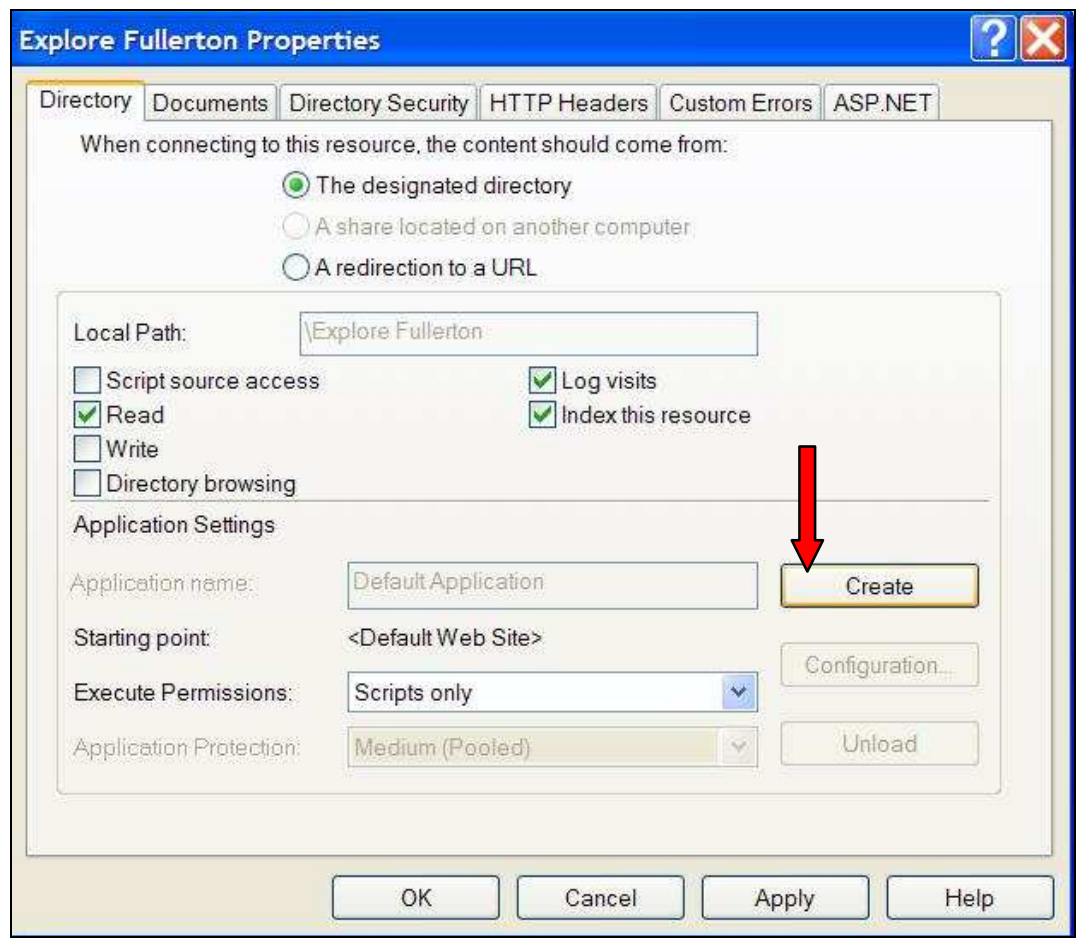

Appendix Figure 17 - Creating Application in IIS.

16. Next, to create the Drive Fullerton application, right click on the Drive Fullerton folder and click Properties.

17. In the Properties window click the Create button under the Application Settings section and then click OK.

18. Next, open Visual Studio and click Open: Web Site (Figure 18).

\begin{tabular}{ll|l|}
\hline Open: & Project... & Web Sit... \\
Create: & Project... & WWeb Sit... \\
\hline
\end{tabular}

Appendix Figure 18 - Opening Web Site in Visual Studio.

19. In the pop-up window click Local IIS in the left panel and then choose Explore Fullerton from the Web Site list in the right panel. After selecting Explore Fullerton, click Open.

20. Once the application and Solution Explorer window open, double click and open Default.axpx (Figure 19). 


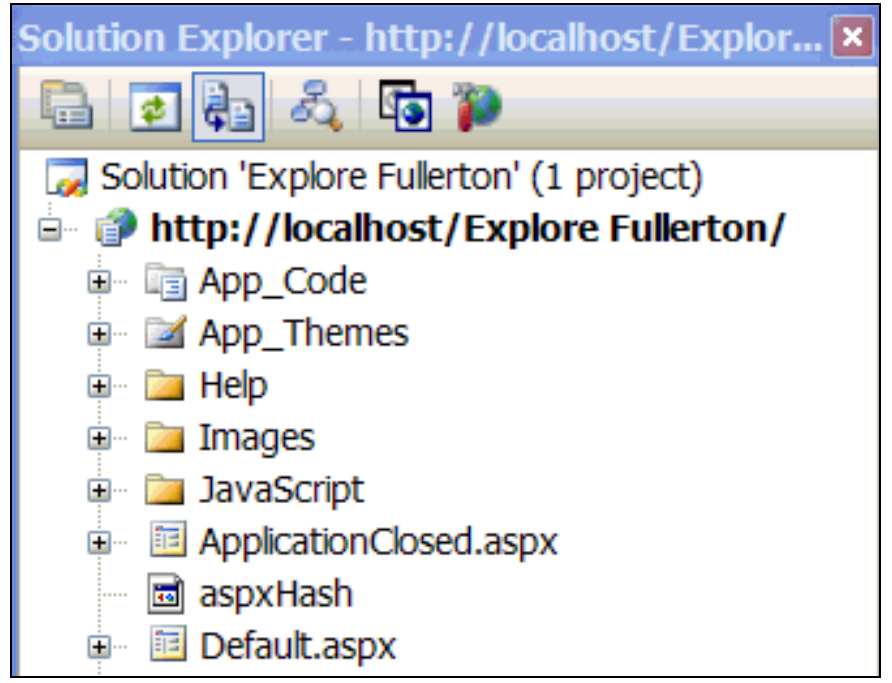

Appendix Figure 19 - Opening Default.aspx in Solution Explorer.

21. When the Default.aspx window opens, click the Design button located in the lower left part of the window.

22. The MapResourceManager is located in the Design view on the top center of the screen. Click on this MapResourceManager and then click on the black triangle that appears to the top right of the WebControl.

23. Next, click Edit Resources to open the manager (Figure 20).

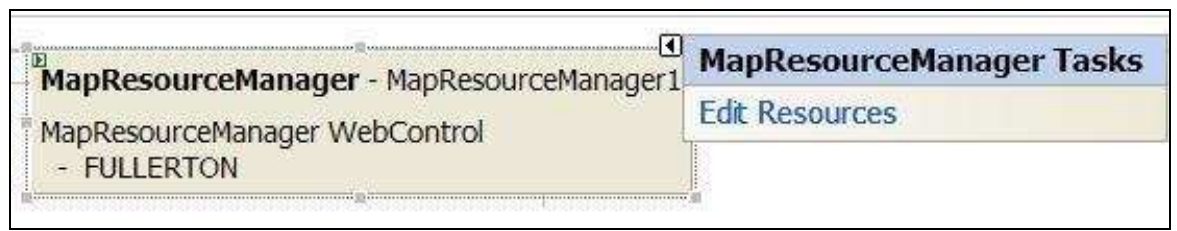

Appendix Figure 20 - Opening the MapResourceManager.

24. In the pop-up window that appears, click on Definition DataSource under the Information section. When clicked, a square box will appear to the right of the DefinitionSource title, click on this box (Figure 21). 


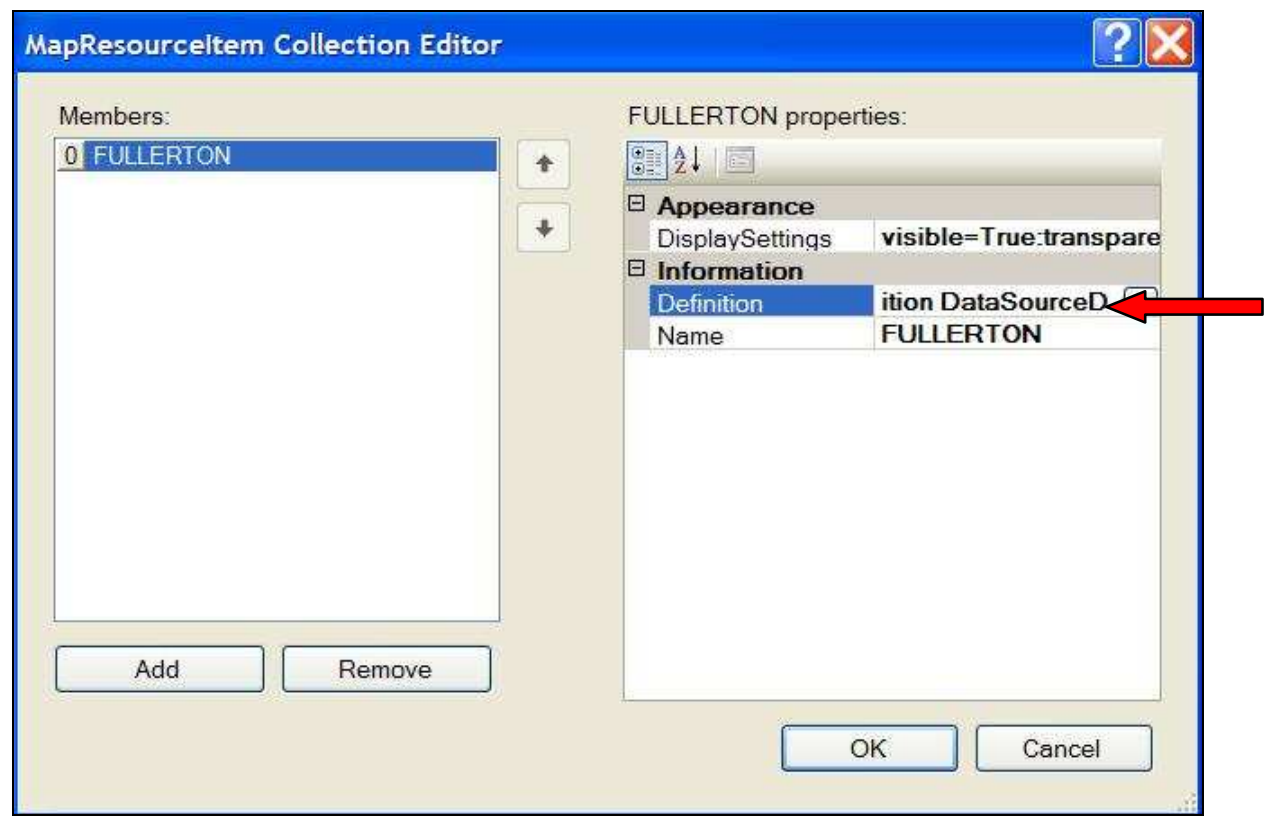

Appendix Figure 21 - Opening the MapResource Definition DataSource.

25. In the Map Resource Definition Editor window that appears, select ArcGIS Server Local for Type from the drop down menu and then click the square box next to Data Source (Figure 22).

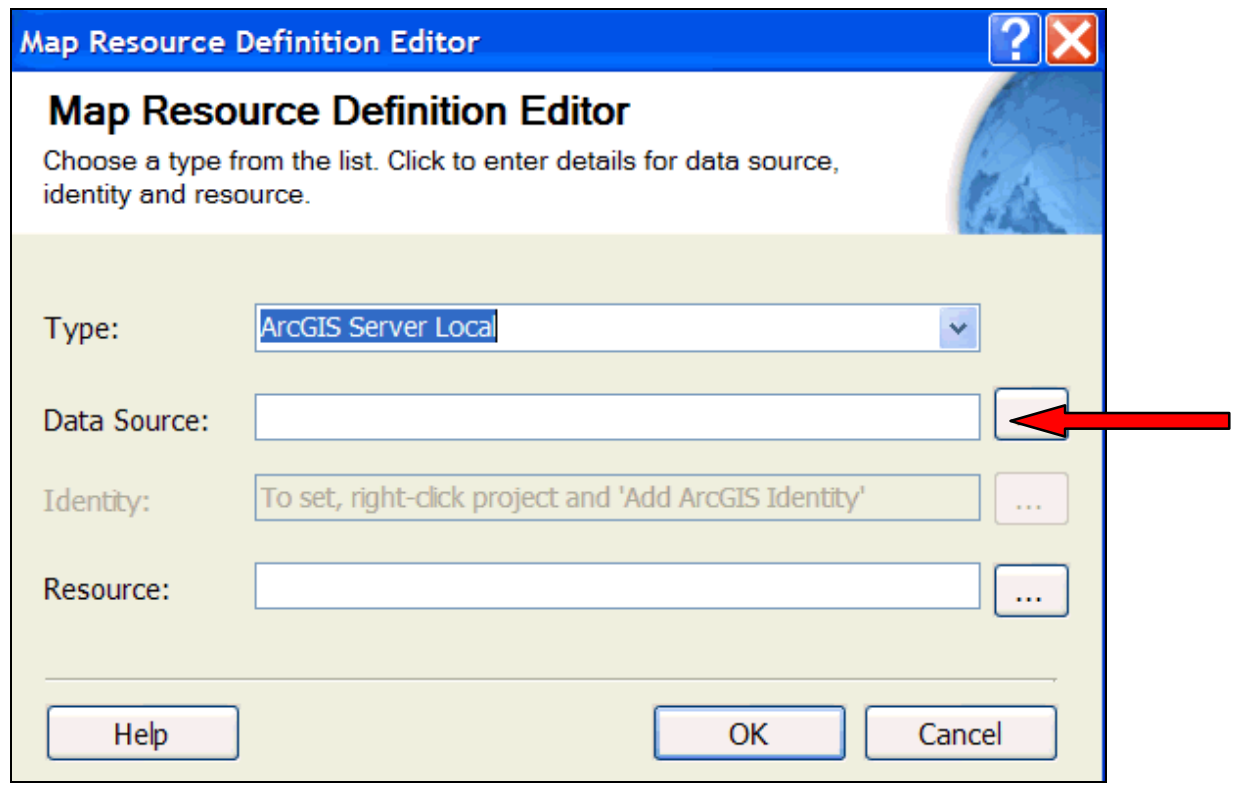

Appendix Figure 22 - Setting ArcGIS Server Local as Type of Map Resource .

26. When the new window opens, type the name of the local server and click OK (i.e., ExploreFullerton) (Figure 23). 


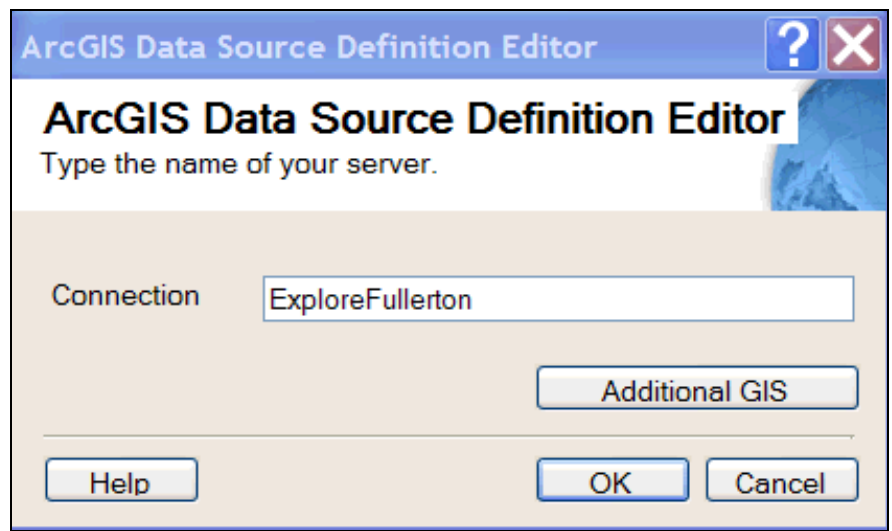

Appendix Figure 23 - Setting ArcGIS Server Connection.

27. Next, click the square box next to Resource to open the Resource Definition Editor.

28. Click the drop down arrow next to Service to select the FULLERTON map service and then click OK three times to return to the Design view window (Figure 24).

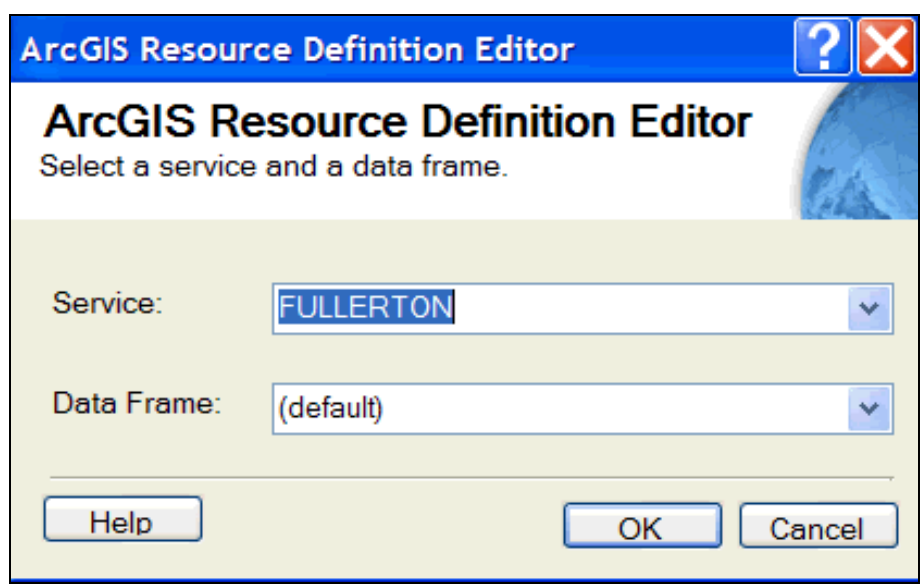

Appendix Figure 24 - Setting FULLERTON as the Map Service.

29. In the lower center of the Design view window is the GeocodeResourceManager. Click on the GeocodeResourceManager WebControl.

30. Next, click on the black arrow that appears on the top right and click on Edit Resources (Figure 25).

\begin{tabular}{|l|l|}
\hline $\begin{array}{l}\text { GeocodeResourceManager - GeocodeResourceManager1 } \\
\text { GeocodeResourceManager WebControl }\end{array}$ & GeocodeResourceManager Tasks \\
\hline - ExploreFullertonLocator & Edit Resources \\
\hline
\end{tabular}

Appendix Figure 25 - Opening GeocodeResourceManager. 
31. In the pop-up window that appears, click on Definition DataSource located under the Information section. When clicked, a square box will appear to the right of the DefinitionSource title, click on this box (Figure 26).

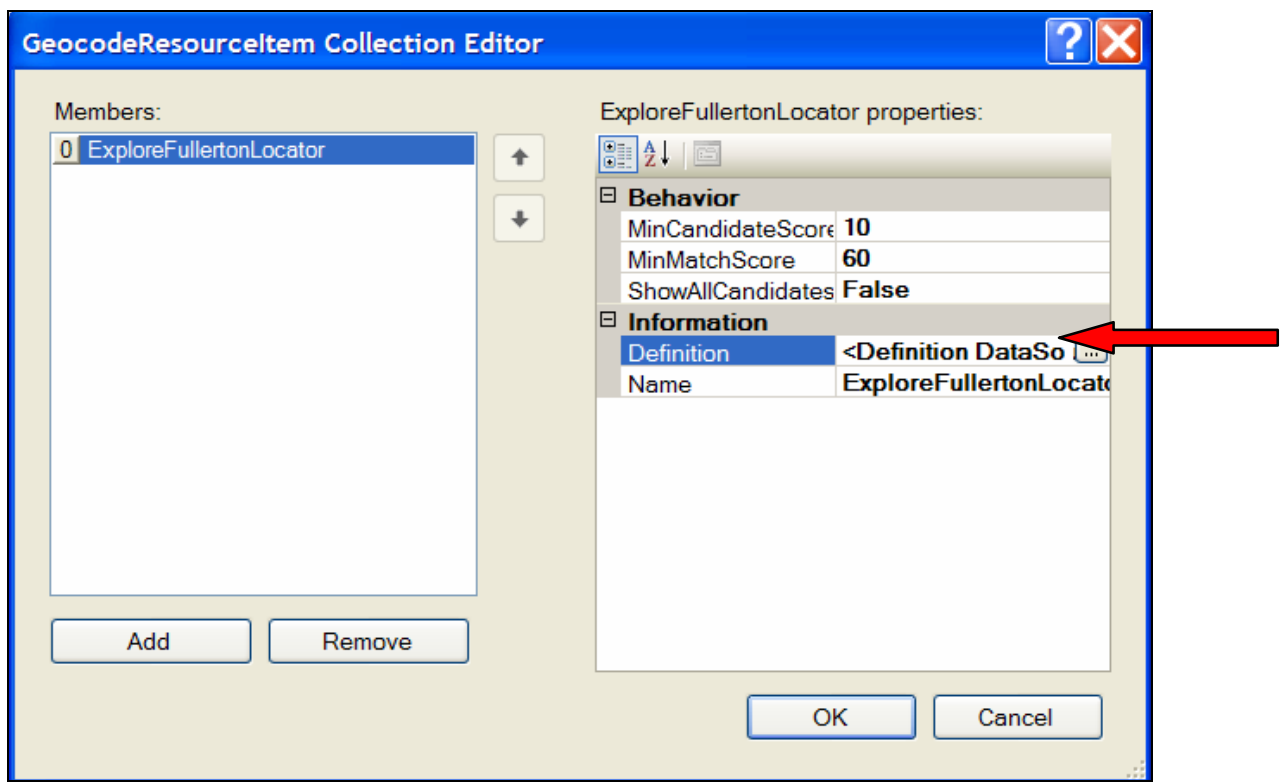

Appendix Figure 26 - Opening the GeocodeResource Definition DataSource.

32. In the Map Resource Definition Editor window that appears, select ArcGIS Server Local for Type from the drop down menu and then click the square box next to Data Source (Figure 27).

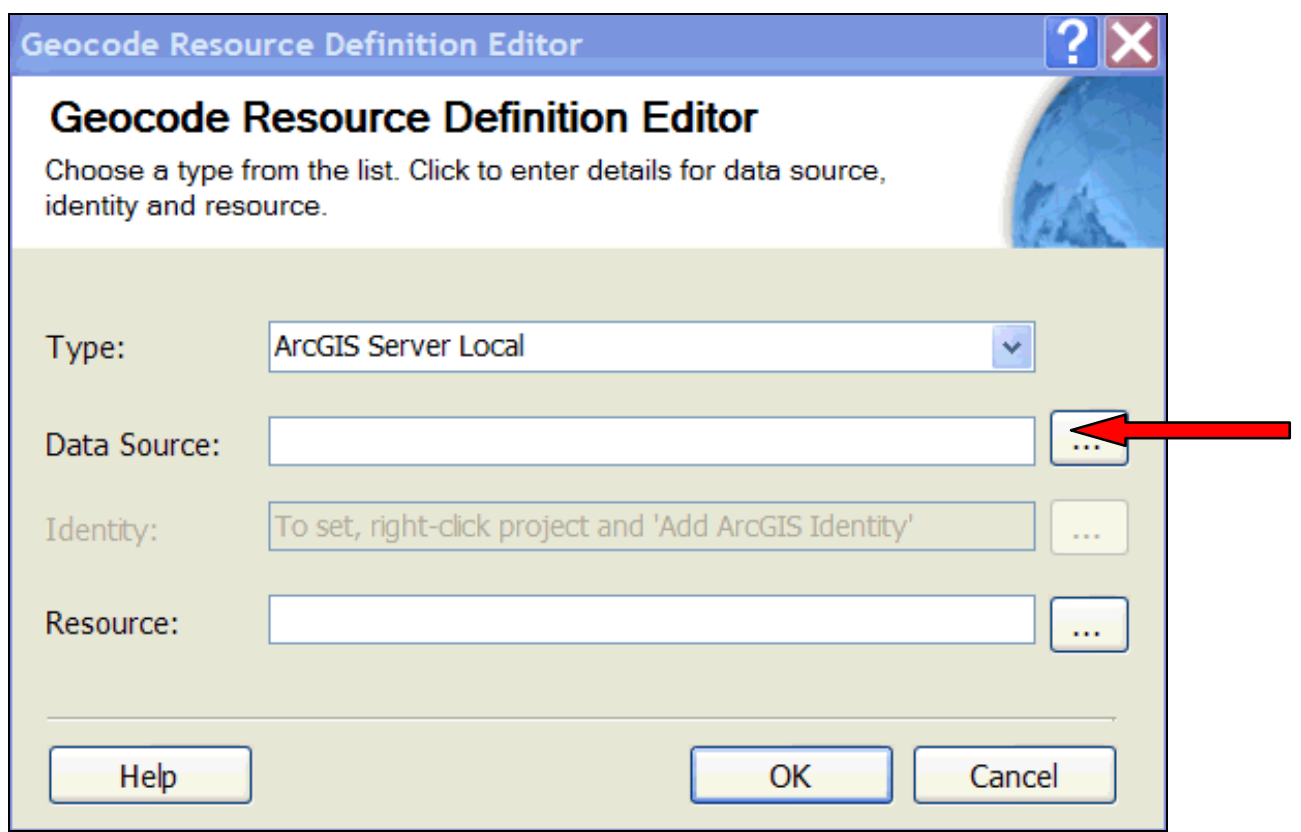

Appendix Figure 27 - Setting ArcGIS Server Local as Type of Geocode Resource.

33. When the new window opens, type the name of the local server and click OK. 
34. Next, click the square box next to Resource to open the Resource Definition Editor.

35. Click the drop down arrow next to Service to select the FullertonAddressLocator geocode service and then click OK three times to return to the Design view window (Figure 28).

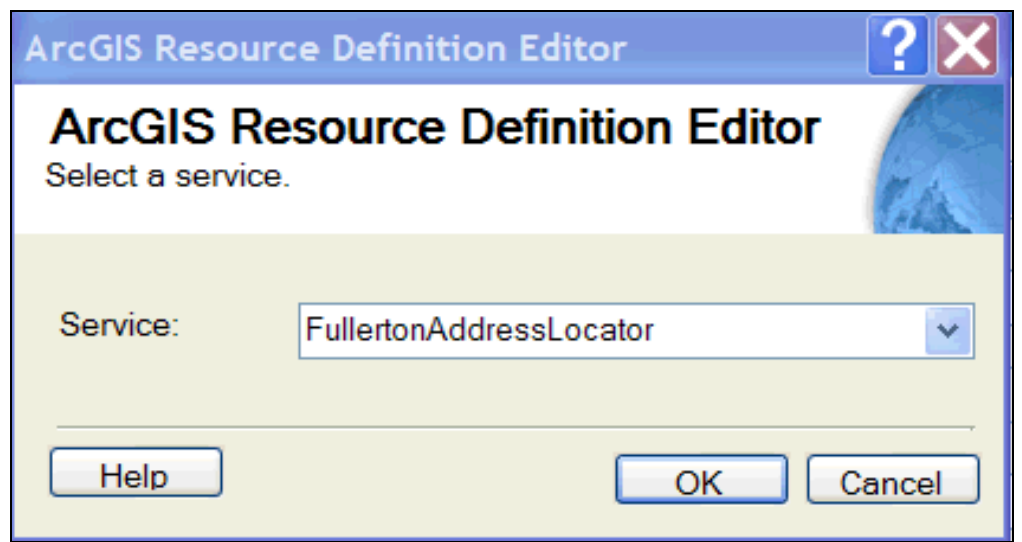

Appendix Figure 28 - Setting FullertonAddressLocator as the Geocode Service.

36. The necessary resource managers have been set and the application's identity needs to be replaced. To do this, double click and open web.config from the Solution Explorer window.

37. When the web.config window opens, search for the identity code and delete it. The code should look like Figure 29. CAUTION: Delete everything between the first and second identity tags including the tags themselves.

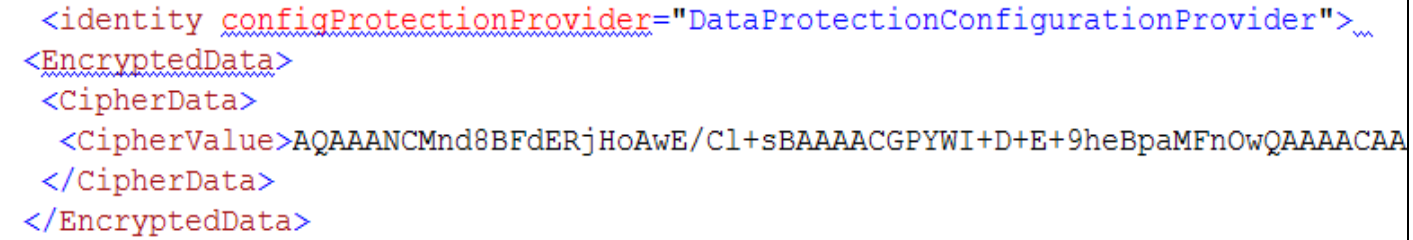

Appendix Figure 29 - Identity Code to Delete.

38. After deleting the identity code, click save.

39. To add the new map identity, right click the web address in the Solution Explorer and choose Add ArcGIS Identity (Figure 30). 


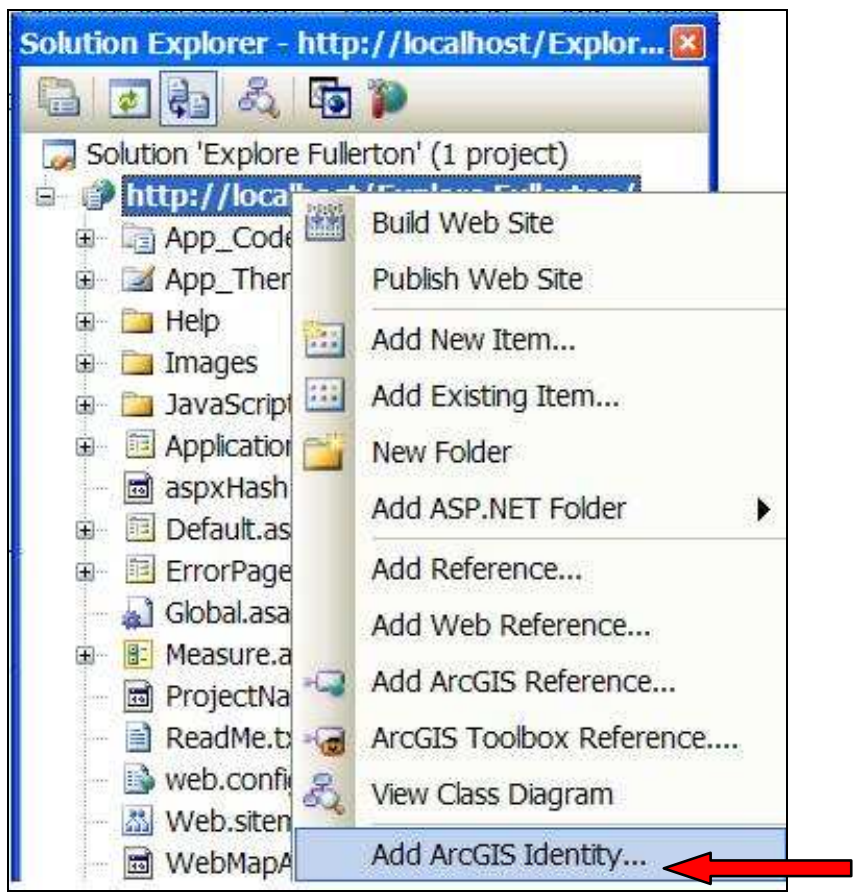

Appendix Figure 30 - Adding an ArcGIS Identity.

40. In the ArcGIS Identity window that opens, enter the desired User Name, Password, and Domain, then click OK (i.e., Jon_Orndorff as the User Name, a personalized password, and ExploreFullerton as the Domain) (Figure 31).

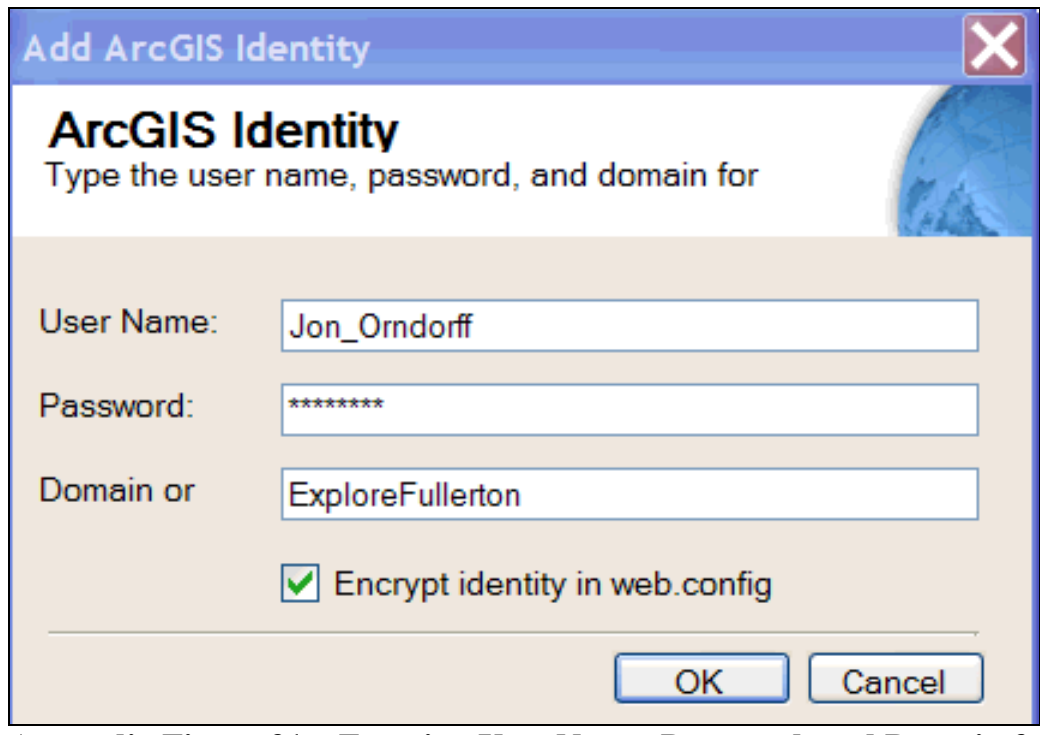

Appendix Figure 31 - Entering User Name, Password, and Domain for Identity.

41. Click Save in the Visual Studio program.

42. In the Visual Studio Menu bar, click File and then click View in Browser. If the Web mapping application is displayed with a map on the screen and has no errors, the "Explore Fullerton" application has been configured correctly. 
43. To add the resource managers for the Drive Fullerton application and to change its identity, begin by clicking File and selecting Open.

44. Next, select Web Site from the Menu Bar.

45. In the pop-up window, click Local IIS in the left panel and then choose Drive Fullerton from the Web Site list in the right panel. After selecting Drive Fullerton, click Open.

46. Once the application and Solution Explorer window open, double click and open Default.axpx.

47. When the Default.aspx window opens click the Design button located in the lower left part of the window.

48. The MapResourceManager is located in the Design view on the top center of the screen. Click on this MapResourceManager and then click on the black triangle that appears to the top right of the WebControl.

49. Next, click Edit Resources to open the manager (Figure 32).

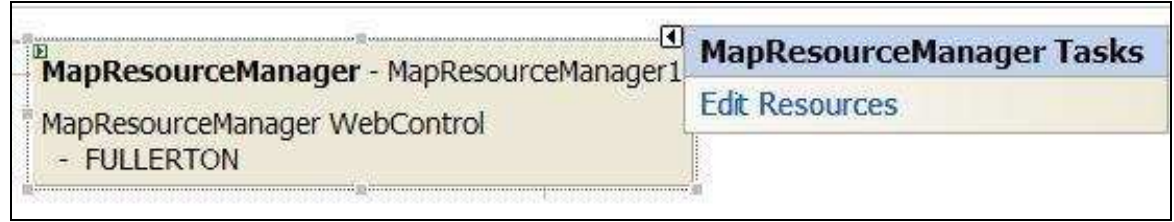

Appendix Figure 32 - Opening the MapResourceManager.

50. In the pop-up window that appears, click on Definition DataSource located under the Information section. When clicked, a square box will appear to the right of the DefinitionSource title, click on this box (Figure 33). 


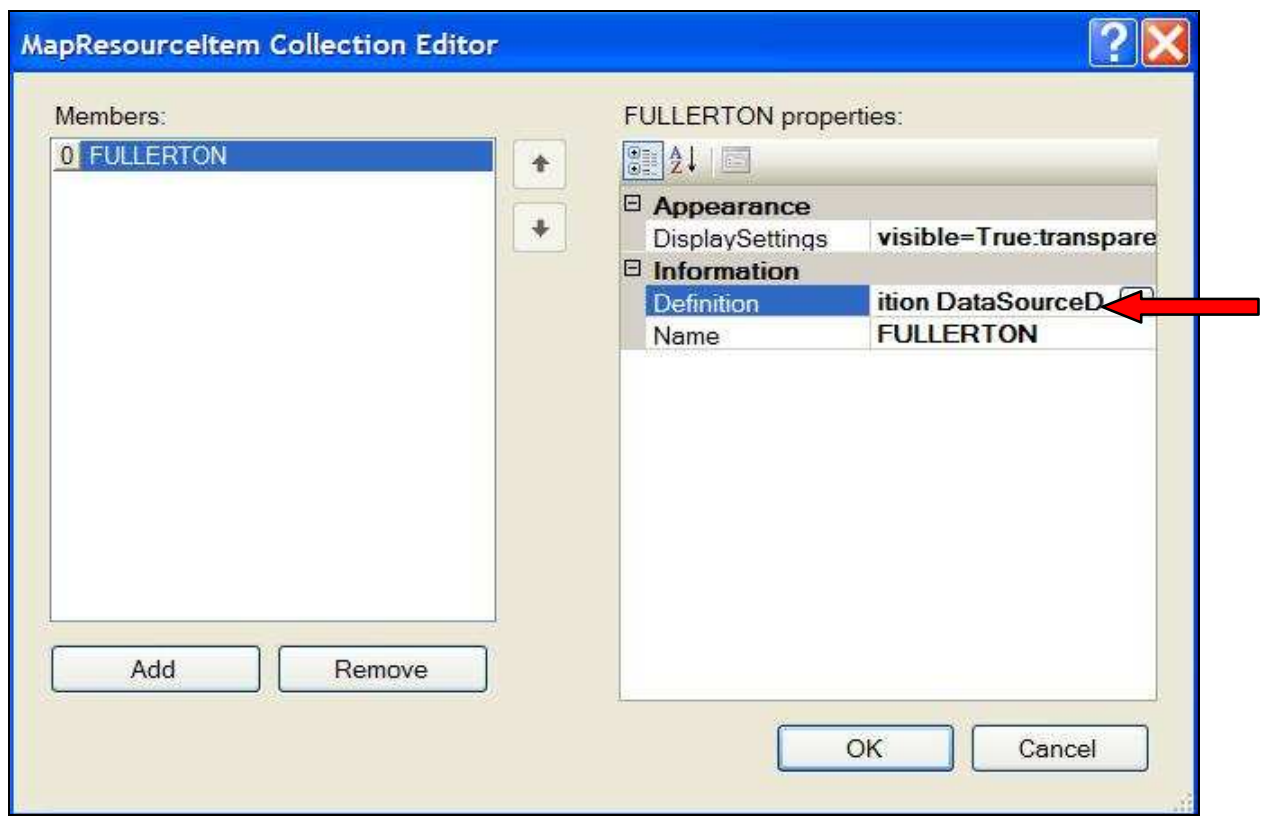

Appendix Figure 33 - Opening the MapResource Definition DataSource.

51. In the Map Resource Definition Editor window that appears, select ArcGIS Server Local for Type from the drop down menu and then click the square box next to Data Source (Figure 34).

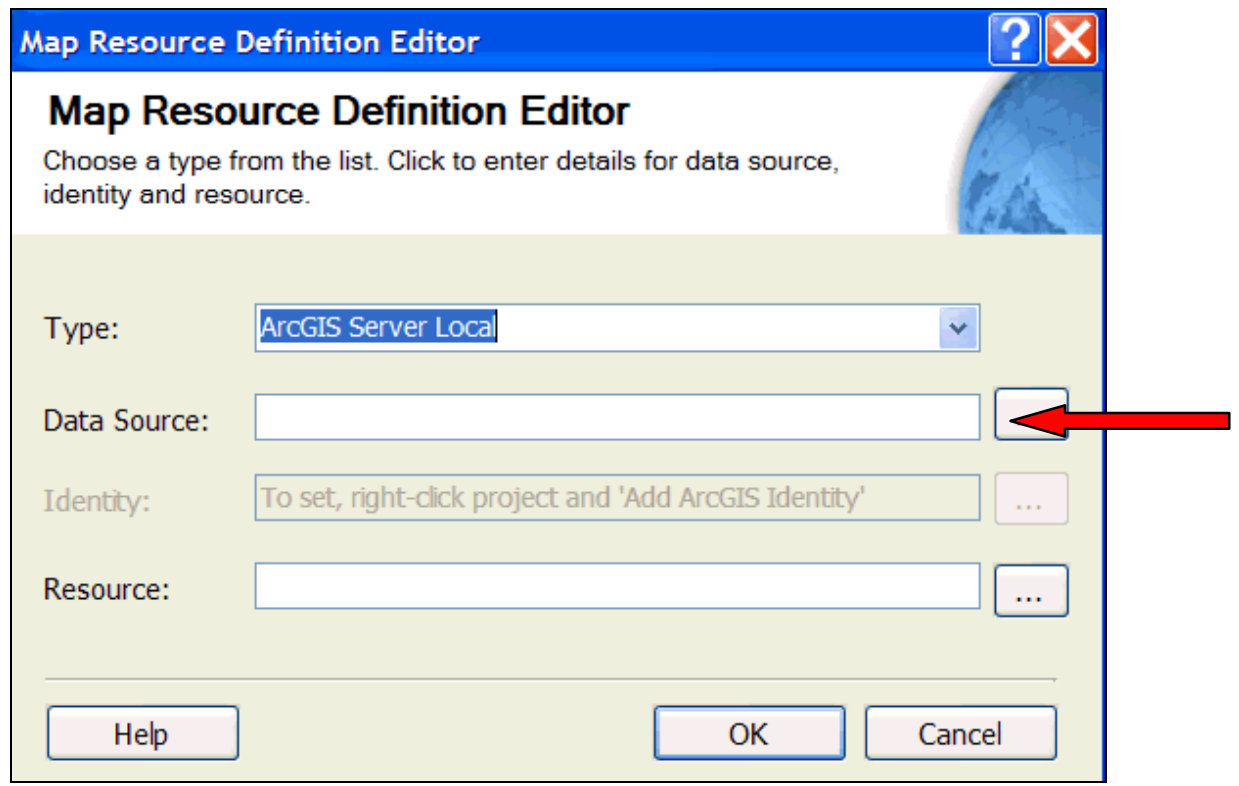

Appendix Figure 34 - Setting ArcGIS Server Local as Type of Map Resource.

52. When the new window opens, type the name of the local server and click OK (i.e., ExploreFullerton) (Figure 35). 


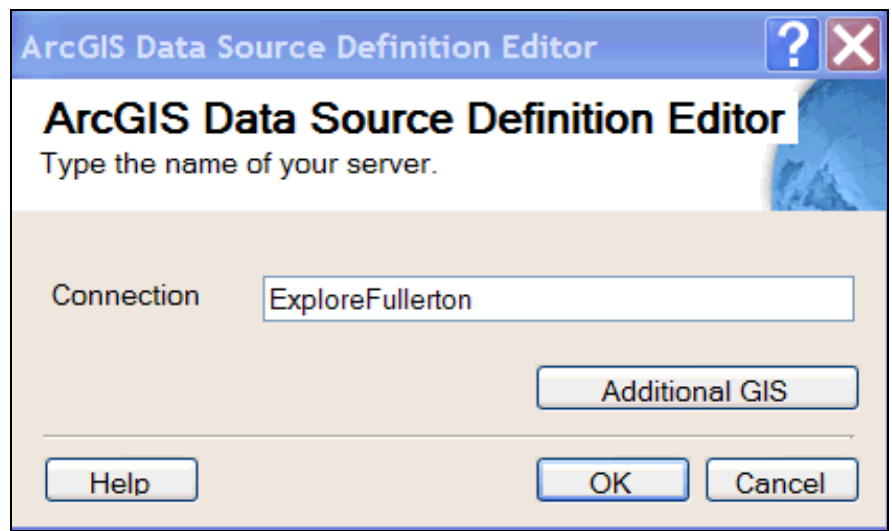

Appendix Figure 35 - Setting ArcGIS Server Connection.

53. Next click the square box next to Resource to open the Resource Definition Editor.

54. Click the drop down arrow next to Service to select the FULLERTON map service and then click OK three times to return to the Design view window (Figure 36).

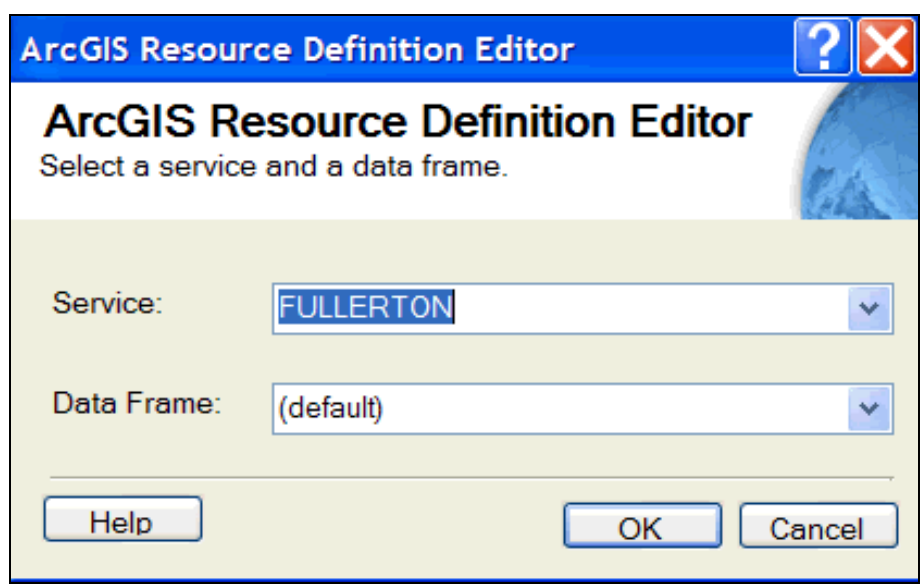

Appendix Figure 36 - Setting FULLERTON as the Map Service.

55. The map resource manager has now been set. The geocode resource manager is read behind the scenes and is imbedded in the code. As a result, it is not necessary to set a geocode resource manager in the Drive Fullerton web mapping application.

56. Next, the map's identity needs to be replaced. To do this, double click and open web.config from the Solution Explorer window.

57. When the web.config window opens, search for the identity code to delete it. The code should look like Figure 37. CAUTION: Delete everything between the first and second identity tags including the tags themselves. 


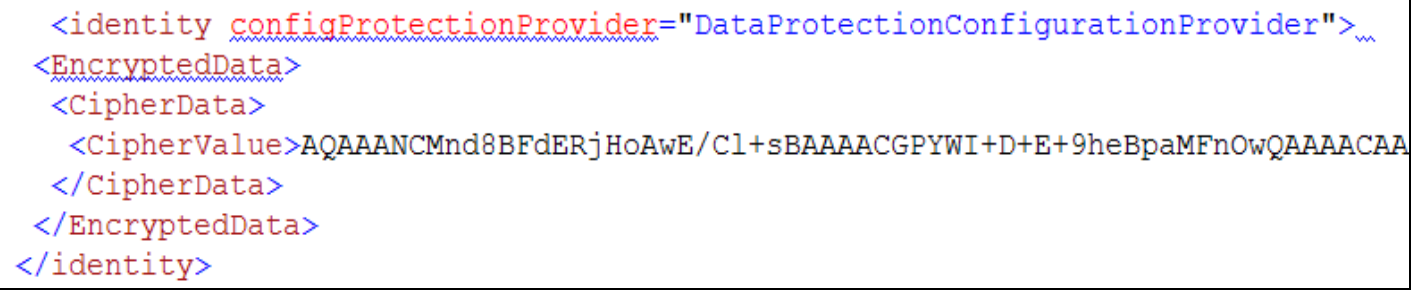

Appendix Figure 37 - Identity Code to Delete.

58. After deleting the identity code, click Save.

59. To add the new map identity, right click the web address in the Solution Explorer window and choose Add ArcGIS Identity (Figure 38).

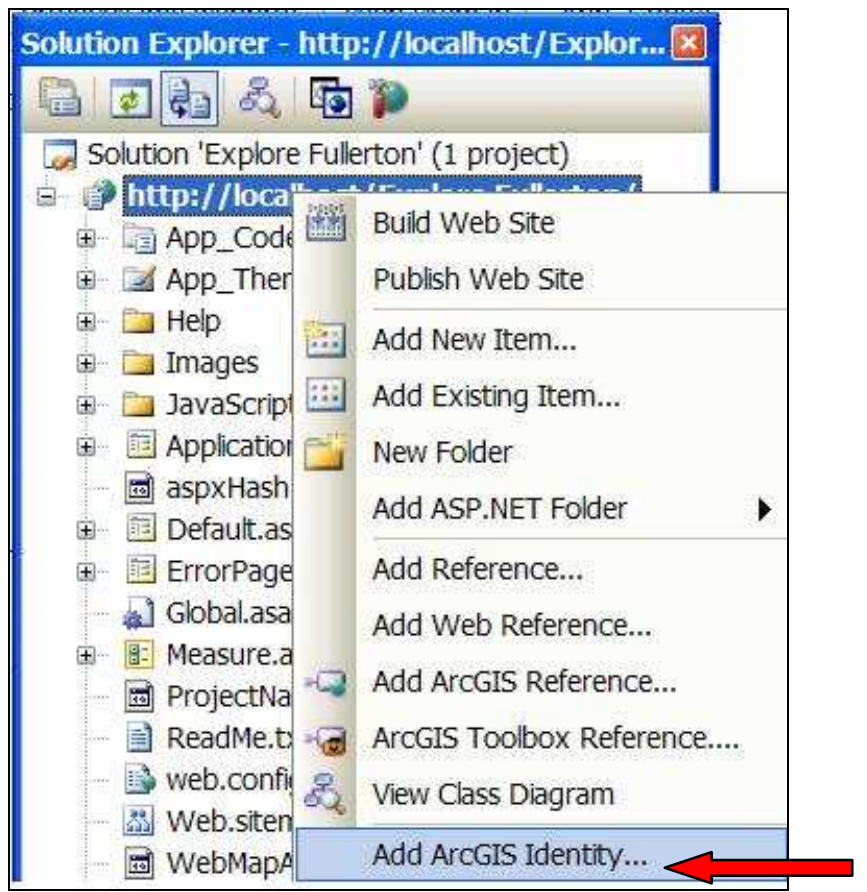

Appendix Figure 38 - Adding an ArcGIS Identity.

60. The ArcGIS Identity window should open. In this window, enter the desired User Name, Password, and Domain, then click OK (i.e., Jon_Orndorff as the User Name, a personalized password, and ExploreFullerton as the Domain) (Figure 39). 


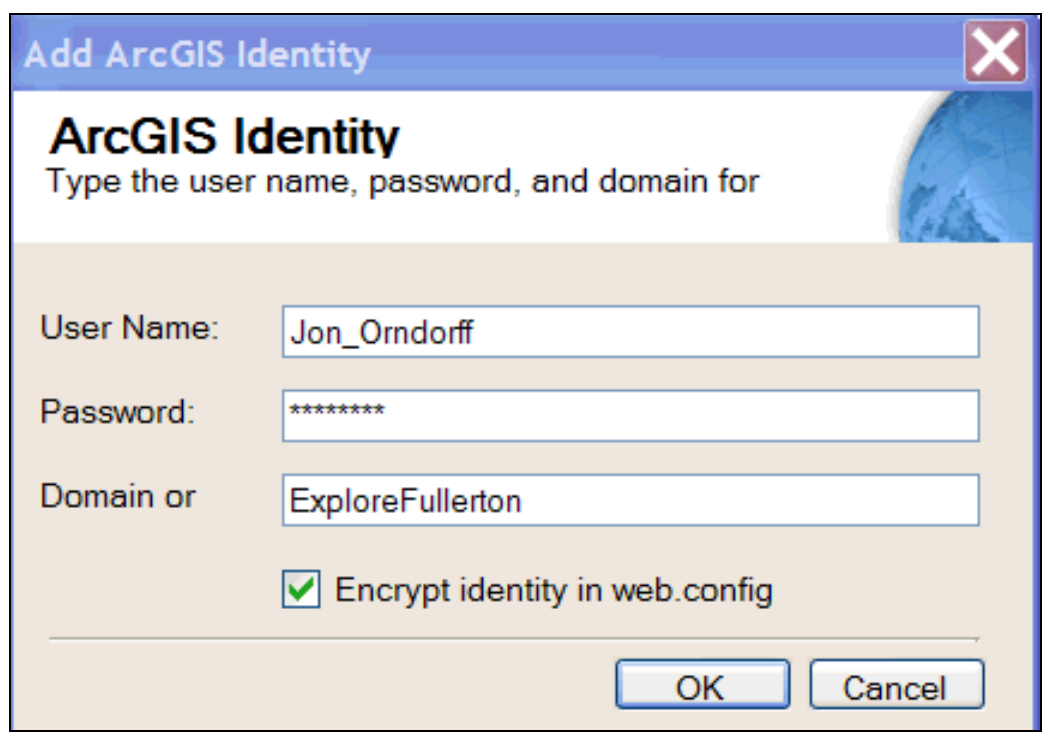

Appendix Figure 39 - Entering User Name, Password, and Domain for Identity.

61. Click Save in the Visual Studio program.

62. In the Visual Studio Menu bar, click File and then click View in Browser. If the Web mapping application is displayed with a map on the screen and has no errors, the "Explore Fullerton" application has been configured correctly and is ready to be viewed via the Internet.

The Web mapping applications have been successfully transferred from the "Explore Fullerton" installation CD to wwwroot and have been declared as applications within IIS. Also, the Resource Managers in Visual Studio have been set to allow the "Explore Fullerton" Web mapping application to read all of the services that were previously created. The applications' identities have been set and the installation of "Explore Fullerton" is complete. 